\title{
WestVirginiaUniversity
}

THE RESEARCH REPOSITORY @ WVU

Graduate Theses, Dissertations, and Problem Reports

2018

\section{Socialization and Mentoring of Community and Technical College Faculty}

Brad Maurice Gilbert

bgilber1@mix.wvu.edu

Follow this and additional works at: https://researchrepository.wvu.edu/etd

Part of the Curriculum and Instruction Commons, Educational Leadership Commons, Higher

Education Commons, and the Higher Education Administration Commons

\section{Recommended Citation}

Gilbert, Brad Maurice, "Socialization and Mentoring of Community and Technical College Faculty" (2018). Graduate Theses, Dissertations, and Problem Reports. 3697.

https://researchrepository.wvu.edu/etd/3697

This Dissertation is protected by copyright and/or related rights. It has been brought to you by the The Research Repository @ WVU with permission from the rights-holder(s). You are free to use this Dissertation in any way that is permitted by the copyright and related rights legislation that applies to your use. For other uses you must obtain permission from the rights-holder(s) directly, unless additional rights are indicated by a Creative Commons license in the record and/ or on the work itself. This Dissertation has been accepted for inclusion in WVU Graduate Theses, Dissertations, and Problem Reports collection by an authorized administrator of The Research Repository @ WVU.

For more information, please contact researchrepository@mail.wvu.edu. 


\title{
SOCIALIZATION AND MENTORING \\ OF COMMUNITY AND TECHNICAL COLLEGE FACULTY
}

\author{
Brad M. Gilbert
}

Dissertation submitted

to the College of Education

at West Virginia University

In partial fulfillment of the requirements for the degree of

Doctor of Education in

Curriculum and Instruction

Nathan Sorber, Ph. D., Chair

Erin McHenry-Sorber, Ph. D.

John Oughton, Ph. D.

Malayna Bernstein, Ph. D.

Department of Curriculum and Instruction

Morgantown, West Virginia

2018

Keywords: Community College Faculty Socialization, Community and Technical College Faculty Mentoring

Copyright 2018 Brad M. Gilbert 


\begin{abstract}
Socialization and Mentoring of Community and Technical College Faculty
\end{abstract}

Brad M. Gilbert

This case study research examined the socialization and mentoring processes at a community and technical college based on the perspectives of new college faculty members transitioning from career professions. Three main areas were the focus of examination: perceptions of institutional socialization structures and processes; perceived impact of processes on providing discipline content and pedagogical knowledge during integration to institutional norms and culture; and perceived impact of processes on classroom pedagogy and student learning. Interviews with sample faculty members having approximately three to five years experience at a community and technical college, located in the Mid-Atlantic Region, provide representative data for similar Applied Technology institutions. In support of this study, a research literature review addressing scholarly work associated with this topic includes: the historical context of postsecondary institutions, socialization processes related to higher education, mentoring practices associated with socialization and its impact of future faculty, the importance of socialization for teaching in college, and representative programs being utilized to enhance socialization of future faculty for their role in higher education. The research methodology is described in detail with emphasis on design of the study, assumptions of case study research, site selection and data collection, analysis of data, and concerns validity of research. Summary and analysis of individual interviews and a focus group interview are presented addressing discovering information. Lastly, findings and conclusions are drawn describing connections between existing research relative to this study and recommendations for additional research. 


\section{Acknowledgements}

This research study has been a valuable learning experience. As a 27 year veteran of community and technical college teaching, this dissertation topic has been a personal journey aligned with my passion for improving the lives of faculty and students engaged with technical professions. During my academic career, I have observed the results of new faculty transitioning to teaching in higher education with little or no socialization and mentoring. Having encountered a similar experience when 1 began my teaching career, I have always empathized with the difficulties new faculty are confronted with during the initial three years of employment. It is my goal to become the director within the program in which I teach and it is my objective to implement the theories and concepts expounded upon in this research.

This research project has also provided me with an opportunity to fulfill a lifelong goal of completing the dissertation process. While pursuing this objective, I have learned to seek and value the guidance of my committee chairperson. Deciding on a dissertation topic aligned with my passion, planning and organizing the conceptual framework and research methodology for this study, examining and writing the literature review, conducting interviews, coding, and discussing the finding have all been extremely beneficial to my personal and professional growth. Finally, it is my sincere hope that this research will improve the quality of teaching and life experiences for all people engaged in community and technical college education.

I would like to express my deepest appreciation to my dissertation committee for their time and attention to this project. I offer my gratitude to my committee chair, Dr. Nathan Sorber for providing guidance and sharing expertise throughout this process. He has been instrumental in mentoring me along this journey during the past three years and I am deeply appreciative. 
My family and friends have been an important source of support and encouragement during the past nine years of doctoral study. I would like to thank my wife Joann and adult children Lauren, Dominique, and Derek for their love and support while coursework and research required absence from family activities. In addition, I would like to thank Annette, Christy, and Lynn, my colleagues at the National Aerospace Education Center. Their moral support was unwavering and the many papers Lynn edited through the years was invaluable. 


\section{TABLE OF CONTENTS}

\section{CHAPTER}

$\begin{array}{lc}\text { Abstract } & \text { ii } \\ \text { Acknowledgements } & \text { iii } \\ \text { Table of Contents } & \mathrm{v} \\ \text { List of Tables } & \text { vii } \\ \text { List of Figures } & \text { vii }\end{array}$

I. INTRODUCTION 1

Problem Statement 1

Research Questions 3

Introduction to the Socialization Process 3

Overview of Socialization Across Institutional Types 8

$\begin{array}{ll}\text { Conceptual Framework } & 15\end{array}$

$\begin{array}{ll}\text { Significance } & 17\end{array}$

$\begin{array}{lr}\text { Practical Significance } & 18\end{array}$

$\begin{array}{ll}\text { Definitions } & 19\end{array}$

II. REVIEW OF LITERATURE 24

Historical Context of Higher Education and Community College 24

Higher Education Context of Socialization 36

What is Socialization For New College Faculty? 45

$\begin{array}{ll}\text { Mentoring } & 62\end{array}$

$\begin{array}{ll}\text { Results of Socialization } & 77\end{array}$

Emphasis on Teaching $\quad 88$

Programs for Enhancing Socialization 95

$\begin{array}{ll}\text { III. METHODOLOGY } & 102\end{array}$

$\begin{array}{lr}\text { Research Questions } & 102\end{array}$

$\begin{array}{ll}\text { Research Design } & 103\end{array}$

Assumptions in Qualitative Research 105

$\begin{array}{ll}\text { Site Selection } & 107\end{array}$

$\begin{array}{ll}\text { Sample Participants } & 110\end{array}$

$\begin{array}{ll}\text { Data Collection } & 113\end{array}$

$\begin{array}{ll}\text { Individual Interview Questions } & 114\end{array}$

$\begin{array}{ll}\text { Focus Group Questions } & 116\end{array}$

$\begin{array}{ll}\text { Analysis Of Data } & 117\end{array}$

$\begin{array}{ll}\text { Validity of Research } & 120\end{array}$

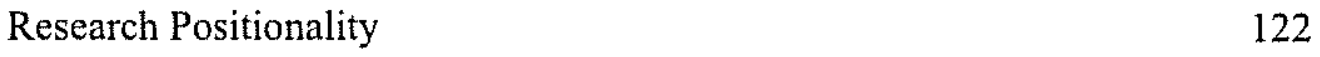


$\begin{array}{ll}\text { IV. FINDINGS } & 124\end{array}$

$\begin{array}{ll}\text { Research Questions } & 124\end{array}$

$\begin{array}{ll}\text { Purpose } & 125\end{array}$

$\begin{array}{ll}\text { Participant Biographies } & 127\end{array}$

$\begin{array}{lr}\text { Interview Analysis } & 132\end{array}$

$\begin{array}{ll}\text { Background Questions } & 133\end{array}$

$\begin{array}{ll}\text { Research Question One } & 140\end{array}$

Research Question Two 146

$\begin{array}{ll}\text { Research Question Three } & 154\end{array}$

$\begin{array}{llr}\text { V CONCLUSION } & 159\end{array}$

$\begin{array}{ll}\text { Conceptual Contribution of Research } & 173\end{array}$

$\begin{array}{ll}\text { Limitations of Research } & 177\end{array}$

$\begin{array}{ll}\text { Problems Arising During the Research } & 178\end{array}$

$\begin{array}{ll}\text { Recommendations For Research and Practice } & 178\end{array}$

$\begin{array}{ll}\text { Contribution to Research } & 180\end{array}$

$\begin{array}{lll}\text { VI REFERENCES } & 182\end{array}$

$\begin{array}{ll}\text { VII APPENDIX } & 191\end{array}$ 


\section{LIST OF TABLES}

$\begin{array}{lll}\text { Table Page } & \text { Pas }\end{array}$

1 Characteristic Differences Between Two-Year and Four-Year Faculty 34

2 The Integrated Faculty Role in the U.S. Higher Education Model 37

3 Emerging Re-configurations of Faculty Functions in the U.S. Higher 37 Education Model

4 Areas For Effectively Improving Socialization of Faculty 43

5 Comparison of Low and High Consensus Fields 60

6 Seven Mentee Skills For Effective Development Mentoring Process 65

7 Effect of Mentoring Process on Mentoring Outcomes 76

$8 \quad$ Interview Response Chart 119

9 Participant Descriptions $\quad 126$

10 Interview Analysis Categories 132

\section{LIST OF FIGURES}

Figure Page

1 Conceptual Framework $\quad 17$

2 Developmental Stages of Graduate Student Development 50

3 Conceptualizing Graduate and Professional Student Socialization 54

4 Conceptual Framework Revisited 161

5 Conceptualizing Graduate and Professional Student Socialization Revisited 166 



\section{Chapter One}

\section{Introduction}

Research universities have long prepared future doctoral faculty, who assume teaching and scholarly careers in higher education. These academic professionals pursue careers across a range of institutional types, including: research universities, master's degree colleges, liberal arts colleges, and community and technical colleges. Researchers have focused attention on the preparation, socialization, and mentorship of graduate students as future faculty, in order to more effectively transfer skills, knowledge, and dispositions necessary to be successful educators in the chosen areas of their expertise. This dissertation expands knowledge to this area of study by examining the socialization and mentoring process within the context of community and applied technology of college faculty. This qualitative case study research examines socialization practices currently in place in the community and applied technology context, the perspective of those transitioning from professional careers to community and applied technology college teaching roles, and the perceived impact they have on teaching effectiveness and the programs in place for implementing future faculty development.

\section{Problem Statement}

There is a significant amount of literature identifying the socialization and mentoring occurring at universities, where graduate students are prepared to transition to roles as four-year college and university teachers and researchers. This dissertation, however, addresses more specifically the perceptions of faculty experiencing mentoring and socialization in Applied Technology disciplines at the community college level. A large volume of higher education activity is occurring at the community and technical college level, where faculty are being 
recruited from career professional ranks with many having limited experience with previous higher education institutions. While the community college faculty play an integral role in higher education, their contributions to postsecondary education is not regarded as highly as that of four-year and university institutions. This predicament likely stems from a mission of the community college system that emphasizes teaching over research and scholarship, and vocational/applied disciplines before those which are more academic/theoretically based. As such, there is currently a dearth of literature pertaining to socialization and mentoring of new faculty beginning careers as Applied Technology faculty at the community college level.

Due to the limited research conducted for faculty at the community college level, scholars and institutional leaders have limited understandings of how community college faculty gain professional competencies to engage in the critical teaching tasks. Nevertheless, research in other institutional contexts have shown the importance of socialization and mentoring for new faculty as a means of improving performance during the early stage of their careers. This dissertation fills a gap in the literature by addressing the mentoring and socialization structures within the context of community college Applied Technology disciplines. Specifically, this dissertation investigates the mentorship and socialization process implemented for Applied Technology faculty during the first few years of their professional academic careers. In this qualitative case study inquiry, the author investigates the institutional resources in place for Applied Technology faculty socialization and mentoring, their processes, and the perceptions of affected faculty as to the effectiveness of the processes for aiding their transition to become successful teachers. 


\section{Research Questions}

This research will be guided by the following questions:

1. What are the unique structures and processes in place at the institution being perceived as aiding socialization, mentorship, and transition of new faculty from professional careers to the Applied Technology college teaching profession?

2. How do new faculty perceive that socialization and mentorship programs provide content and pedagogical knowledge during the transition from career professional to higher education professional careers and support integration to the norms and culture of community college institutions?

3. How do new faculty perceive the effectiveness of socialization and mentorship processes, structures, and strategies on pedagogy and student learning in the Applied Technology college environment?

\section{Introduction to the Socialization Process}

Socialization is the process whereby individuals internalize the values, beliefs, and norms of a society. Calhoun (2002) stated that individuals learn to function as societal members and adapt to social roles, such as workers, friends, citizens, and college faculty. The early research on socialization focused primarily on childhood and development to adulthood, when the adaptation to social norms is concentrated. Since that time, the theory of individuals adopting and acquiring different roles during their lives has broadened. Socialization theorists have two fundamental schools of thought, modern (functionalist tradition) and postmodern (alternative tradition). The modernist describes socialization as "the learning of any orientations of functional significance to the operation of a system of complementary role-expectations" (Calhoun, 2002, p. 157). This 
is considered a top-down process and functions as a service of social-structural forces that fits individuals into fixed roles. The postmodern (alternative tradition) theory considers individuals as active participants in meeting, negotiating, and redefining their social roles. In the postmodern view, socialization appears as a much more flexible and less strongly determined process. Lastly, there are formal and informal processes of socialization that allow newcomers to become familiar with an organization or workgroup, as they learn its norms and begin to share its values. Formal process of socialization includes induction or orientation, at which time the new employees are introduced to co-workers and managers, given a tour of the workplace, and told about rules and procedures. Informal socialization is comprised of gradual processes, whereby the newcomer learns about the organization and the values and beliefs of its members through social interaction with fellow members (Heery, 2008). As a result of the formal and informal socialization processes, existing members of the organization form an understanding of the newcomer, and the newcomer comes to understand the organization.

Anticipatory socialization addresses the practice of individuals preparing for roles that will be assumed in the future, for example, graduate students considering college teaching roles. Anticipatory socialization can be contrasted with more formal processes as the prospective member adopts the norms or behaviors associated with a group in anticipation of future membership (Scott, 2014). In short, the individual is provided an experience of a role or status without having actually being inducted. For example, a graduate student may anticipate the role of professorship by observing and working under the guidance of a mentor as a role model.

After the induction process, new faculty begin gaining familiarity with the norms and cultures specific to the organizations and within sub-units like departments. Organizational 
socialization, which for this dissertation includes occupational and work socialization, describes learning on the part of the individual who is adjusting to a new or changed role within an organization. Emphasis on the individual's perspective is critical, because individual differences will affect how socialization experiences will be learned and interpreted. To be more specific, Chao, O'Leary-Kelly, Wolf, Klein, and Gardner (1994) described six dimensions of organizational socialization that conceptualize this theory as follows:

Performance Proficiency

People

Politics

Language

Organizational Goals and Values

History
Addresses how well individuals learn tasks involved with a job. Identification of an individual's mastery of required knowledge, skills, and abilities influences the socialization process.

Addresses how personality traits, group dynamics, and similarity of nonwork interests, as well as work interactions and behaviors are accepted by organizational members.

Addresses the individual's success in gaining information regarding formal and informal work relationships and power structures within the organization.

Addresses knowledge of the profession's technical language as well as the organization.

Addresses an understanding of the rules or principles that maintain the integrity of the organization. This extends to unwritten, informal, tacit goals, and values exemplified by those in more powerful positions.

Addresses how an organization's traditions, customs, myths, and rituals transmit cultural knowledge and perpetuate a particular organization member (p. 79).

These dimensions of occupational socialization contribute to organizational laws and the approximation of attitudes and behaviors necessary for achieving recognized and sustainable competence within a context of employment. These include skills typically acquired through 
training, informal work norms, and peer-group values and relationships (Scott, 2014). A related concept is work socialization, which is defined as the process of learning to labor in paid employment and conforming to the associated ideological structures: internalizing the norms, values, and culture of the workplace, employing organization, profession, or occupational group. Included in this process is an accommodation to the power and authority relations at the workplace administration (Scott, 2014). For example, with regard to higher education this scholarship relates to complying with the particular role and functions of institutional expectations for service, teaching, and research. More generally, it involves learning to value the attitudes that reinforce the worth of work in general and the expectations for the particular institutional type to which faculty are employed.

Taking these theories in context of preparing new faculty for higher education institutions, Rosser (2004) explained that "doctoral education at major universities is an intense socialization experience designed to prepare students for a lifetime of scholarship and research" (p. 29). Socialization into the professoriate consists of both formal and informal faculty socialization occurring at both anticipatory and organizational stages. Anticipatory socialization occurs before an individual arrives on campus, most notably through the graduate school exposure. During this time, the individual observes, participates, and interacts with faculty members and mentors. As a result, the individual is exposed to roles, behaviors, and expectations, and is provided the opportunity for learning the culture of college faculty. Secondly, organizational socialization occurs during the graduate student's initial entry to the university and continues during the student's enrollment. Role continuance and socialization will occur throughout the duration of the student's enrollment engaging with fellow students, 
gaining exposure to faculty and mentors, through teaching experiences and researching specific disciplines. The processes are considered formal; however, much knowledge and socialization occurs during informal casual conversations individuals have throughout the experience.

The socialization process continues during new faculty transition. Coleman, Christie, Culver, Erickson, Hunt, Williams, Kinsey, Smith, and Tareilo (2006) claimed that it takes several years of consistent, systematic mentoring during the socialization process in order to retain teachers. They found, "without collegial support new faculty often experience feelings of alienation, isolation, and disenfranchisement" (p. 3). As an example of best practices, Cariaga-Lo, Dawkins, Enger, Schotter, and Spence (2010) described steps taken by Wagner College, to create a more welcoming campus climate for junior faculty. These included a mentoring program introduced by the provost that matched new full-time faculty with mentors outside their department and scheduled two receptions each semester. These events included the department chairs, new faculty, and their mentors. Cariaga-Lo et al. explained, "to address concerns of junior faculty members more directly, the college also introduced a September workshop, sponsored by the Personnel Committee, to answer questions about the reappointment, promotion, and tenure process and to offer advice on portfolio preparation." (p. 3) The programs at Wagner College exemplify strategies at several colleges to promote successful faculty socialization.

On a departmental level, and in the context of Applied Technology curricula, Delaware Technical and Community College adopted an innovative strategy designed to ease transition into the nurse educator role. Duphily (2011), explained that the institution was tasked by their state legislature to increase admission rates by $40 \%$. To achieve the goal, the nursing 
administration was faced with hiring, orienting, and mentoring additional full-time nursing instructors. "Following a 2-year integration process, the program was able to increase student enrollment, provide and retain competent faculty, and maintain the quality of the nursing program." (p. 125) In a study analogous to this, Dunham-Taylor, Lynn, Moore, McDaniel, and Walker (2008) claimed that when institutions are fortunate enough to obtain individuals willing to enter the world of academia it is important to support their passion for teaching. Related to the example above, they state it is essential that the:

...institution take special care to cultivate a nurse educator who will not only remain but also flourish in academia. Such cultivation must include a clear and purposeful plan with the commitment to provide opportunities for professional development, as well as mentoring and institutional support, for new faculty. This support must begin with a strong mentoring process and continue throughout the faculty's academic career. Mentoring should be viewed not only as a list of short-term objectives that assist the novice nurse faculty in assuming the teaching role but also as a process that ultimately transforms the mentee into a mentor for the future preservation of the nursing profession. (p. 339)

The examples above demonstrate the importance of creating socialization strategies, structures, and processes at both the institutional and departmental level for supporting new faculty as they journey through their academic career.

\section{Overview of Socialization Across Institutional Types}

Socialization processes in higher education vary across institutional types, and an understanding of this diversity is necessary to fully grasp the faculty transition processes 
explored in this dissertation. McCormick and Zhao (2005) explained that the Carnegie Commission on Higher Education was established by The Carnegie Foundation for the Advancement of Teaching in 1967 to study and make recommendations regarding the major issues facing U.S. higher education. The commission soon confronted a problem: no extant classification system differentiated colleges and universities along the dimensions that were most relevant to its work. So in 1970 the commission developed a new classification scheme to meet its analytic needs, known since then as The Carnegie Classification. Three years later, it published the classification listings of colleges and universities, although modified since its origination, it is currently in use for helping to clarify the various institution types engaged in teaching and research throughout the spectrum of higher education. The result of this classification system organized institutions by degree level and specialization: doctorate-granting universities, master's-level institutions (called comprehensive colleges), undergraduate liberal arts colleges, two-year colleges, and specialized institutions, with all but the two-year colleges further broken into subcategories. The nation's high-status research universities were clustered together, as were the most prestigious liberal arts colleges.

The Carnegie Classification presents an institutional hierarchy of American higher education, which positions the research university as the model to which many other institutions aspire. Austin (1990) professes that wide ranging acceptance of this hierarchy has made research the primary professional endeavor and the focus of the professoriate; it is accepted as the route to national status. Given the acceptance of this hierarchy, McCormick and Zhao (2005) explained shortcomings in the classification system stating: 
Significant problems arise when classification is seen as an adequate representation of an institution's identity or character. Colleges and universities are complex organizations that differ on many more dimensions than the handful of attributes used to define the classification categories, and of course the very act of asserting similarity among institutions runs counter to the rhetoric of distinctiveness on our campuses. More important, the host of intangibles that constitute institutional identity could not possibly be incorporated into an empirically based classification system. (p. 55)

Austin claims that key elements contributing to a:

...college or university's culture include mission and goals of the institution, governance structure and leadership style of administrators, curricular structure and academic standards, student and faculty characteristics, student-faculty relations, size and location, and physical environment. The characteristics of each element and their interactions with each other create a unique culture for each college and university. (p.66)

The following delineation of common values for various institutional types is important to consider when trying to understand for socialization of graduate students and new college faculty within these respective contexts:

Research Universities Professors in major universities feel strong kinship in their disciplines, place priority on research, and value stimulation from interactions with disciplinary colleagues. They tend to be cosmopolitan and well traveled, attending conferences, enjoying considerable autonomy, and maintaining control over their time. Here, the disciplinary culture dominates faculty values and behavior more than in any other institutional type.

State Colleges

Heavy emphasis on undergraduate instruction is often coupled with institutional aspirations to move up in the pecking order; teaching loads remain full even as expectations for faculty 
Liberal Arts Colleges

Community Colleges publication increase. Faculty often have little time for research and writing and have few advanced graduate students. As a result, they often feel conflicts between the research activities to which they were socialized and that their institutions would like them to pursue and the day-to-day demands of teaching.

The emphasis is on the development of undergraduates as "whole persons," excellence in teaching is the most highly valued element of faculty work. Small departments mean that few colleagues with similar disciplinary interests are readily accessible. In the nationally renowned liberal arts colleges, faculty still maintain connections with their disciplinary networks and carry out research agendas, though limited time and resources may influence the dimensions of the research. In the less prestigious liberal arts colleges, narrowly defined disciplinary research and publication in scholarly joumals occurs less frequently. Generally, for faculty in liberal arts settings, commitment to institutional responsibilities diminishes disciplinary involvement and commitment.

Faculty experience an institutional culture different on many dimensions from the other institutional types. Heavy teaching loads, an absence of upper-level students, and, often, the need to provide remedial assistance are the norm. In this setting, many faculty are motivated primarily by seeing students learn and the intrinsic rewards and satisfaction they derive from this work. (Austin, 1990, p. 67)

There is a disparity between the volume of literature focusing attention on four-year colleges and research universities, opposed to that of community and technical colleges. Sledge (1986) claimed community college institutions were entirely neglected in the controversial 1983 report $A$ Nation at Risk. This report, prepared by the National Commission on Excellence in Education, scored four-year colleges and universities poorly for their lack of leadership with 
respect to setting standards and monitoring high schools' curricula for preparing future college students. Sledge states the following:

The omission of community colleges from the report is striking not simply because community colleges currently employ one-third of all college teachers and enroll one-third of all college students but because they have been successfully engaged throughout their century-long history in doing exactly what the report claims colleges and universities have failed to do: facilitating the entry of high school graduates into the worlds of education and work. (p. 4)

A large volume of higher education is taking place at the community and technical college level at which faculty are being recruited from career professional and non-graduate student ranks and have limited experience teaching in higher education institutions. However, the research on socialization of new college faculty emphasis is almost exclusively on graduate students for research universities. To illustrate this dilemma, Sledge documented a Center for Community College survey indicating that " $33 \%$ of teachers come from high school faculties; $11 \%$ from four-year college faculties; $25 \%$ from graduate schools (with or without completed degrees); $5 \%$ directly from undergraduate institutions; and the remaining $25 \%$ from trades, government and industry." (p. 4) These statistics clearly indicate the importance of investigating methods socializing new faculty for community college ranks.

In order to expand knowledge necessary for attracting and socializing new faculty, additional focus must be placed on effective methods of hiring, induction, orientation, and mentoring throughout the socialization processes. The scarcity of literature on this subject in the community college context is problematic for affecting faculty assuming teaching roles with 
community colleges. Added to this matter, Twombly (2005) claimed, a significant number of expected faculty retirements and vacancies is creating "a demand for faculty not seen since the community college growth spurt of the 1960s and 1970s" (p. 424). Thus, even though community colleges employ a significant portion of all higher education faculty, little research is available to reference regarding values and practices required to guide new faculty during their transitional journey.

The community and applied technology college faculty play an integral role in higher education; however, much of the literature ignores or minimizes their contribution to post-secondary education. As Twombly and Townsend (2008) explained, "community college faculty receive scant attention from post-secondary researchers -- or worse, are simply dismissed as a separate, and by implication lesser, class of college professors" (p. 5). Townsend and LaPaglia (2000) argued that community college faculty "must constantly contend with the nagging sense that teaching at a community college places them at the bottom of... [the higher education] hierarchy" (p. 41). Furthermore, the mission of the community college component of higher education is specifically addressed by Palmer (2002) who professed, "the fundamental fact that the institution's (community college's) main purpose is to help students learn academic disciplines and career skills" (p. 9). Thus, it is the role of subject specialists in each discipline who do the core work of teaching to connect students to specific bodies of knowledge.

An examination of the characteristics inherent in Applied Technology education will establish a foundation for further inquiry. With regard to the career path for vocational educators, literature presented by Palmer (2002), differentiates between traditional routes graduate students followed to obtain teaching employment in humanities and other academic 
fields, whereas teaching was more an extension of work outside the academy for Applied Technology faculty ( p. 18). Adding to this, Ulmer, Koch, and Ollison (2014) claimed, Applied Technology college educators often begin teaching careers "straight out of the industrial trenches" (p. 42). He found that the primary reason for this career shift from industry to academia was their strong desire to teach. Because of their direct experience in industry, advanced academic degrees are not often pursued to gain professional expertise. As Ulmer et al. pointed out, "an individual may have excellent work experience but may lack the required education or terminal degree required for many jobs in higher education" (p. 42). As a result of this non-traditional path into higher education, college faculty in Applied Technology disciplines experience their own unique types of socialization factors during their career transition.

For many new faculty, the adjustment from professional careers to community college instructor can be made smoother with adequate socialization. Fugate and Amey (2000) described this as follows:

Many faculty expressed concern with the lack of knowledge they had about community colleges as academic institutions and employment venues prior to beginning their current jobs. For these faculty, orientation was viewed as an important opportunity to learn the philosophy of the institution as well as the key players and institutional priorities. A number of faculty felt orientation should be expanded to include practical classroom teaching advice specific to the community college and its student population. (p. 13) Related to the importance of orientation for new community college faculty in general, there are topics Applied Technology faculty deal with specifically, which Ulmer et al. noted as follows: 
- A potential shortage of well-prepared Applied Technology faculty and concerns of salary compression or low salaries.

- An ever-changing population of students and their skills and abilities they bring with them out of high school. Applied Technology college-level educators are being called upon to deliver remedial, introductory, intermediate, and advanced technical content to students in traditional, hybrid/blended, and $100 \%$ online delivery methodologies.

- Many faculty members are not only teaching typical lecture courses but also being tasked with running student laboratories, advising students, participating in professional associations, serving on governance committees, having responsibility of finance and keeping technical education for themselves, and their students, at a high level of competency.

- Applied Technology educators leave the teaching profession due to "low salaries, lack of career advancement, or administrative support, student and peer issues, and other school and environment-related concerns. (p. 40)

With these factors in mind, this dissertation explores how mentoring and other socialization activities contribute to the successful transition of new faculty, and to facilitate improvement to Applied Technology college instruction.

\section{Conceptual Framework}

The conceptual framework, presented in Figure 1, graphically depicts the areas of the socialization and mentoring process for which this research addresses. As shown in this case, future community college faculty are represented on the left hand side of the diagram. These are individuals who have acquired technical education, knowledge and experience while employed 
in his or her professional careers. For these new faculty the transition process begins with his or her decision to initiate a change from a career professional to an academic professional. The hiring process in this case is considered the starting point, whereby new faculty members enter the collegiate institutional culture. Therefore, it is at this point in the new faculty experience that this research seeks to discover what structures, processes, and/or opportunities are being provided by the institution to aid faculty transitioning from professional careers to collegiate teaching roles. This research is examining the perceptions of new faculty regarding the structures and processes they experienced during this phase of his or her socialization process.

Focusing on the next phase of the socialization process, this research will investigate the perceptions of new faculty regarding his or her transition to the role of teaching at a higher education institution. This dissertation intends to discover how the socialization process is perceived by new faculty members, for providing content and pedagogical knowledge while integrating the new faculty into the norms and culture of community college institutions.

Lastly, since teaching is a dominant role of new college faculty, this research will examine the impact socialization processes have on the faculty role as professional educator at an institution of higher education. This study seeks to discover the perceptions of new faculty regarding how the socialization process impacts his or her teaching role and student learning, peer relationships, service to the institution, and inspiration for continued research in respective disciplines. 
Figure 1

Conceptual Framework

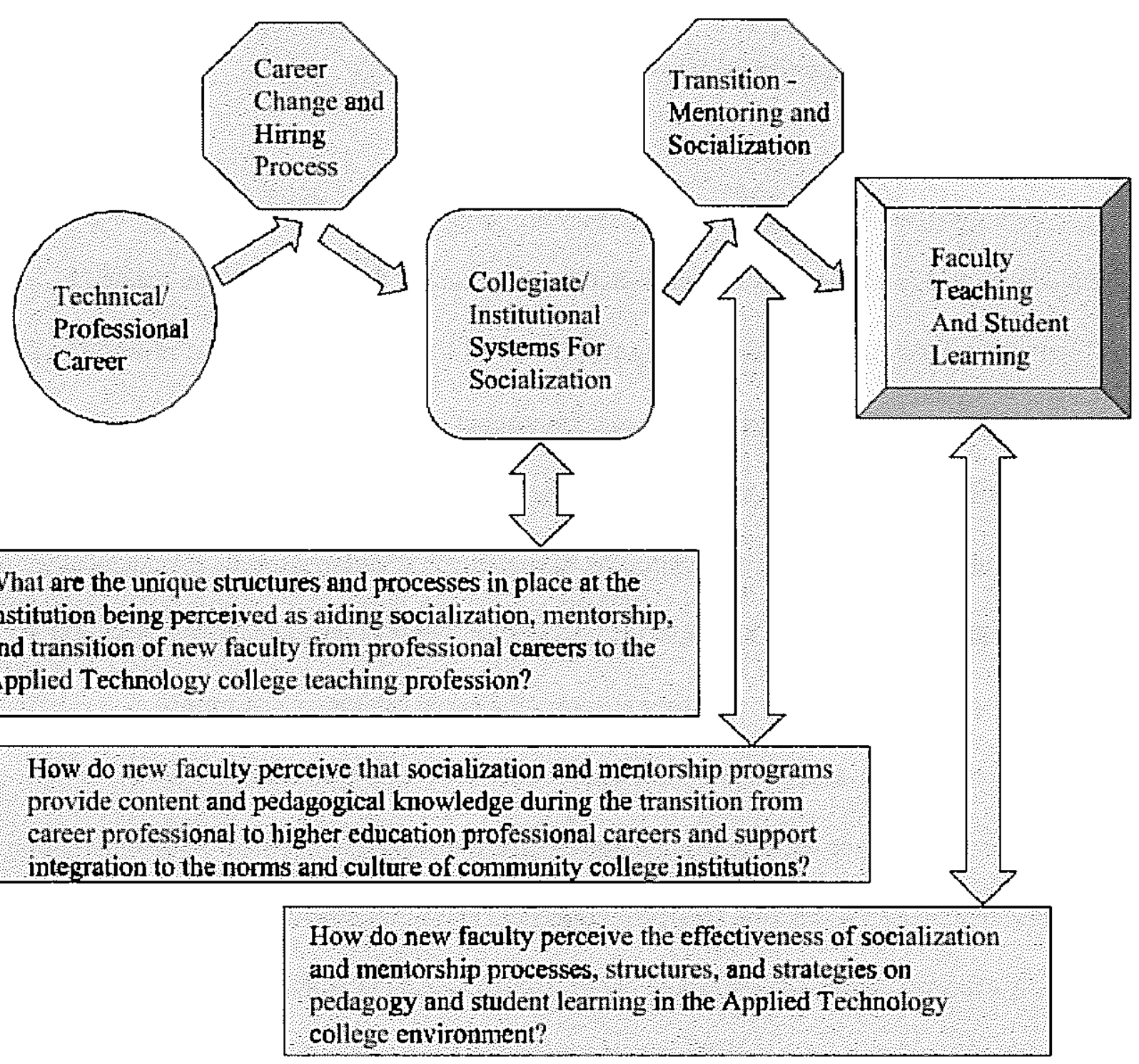

\section{Significance}

There is abundant literature addressing socialization and mentoring in general terms, and also extensive information on this topic related to graduate students aspiring for college faculty positions; however, this research will advance knowledge of an under-researched faculty socialization and transition process: Applied Technology faculty transitioning from their former 
professional careers. This study addresses the perceptions and experiences of new faculty who have recently moved from professional careers, having limited college backgrounds and without formal graduate study experiences, into college teaching careers.

\section{Practical Significance}

The practical significance of this study is bringing a greater awareness of the importance socialization and mentoring have on new faculty transitioning from professional careers to community and technical college teaching positions. Although effectiveness of instruction is a topic for another study, it is anticipated that a by-product of this dissertation will serve to impact the quality of instruction and retention of new faculty teaching at post-secondary community and technical college institutions. This awareness of socialization and mentoring of new faculty members will provide impetus for impacting students and will likely enhance the experience of community and technical college personnel across the range of similar institutions.

Based on the five interviews conducted for this case study, perceptions of the interviewees will provide specific data related to their transition experiences at their institution and department. The number of interviews, conducted at one specific community and technical college, is expected to provide a low level of risk and a broad deviation in data collected. The research findings and recommendations will provide administrators, new faculty, and future faculty direct access to the perceptions of faculty experiences from a typical community and technical college. It is expected that findings from this dissertation will provide administrators, in particular, a basis for justifying their future policies regarding socialization and mentoring of new community and technical college faculty. 


\section{Definitions}

The following terms and definitions associated with this dissertation are referenced from the Wikipedia Glossary of Education Terms as follows:

- Academia: A collective term for the scientific and cultural community engaged in higher education and research, taken as a whole. The word comes from the akademeia just outside ancient Athens, where the gymnasium was made famous by Plato as a center of learning.

- Academic institution: An educational institution dedicated to higher education and research, which grants academic degrees.

- Applied academics (Applied Technology): An approach to learning and teaching that focuses on how academic subjects (communications, mathematics, science, and basic literacy) can apply to the real world. Further, applied academics can be viewed as theoretical knowledge supporting practical applications.

- Experience: Comprises knowledge of or skill in or observation of something or some event gained through involvement in or exposure to that thing or event. The history of the word experience aligns it closely with the concept of experiment. The concept of experience generally refers to know-how or procedural knowledge, rather than propositional knowledge. Philosophers dub knowledge based on experience "empirical knowledge" or "a posteriori knowledge". A person with considerable experience in a certain field can gain a reputation as an expert.

- Higher education: Education provided by universities and other institutions that award academic degrees, such as community colleges, and liberal arts colleges. Higher 
education includes both the teaching and the research activities of universities, and within the realm of teaching, it includes both the undergraduate level (sometimes referred to as tertiary education) and the graduate (or postgraduate) level (sometimes referred to as quaternary education or graduate school). Higher education differs from other forms of post-secondary education such as vocational education. However, most professional education is included within higher education, and many postgraduate qualifications are strongly vocationally or professionally oriented, for example in disciplines such as law and medicine.

- Knowledge: Information of which someone is aware. Knowledge is also used to mean the confident understanding of a subject, potentially with the ability to use it for a specific purpose. The unreliability of memory limits the certainty of knowledge about the past, while unpredictability of events yet to occur limits the certainty of knowledge about the future. Epistemology is the philosophical study of the nature, origin, and scope of knowledge.

- Learning: The process of acquiring knowledge, skills, attitudes, or values, through study, experience, or teaching, that causes a change of behavior that is persistent, measurable, and specified or allows an individual to formulate a new mental construct or revise a prior mental construct (conceptual knowledge such as attitudes or values). It is a process that depends on experience and leads to long-term changes in behavior potential.

- Lecture: An oral presentation intended to teach people about a particular subject, for example by a university or college teacher. Lectures are used to convey critical information, history, background, theories and equations. A politician's speech, a 
minister's sermon, or even a businessman's sales presentation may be similar in form to a lecture. Usually the lecturer will stand at the front of the room and recite information relevant to the lecturer's content.

- Liberal arts: Studies that are intended to provide general knowledge and intellectual skills, rather than more specialized occupational or professional skills. The scope of the liberal arts has changed with society. It once emphasized the education of elites in the classics; but, with the rise of science and humanities during the Age of Enlightenment, the scope and meaning of "liberal arts" expanded to include them. Still excluded from the liberal arts are topics that are specific to particular occupations, such as agriculture, business, dentistry, engineering, medicine, pedagogy (school-teaching), and pharmacy.

- Mentoring: A developmental relationship between a more experienced mentor and a less experienced partner referred to as a mentee or protégé. Usually - but not necessarily - the mentor/protégé pair will be of the same sex. The roots of the practice are lost in antiquity. The word itself was inspired by the character of Mentor in Homer's Odyssey. Though the actual Mentor in the story is a somewhat ineffective old man, the goddess Athena takes on his appearance in order to guide young Telemachus in his time of difficulty.

- Mentorship: A relationship in which a more experienced or more knowledgeable person helps to guide a less experienced or less knowledgeable person. The mentor may be older or younger than the person being mentored, but she or he must have a certain area of expertise. It is a learning and development partnership between someone with vast experience and someone who wants to learn. 
- Pedagogy: The art or science of teaching. The word comes from the ancient Greek paidagogos, the slave who took little boys to and from school as part of paideia. The word "paidia" ( $\pi \alpha \iota \delta ı \alpha$ ) refers to children, which is why some like to make the distinction between pedagogy (teaching children) and andragogy (teaching adults). The Latin word for pedagogy, education, is much more widely used, and often the two are used interchangeably.

- Post-secondary education: Any form of education that is taken after first attending a secondary school, such as a high school. The purpose of a post-secondary education can be to receive vocational education and training or to prepare for professions or scientific/academic careers through higher education.

- Research: Often described as an active, diligent, and systematic process of inquiry aimed at discovering, interpreting and revising facts. This intellectual investigation produces a greater understanding of events, behaviors, or theories, and makes practical applications through laws and theories. The term research is also used to describe a collection of information about a particular subject, and is usually associated with science and the scientific method.

- Socialization: A term used by sociologists, social psychologists, anthropologists, political scientists, and educationalists to refer to the lifelong process of inheriting and disseminating norms, customs, values and ideologies, providing an individual with the skills and habits necessary for participating within their own society. It is the means by which social and cultural continuity are attained. 
- Technology education: The study of the human ability to create and use tools to shape the natural environment to meet their needs. The goal of technology education is to spread technological literacy which is accomplished by bringing laboratory activities to students. The term "technology education" is frequently shortened to "tech ed".

- Vocational education: (or Vocational Education and Training (VET)) Prepares learners for careers or professions that are traditionally non-academic and directly related to a specific trade, occupation or vocation, hence the term, in which the learner participates. It is sometimes referred to as technical education, as the learner directly specialises in a particular narrow technique of using technology. (https://en.wikipedia.org) 


\section{Chapter Two}

\section{Review of Literature}

The individual pursuit of higher education as a path for future college faculty assimilating to the culture of academic careers is essential, but the diversity of institutions and relative institutional missions' impact on new faculty careers is evident when reviewing relevant literature. Following a historical context of higher education and community college, this chapter will examine the higher education context of socialization, the meaning of socialization related to new college faculty, mentoring as an aspect of socialization, the results of socialization, the emphasis of socialization on teaching, and programs for enhancing socialization of new college faculty.

\section{Historical Context of Higher Education and Community College}

The wide range of higher education institutions and diversity of curriculum, available in American colleges and universities today, creates a situation, whereby graduate students from research universities are not adequately socialized for faculty positions into which they are hired. The system of higher education today has "something to offer virtually everyone, to some extent now without having to show evidence of academic talent or qualification" ("History of American," p. 3). This accessibility to higher education is in contrast to the historical roots of academia that evolved from a system of exclusivity. The concept of post-secondary education has expanded from the colonialists' original ideals to the broader two- and four-year institutions now thought of as "college." For that matter, today's version of higher education now "includes all the trade, vocational, and career institutes, as well as academic colleges and university programs offered by thousands of institutions nationwide" ("History of American," p. 1). To 
understand this phenomenon, a historical perspective of higher education evolution, with an emphasis on developments in community colleges, will serve as a context for socialization of higher education faculty.

The oldest institution of higher learning in the United States is Harvard University, which was founded in 1636 in present-day Massachusetts. The Puritans of Boston believed strongly that young men from New England should be able to advance their education in their own country. "Their model was a college of the sort some had known at Cambridge and the new institution's principal function was the training of clergymen" (Silber, 1985, p. 1). Prior to the Revolutionary War of 1776 , nine institutions were granted charters to educate the more privileged class of colonists. As a result, many of today's prominent universities in the United States originated during this period under the control of religious affiliations of Puritans, Presbyterians, Baptists, and the Church of England, for example:

The colonial colleges - Harvard, William and Mary, Collegiate School (which became Yale), Academy of Philadelphia (University of Philadelphia), College of New Jersey (Princeton), King's College (Columbia), College of Rhode Island (Brown), Queen's College (Rutgers), and Dartmouth - were, however, modeled upon Cambridge and Oxford and, like their English models, in many cases required religious affiliation ("History of American," p. 2).

According to Silber (1985), two trends became apparent after the Revolutionary War; first was the hesitant entry of the states into higher education, whereby states set aside land for colleges that were privately funded. Secondly, a vigorous program of college building was undertaken by the various religious denominations. In addition, some of the religious groups were dedicated to 
the education of students without regard to creed, hence "the vigor and diversity of the system of education thus created is an enduring contribution to our national educational life" (p.706). Correspondingly, the American Enlightenment experience fostered the foundation of secularism and human rights that influenced the colonial education system. "Thomas Jefferson was among the earliest proponents of stated education in America (from primary school through college) based on scientific exploration as a pursuit wholly distinct from religious teachings and indoctrination" ("History of American," p. 2). Jefferson's ideal higher education system emphasized the lecture method of instruction and also implemented an elective curriculum, free from religious affiliations. In effect, this was a system of education that would be adopted by the growing network of colleges during that time and has expanded to "nearly 117,000 primary and secondary schools, nearly 6,000 post-secondary career and technical schools, and just under 4,000 degree-granting institutions of higher education" (International Affairs Office, U.S. Department of Education, 2008) currently in the United States.

Many of the colleges and universities providing post-secondary education to students today exist as a result of federal legislation passed during the 1860s. The Morrill Act of 1862, also known as the Land Grant Act of 1862, was signed into law by President Abraham Lincoln, "which set aside federal lands in each state to endow a state-operated institution devoted to agriculture and the mechanical arts" (Silber, 1985, p. 707). The original legislation endowed each member of Congress 30,000 acres of land, which fostered the expansion of the system of normal schools, known as teachers' colleges, further developing programs in areas of science and technology. According to Jurgens (2010), "this Act was followed by the Morrill Act of 1890 , with a goal of fostering educational opportunities in public higher education for all 
students, including women and minorities" (p. 252). In addition to the Morrill Act, the influence of American academics, who had completed their education in German universities, was significant. Silber (1985) noted, in the German system of education, they found curriculum and instructional methods not being practiced in the United States or in England. "Some of them determined to return home and establish institutions of higher learning that would try to emulate the comprehensiveness of the German university while maintaining the concern for the undergraduate curriculum that was typical of the American college" (p. 707). Describing the contrasting influence of the English and German models of higher education Fincher (1996) explains:

The prominence of the Doctor of Philosophy degree (Ph.D.) as a "license to teach" in American universities, a pronounced emphasis on research and publication in scholarly journals, and the prestige that is often attached to scientific status in economics, political science, and sociology are indicative of Germanic influence. A continuing concern for the liberal arts as the core of undergraduate curricula, a commitment to students in the form of numerous services and scheduled activities, and the organization of our universities into separate colleges for purposes of teaching and learning are indicative of British heritages. (p. 1)

The two influences of English and German higher education practices combined to affect the development of the American college and university system during the early 19 th century. As the university system continued to evolve during the late 19 th century, a plan to separate the first two years of college from the second two years was developed by the president of the University of Chicago president, William Rainey Harper. Kane (1999) explained, 
university-affiliated six-year high schools and two-year colleges were created using the German university model. The institutions were, "called 'junior colleges,' that would teach students the lower-division 'preparatory' material. Although their evolution differed across the country, junior colleges were generally designed to increase access to higher education without compromising and burdening the existing four-year colleges" (p. 64). These two-year colleges were typically distinguished for being accredited to award associate degrees in arts and science as the terminal degree. According to Kane, "these schools include both public and private two-year colleges and many technical institutes, but excludes publicly funded vocational schools, adult education centers, and most proprietary schools" (p. 64). The programs prepare students for two primary educational paths, one being the traditional college-level courses for an associate degree and preparation for further study toward a bachelor's degree, and secondly, vocationally oriented degrees for career preparation (Kasper, 2002, p. 14). In contrast, the career and technical colleges were to focus on short training courses, and sometimes specialized degree programs, and were typically termed post-secondary vocational education. Consequently, unlike four-year colleges and universities, two-year colleges carry out their mission while serving as open-access institutions, often accessible to individuals who would not otherwise participate in higher education (Bragg, 2001, p. 94).

Evolution of higher education during the 20th century was advanced as the Second World War came to a close. The Servicemen's Readjustment Act (GI Bill) of 1944 began an increase of enrollments at colleges and universities; this legislation proved to have more dramatic long-term implications for higher education than any other legislation since the enactment of the Morrill Act. Silber (1985) claimed, "it gave real meaning to the concept of educational opportunity - 
including both access and choice - for all who had served their country in the war, without regard to their economic or social background" (p. 2). The funds from this Act allocated money to students for the cost of a full-time education for three years. As a result, some 4.4 million of the 15 million veterans receiving GI Bill benefits went to college ("History of American," 2008). Henceforth, after the GI Bill, the 1947 Truman Commission Report was drafted, resulting in a bold support of vocational education as a means of improving and expanding access to higher education. Regarding the impact of the Report's emphasis on accessibility of higher education, Jurgens states:

The Report called for the establishment of a network of public community colleges, which would combine the finest vocational and technical education with the more conventional junior college education. The objective was to open higher education for little or no tuition, to a diverse group of students, including women and ethnic minorities, while serving community needs. (p. 254)

As a result, during the first half of the twentieth century the ideal of a college education as a means of socio-economic upward mobility had taken shape.

During the 1950s, a number of federal government programs were initiated to enhance enrollments by increasing the availability of grants and loans. Federal legislation was a significant stimulus, "the National Defense Education Act of 1958, demonstrated the government's belief in the need for Americans with degrees in science and engineering, as a result of fears that developed when the Soviet Union launched Sputnik the year before" ("History of American Higher Education," 2008). Silber (1985) described, in 1957 the first Russian satellite was launched, which created a "headlong" rush by the United States to compete in the 
area of educational excellence. During this time period, federal and state governments began offering new programs with financial inducements for substantial expansion of higher education. "Massive new subsidies, directed by state legislatures to the state sector, greatly increased appropriations for building new campuses and greatly increased subsidies for the price of tuition" (p. 3). The influx of financial allocations was dramatic:

Consequently, between 1950 and 1990, the number of colleges and universities almost doubled, from 1,851 to 3,535 , and state and federal spending on higher education has soared. Higher education is, simply put, perhaps the single "most successful industry of postwar America. Status, students, and optimism fueled the drive to expand resources and facilities and build stronger institutions during this "golden age" of American colleges and universities. ("History of American," 2008)

Under those circumstances, with regard to community colleges in particular, enrollments soared during the 1960s. Jurgens (2010) claimed, community colleges "student enrollment increased from about 1 million in 1965 to about 2.2 million by 1970 . This explosion continued through the 1970 s and by 1980 s hit 4.3 million" (p. 255). Furthermore, during this period, community colleges created joint ventures with businesses and partnerships with high schools were strengthened. As a result, the total number of community colleges increased from 457 during the 1960s to 1106 by 1990 (p. 256). In addition, Kasper (2002) stated: ...of the students attending degree-granting institutions in 1965,74 percent were enrolled in four-year schools while 26 percent were attending two-year colleges, emphasizing the growing community college contribution to higher education. The ratio changed 
dramatically by 1992 ; whereby the percentage of public college students enrolled in community colleges almost doubled, to 48 percent. (p. 19)

Additionally, Kasper described the growing contribution of community colleges to higher education as follows:

Enrollments at community colleges leaped 413 percent from 1965 to 1999 , increasing from about 1 million to about 5.3 million, while those at public 4-year institutions increased 104 percent, from about 2.9 million to about 6 million during the same period. The growth of community college enrollments is expected to continue outpacing increases in enrollments at public 4-year baccalaureate colleges and universities. This is because many 4-year colleges are becoming increasingly selective in an effort to improve the academic quality of their incoming students. Furthermore, growth in certification programs and workforce training classes will continue to boost enrollments in community colleges. (p. 19)

The programs being offered by the two-year colleges, as an effort to support community business partners, high schools, and non-traditional student market, affected significant growth to student enrollments.

The expanding enrollment of community colleges, is in large part, due to the demographic characteristics of the students and the criteria established for acceptance to higher education programs the institutions offer. Research by Bragg (2001) concluded, community college students are typically older, more often women and members of racial or ethnic groups, not attending full-time due to job requirements or family responsibilities, and likely the first family member to attend higher education, compared to the 4-year student body. Bragg claimed, 
"student populations of community colleges have been much more diverse than populations of 4-year colleges. However, as community college enrollments rose since the 1960 s, community college students as a whole became more diverse - more nontraditional - than in earlier years" (p. 95). A study of community college student characteristics by Kane (1999), determined these institutions are appealing to a demographic of students considering a lower cost of attendance for higher education and more flexible schedules. Kane claimed:

The average tuition is less than one-half that at public four-year colleges, and because community colleges are located in most towns and cities, many students can live at home while attending college. Community colleges have also lowered other costs of attendance. Courses are not only offered during the "traditional" daytime hours, but also at night and on weekends. Many community colleges offer courses at work sites, or via audio, video, or computer technologies. As a result, 84 percent of community college students work while also attending college compared to 78 percent of students attending comprehensive four-year colleges. (p. 66)

Finally, increases in community college enrollments are attributed to their open admission enrollment policies. These institutions provide comprehensive programs and services to a wide range of student demographic, rarely excluding anyone from course work on some level. Jenkens (2017) stated, "many unprepared students will continue pursuing higher education to chase the American dream. And most of them will end up at two-year colleges, and because two-year institutions are about the only ones actively recruiting remedial students these days" (p. 2). Having an inclusive enrollment policy, community colleges attract students pursuing both transfer programs to those who have yet to graduate high school. As Bragg explained, 
community colleges focus on offering all types of programs to suit the needs of students and business community, emphasizing flexible schedules, small class sizes, and innovative formats to meet individual needs (p. 97). These programs are uniquely designed for the two-year college mission, versus that of typical four-year colleges and universities.

The community college context is only partially understood by examining student demographics; the characteristics that distinguish two-year from four-year faculty are equally important. According to the International Affairs Office, U.S. Department of Education (2008) community colleges are "comprehensive public institutions that provide a wide variety of educational services, ranging from adult and community education services, through post-secondary career and technical education to academic and professional studies at the university level permitting transfer to higher level studies" (p.2). In order to fulfill that mission, Jenkins (2017) stated, at community colleges, teaching is the core of the institutional mission. An emphasis on teaching is the highest priority when recruiting new faculty. At Jenkin's community college, when hiring new faculty, the administration looks for the best teachers they can find - not the best researchers or the biggest names. To put this in perspective, the following point is made:

Sure, if you love Shakespeare, it might be wonderful to take a course from a famous Shakespearean scholar at one of the world's great universities, even if "taking the course" simply means watching videos on your computer. But all of those students who don't love literature-or biology, or calculus, or whatever-are just looking for a teacher who can help them learn the material and get through the course. And an increasing number of them are looking for those teachers at community colleges. (p. 3) 
Furthermore, excellence in teaching may be difficult to quantify; however, the amount of time teaching and the qualifications of faculty dedicated specifically to instruction can be measured. The research of Kane (1999) documented differences between two-year and four-year faculty that is presented in Table 1 as follows:

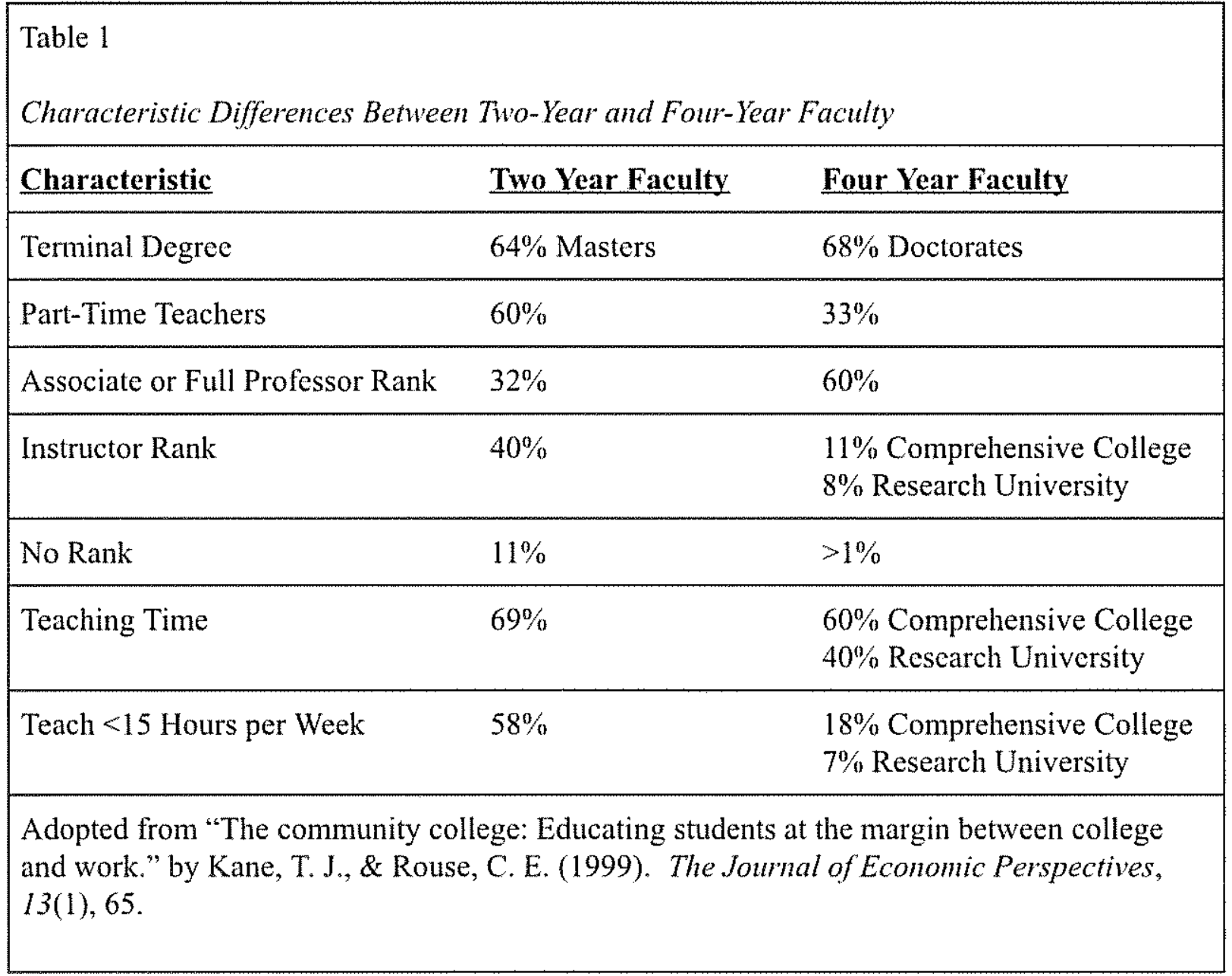

Table 1

As indicated above, community college faculty dedicate the majority of their time and expertise focused on teaching activities in the classroom and laboratory. Their emphasis is on improving 
methods of instruction and advising, versus seeking advanced degrees and participating in original research activities.

Community colleges have traditionally provided access to higher educational opportunities to students who otherwise would have been denied acceptance to four-year institutions. The two-year colleges offer certificates, associate degrees, and often have transfer agreements with four-year colleges and universities. These agreements allow students to complete the first two years of their coursework at a community college, thus reducing the cost of obtaining a four-year bachelor's degree. Jurgens (2010) stated, "the influence of the community college system in our society is astounding with $46 \%$ of the nation's undergraduates attending community colleges" (p. 257). Jurgens explained further, that the challenge these colleges face is overcoming perceptions by some, that the quality of coursework and instruction is inferior relative to four-year institutions (p. 258). In addition, community colleges are challenged by having to adapt quickly to technology factors affecting most of the demographic, economic, and academic demands. Those entering the labor force are increasingly in need of added skill sets provided through post-secondary education. Kasper (2002) claimed, "as higher education evolves, it increasingly emphasizes the value of credentialed and non-credentialed knowledge and skill" (p. 21). Thus, community colleges continue to focus on curriculum flexibility in addressing changing educational and training needs of students and industry.

Having addressed the historical context of higher education and community college system, a foundational perspective has been presented regarding the institutional framework into which new faculty begin professional academic career. Further discussion regarding the cultural 
dynamic of the higher education into which new faculty are being socialized will provide a contextual basis for understanding the socialization process for future academic professionals.

\section{Higher Education Context of Socialization}

To begin a discussion of the socialization for those entering the ranks of college and university professorial careers, it is important to provide a perspective of the culture into which graduate students and clinical professionals are transitioning. Although many aspects of higher education have changed in the past decades, those associated with economy, efficiency, and accountability have been at the forefront for the past 40 years. Cady (1973) described higher education in a context with many pressures associated with faculty being tasked with performing to higher standards with fewer resources expended. Both direct and indirect mandates require faculty to become more economical and budget conscious, use less resources to achieve higher standards of quality, and become more efficient in producing graduates in a shorter amount of time. In addition to these areas of accountability, academic faculty members are under continual scrutiny regarding effectiveness of their teaching and contribution to the institutional mission. As a result of interviews with junior faculty, Trower (2010) described concerns of time management challenges as novice faculty strive to juggle the current demands of the academic career culture. Prioritizing what matters, without neglecting other responsibilities or alienating departmental colleagues by forgoing additional teaching and service work, is a delicate balance. Therefore, given the forces shaping higher education, the role and responsibility of academic faculty has transformed into a culture much different from that of forty years ago. The full-time faculty core mission of teaching, research, and service, shown in Table 2 , is slowly giving way as 
institutional efforts emphasize hiring larger segments of their staff into part-time and/or non-tenure track roles, Table 3.

\section{Table 2}

The Integrated Faculty Role in the U.S. Higher Education Model

Teaching

- Course preparation

- Course delivery

- Student interaction

- Assessment

- Tutorial

- Clinical supervision

- Thesis guidance

\section{Research}

- Proposal preparation

- Infrastructure maintenance

- Research execution

- Staff supervision

- Budget administration

- Report preparation and publication

\section{Service}

- Internal

o Department

o Institution

- External

o Local community

o Professional associations

Adapted from "A new higher education: The "next model" takes shape." by Finkelstein, M., M. Seal, and J. Schuster, (2011) Advancing Higher Education, p. 4.

Table 2

Table 3

Emerging Re-configurations of Faculty Functions in the U.S. Higher Education Model

\begin{tabular}{|l|lll|}
\hline Part-time Adjunct & Full-Time, Limited Contract & \\
\hline Teaching & Teach - Only & Research - Only & Service - Only \\
\hline - Course delivery & - Course preparation & - Research execution & - Program \\
- Student interaction & - Course delivery & - Presentation & director \\
- Partial assessment & - Student interaction & - Report preparation and & - Limited \\
& - Assessment & publication & teaching \\
& - Academic advisement & & \\
& - Tutorial & & \\
& - Clinical supervision & & \\
\hline
\end{tabular}

Adapted from "A new higher education: The "next model" takes shape." by Finkelstein, M., M. Seal, and J. Schuster, (2011) Advancing Higher Education, p. 4. 
In addition, Finkelstein, Seal, and Schuster (2011) note that these developments strike at the model of "integrated" academic roles and the model of "institutionally based" academic careers. These changes in the institutional model have been influenced by demographic shifts in the academic workforce, along with increased prominence of professional fields and emergence of non-research sectors within higher education. "This has meant the introduction of large numbers of faculty who come to academic work without the traditional socialization in doctoral programs and not infrequently from post-professional training work-roles outside academe" (p. 1). Lastly, Altbach (2006) pointed out a fundamental shift in the academic profession in the United States, where more than half of the new appointments to teaching positions are either part-time or full-time, but non-tenure track. "These new job categories are much less attractive, and the "best and brightest' will avoid them" (p. 160). Not only have the roles changed, but the institutional structure has also transformed into segments of higher education with unique characteristics to which socialization is necessary.

As these institutional structures have developed, the role of higher education has also been adjusting to influences that shape demand for both research scholars and an educated workforce alike. For graduate students aspiring to professional academic careers, a dilemma exists due to the limited number of positions available at research institutions, at which they are being socialized. Gardner (2007) noted that a knowledge of the culture in which graduate students exist leads to a better understanding of challenges of higher education. The culture, norms, and rules will vary; however, depending on the employment at a research university, liberal arts college, community college, or other specialized type of institution. Rosser (2004) pointed out: 
Different institutional types have different criteria for faculty work that is conducted and rewarded in terms of teaching, research, and service, and of course for earning promotion and tenure. So the notion goes, if you don't like doing research, you shouldn't be working as a faculty member in a doctoral/research extensive or intensive university. (p. 28)

Graduate students and career professionals transitioning into the academic profession should understand that, "it is difficult to generalize about the professoriate because the working conditions, salaries, and culture vary so much according to institution type, discipline, and other variables" (Altbach, 2006, p. 161). Research conducted by Braxton and Berger (1999) concluded that differences among academic disciplines are wide-ranging and have significant implications for academia. The differences in phenomena vary on a broad scale of disciplines, institutions, departments, and individual faculty members. "Thus it is not unreasonable to expect that new faculty in various academic disciplines will differ in their experiences with psychological and organizational factors" (p. 244). Therefore, it is essential that graduate students and career professionals, preparing for future higher education teacher roles, become socialized for the various roles for which they will be responsible.

The dynamic roles which new college faculty are in need of socialization have been dramatically impacted by the technology in place for expanded communication, research, and course delivery. Recent technology developments during the past two decades provides digital access to educational opportunities on a global basis. Finkelstein et al. (2011) stated:

Young people come to college oriented more toward digital than text literacy, with shorter attention spans, expectations of immediate access and gratification, and with different 
sources of knowledge and approaches to investigating the world. Teaching almost certainly involves a digital component or platform, is less time- and place- bound and generally more public. Scholarship has changed as well with digital access to almost any piece of knowledge in moments and instant collaboration with colleagues both synchronously and asynchronously. (p. 2)

It is further noted that the traditional classroom-based model of instruction is changing. Professional academics who simultaneously engage in research and teaching during face-to-face interaction with limited groups of full-time traditional resident students are no longer an efficient means of delivery to the majority of the college-age population. Due to institutions creating more online courses, research indicates new faculty is expected to adopt a more diverse skill set than older generations. Sabin (2007) commented that new faculty coming out of graduate school have difficulty motivating students in this dynamic educational environment. They are often not prepared to deal with the disruptive and nonparticipating students as they transition to a teaching role. Sabin stated:

New faculty are in need of socialization, so they can learn what the expectations are, and how to meet those expectations. Unfortunately, because many schools do not make a concerted effort to socialize new faculty, the tensions of new faculty actually increase during the pre-tenure years. (p. 8)

Analogous to this dilemma is the adjustment career professionals encounter while transitioning to a faculty role.

Within the context of higher education institutional dynamics are the expectations academic administrators have regarding potential new faculty. There continues to be an 
increasing demand from the public for accountability and transparency regarding the costs and benefits of higher education. According to Trower (2010), an increasing number of first generation of students, pressing on institutions for their higher education needs, will continue to place expectations on higher education faculty productivity in the classroom, the laboratory, and beyond (p. 30). Administrators are seeking faculty members who are aware of these expectations and can contribute to the welfare of their discipline and institution. As Meacham (2002) stated:

The faculty they would like to hire would understand what it means to be in a community of scholars day in and day out, help make departments run smoothly, understand the institution and be committed to institution building, be good colleagues, contribute to advising, to faculty governance, and to the campus community, bring out the best in their colleagues and empower them to be better, be agents of change right away and not wait until after tenure, have a sense that what they do -- and what the institution does -- makes a difference in the community, and would be comfortable juggling a lot of balls at once. (p. 24)

In contrast, research by Lindholm (2004) revealed reasons for individuals attracted to higher education faculty careers include an inherent personal need for autonomy and independence, a drive for gaining a greater understanding of their discipline or field of study, and a belief their talents and knowledge will be congruent with the culture and demands of an academic career (p. 624). It was discovered that this expectation was consistent throughout the broad scope of higher education institutions (comprehensive state college, private non-sectarian college, religiously-affiliated college, public university, or private university). 
As a result, this dichotomy is one form of cultural misconception newcomers to college careers confront. For those graduate students and transitioning career professionals new to higher education, they must adapt to a reality that not many graduates will find employment at research universities similar to those where they were educated. Also, newly hired faculty who have graduated from research universities will have to adjust to the reality that various institutions of higher learning have diverse governance characteristics depending on the academic mission.

Many aspiring graduate students and career professionals seeking higher education faculty positions will not be filling that role at four year colleges and research universities; their path will lead them to community and technical colleges. The faculty will assume some similar responsibilities as college and university faculty with regard to teaching and service to the institution, but research is often substituted for duties such as recruiting, orienting, advising, counseling, assessing, tutoring, graduating and job placing. In research on Louisiana Technical College faculty, Thornton (2010) pointed out the low priority for faculty to produce scholarly publications because the amount of time teaching. The research by Thornton found classroom teaching comprises $70 \%$ of faculty's work week during the first three years of his or her appointment. Furthermore, teaching responsibilities at these institutions consisted of 30 contact hours of classroom teaching per week, for full-time faculty. Thornton explained:

This concept is difficult for other higher education institutions to comprehend because faculty workload is usually defined by credit hours and course work, not classroom contact hours. In the technical college, instructors are seen as facilitators of learning. 
Courses are taught to mastery levels of learning, as students need them, regardless of where they are in the curriculum. (p. 32)

For new faculty entering the academic workforce immediately upon completion of graduate school, this can require a period of adjustment. In a like manner, career professionals will discover a culture in higher education much different from their experience in industry. Finkelstein et al. (2011) described the changing role professional schools are playing on campuses as:

...engines of fundraising, resource acquisition and power. This has meant the introduction to American campuses of center of influence and large numbers of faculty outside the traditional arts and sciences. They come to the university without traditional socialization in doctoral programs and not infrequently from post-professional training work roles outside academe. (p. 7)

Post-professionals beginning their academic teaching career find themselves in a culture much different from which they experience in industry. Jensen, Rabe, Runde and Wee (2006) pointed out differences in job demands, competition of advancement, decision making, scholarship, and faculty meetings are all areas where socialization can be effective for improving transition.

These differences are highlighted in Table 4 as follows:

Table 4

Areas For Effectively Improving Socialization of Faculty

\section{Topic: $\quad$ Difference:}

Job demands

- Not the same pressure of large budgets and quick decisions.

- Demand of daily deadlines for class preparation

- More autonomy as "your own boss"

- Limited opportunity to delegate tasks 


\begin{tabular}{|l|l|}
\hline Table 4 Continued & Difference: \\
\hline $\begin{array}{l}\text { Topic: } \\
\text { advancement }\end{array}$ & $\begin{array}{l}\text { Recruited faculty fill an open position and are promoted to higher } \\
\text { rank based on performance } \\
\text { - }\end{array}$ \\
\hline Limited peer competition for advancement
\end{tabular}

Table 4

Given these points, an understanding of the personal goals of new faculty and the changing culture shaping institutions emphasizes the importance of socialization to attract and facilitate their careers as they begin their transition. Advantages tend to favor the adjustment of faculty who tend to understand and match their expectations with those of their chosen institutional career path. Braxton and Berger (1999) claimed, "new faculty may select themselves into the type of institutional setting that best fits their perceived abilities and role preferences. Thus, adjustment to the faculty role by new faculty is easiest for the professional role that is given greatest emphasis by the employing college or university" (p. 251). 
In summation, it appears evident that the primary process by which new faculty transition to higher education careers is socialization. With this in mind, further discussion of the various aspects of the socialization process for new college faculty will aid in defining and explaining how to tie faculty expectations with institutional culture.

\section{What is Socialization For New College Faculty?}

The socialization process for developing future academic professionals is as varied as the multitude of institutional settings and program disciplines into which graduate students and career professionals aspire. Given the diverse nature of institutions and programs, this discussion of socialization will focus on four conceptual areas that can be applied on a broad scale. Initially, an examination of the stages of development during the socialization process will establish a foundation of this concept. Secondly, a description of the interactions occurring in the process will address the various levels of cultural blending encountered. Thirdly, theories of identity development and grooming will be described based on their contribution to the socialization process of academic professionals. Lastly, this discussion will make note of the ethics and collegial responsibilities future academic professionals will encounter as they become socialized. All in all, each of these topics can be considered applicable to many of the diverse academic disciplines future collegiate faculty will encounter.

When considering socialization in general terms, it can be considered a process of adapting to the norms, customs, values, and principles associated with an organization, group, or culture with which an individual associates. To clarify, Woods (1999) explained culture as being reflected in the beliefs held by the members of an organization or group. Norms, however, are the shared beliefs among a group which communicate the expectations of individual behavior. 
The norms are important because they make individual behavior uniform and predictable, therefore, limiting awkward exchanges among group members. The norms work to shape perceptions of faculty performance standards and can be modified to shift with changing group membership and new institutional policies. Thornton (2010) described socialization in terms of an individual conforming to the norms and values needed to function in a given society. Therefore, it is considered a process through which a person transforms to become part of a group or organization. With regard to higher education, it is thought of as a rite of passage whereby instructors become inclusionary members of the post-secondary institution. Lastly, Thornton suggested socialization encompasses more than merely acquiring skills, values, and knowledge; it is a process of cognitive and affective maturation that culminates in a commitment to and identification with a particular profession.

From similar perspective, Sabin (2007) defined socialization as a lifelong process of becoming a participating member of a group, whose norms and culture are internalized individually. In addition, Sabin described socialization as a process through which an individual transitions from being a new entrant to becoming an accepted member of a group, organization, or community. It is an accommodating process which takes place when new entrants into an organization engage with the cultural norms, expectations, and needs of their new organization. Furthermore, Chao, O'Leary-Kelly, Wolf, Klein, and Gardner (1994) referred to socialization from an organizational perspective. As such, socialization addresses learning the content, and processes so an individual adjusts to specific roles within the organization. This concept has progressed from the idea of "learning the ropes" to a more refined definition of a process whereby individuals assimilate the values, abilities, expected behaviors, and social knowledge 
necessary to become a participating member of the organization. This is therefore considered a primary process whereby people adapt to new jobs and organizational roles. With regard to higher education institutions, Mendoza (2008) suggested the socialization process occurs both formally and informally. Within this concept:

Formal socialization is explicit and includes faculty development programs as well as promotion and tenure processes. However, most of the time, socialization occurs informally. Informal socialization is difficult to observe and analyze since it can occur through informal contacts, such as conversations with senior faculty members over coffee or by observing the actions of faculty in leadership positions. (p. 105)

Finally, the dynamic nature of higher education institutions impacts both newcomers and incumbent faculty members causing an ongoing process of organizational socialization. Chao et al. (1994) noted that socialization research focuses predominantly on newcomers, but a core aspect of the socialization process is that it continues throughout an individual's career. Thus, there can be a wide range of role changes of organizational members ranging from formal job/career changes to personal life changes which redefine priorities and perspectives. Based on the array of changes occurring at higher education institutions, new learning and resocialization of current and future faculty are essential.

Having established a working definition of socialization, a closer review of various theories, starting from a basic perspective and moving to more complex ideas, will aid in application of this concept. To begin this examination, a two-stage process is described by Mendoza (2008), in which the anticipatory and the organizational are posited as a framework for faculty socialization. The first stage occurs for traditional graduate students as anticipatory 
socialization, whereby future faculty will learn the attitudes, actions, and values inherent in their discipline of study. While interacting with their professors, graduate students become aware of and begin to internalize the behavioral norms, support systems, demands for research and publication, and institutional ethics ascribed to their field of study. During the second organizational stage, new faculty members embark on their academic careers in earnest. Within this stage faculty will experience two phases: initial entry and role continuance. Formalities associated with entry phase of organizational employment include recruitment, selection, and orientation when hired by the institution. Once new faculty members become formally established, the continuance role begins. Because the organizational socialization stage is framed by the prior anticipatory stage, the new faculty member is subject to either congruence or discord depending on whether his or her role expectations are affirmed or not. In many instances, a mutually adaptive process may be necessary whereby both sides strive to modify their cultures to find common ground.

For example, a new faculty member who has been trained in a research university and goes to a liberal arts college could have socialization mismatches at the organizational stage given the differences in teaching and research values at both types of institutions. (Mendoza, 2008, p. 105)

This process provides an introduction to other theories that further examine faculty socialization.

To expand upon the two stage process, Sabin's (2007) research described faculty socialization as a three-step process to promote adaptation and influence personal investment in a department and institution. According to Sabin, the process consists of three steps: exploring career options, giving up the previous roles, and accommodating the new roles. It is during 
graduate school and the job search timeframe when the exploration phase occurs, as potential faculty focus on the first stage of their career and institution. Upon entering their new academic career, they begin to relinquish previous role traits. Lastly, the new faculty assimilate to their new positions and learn to adapt to their new roles. Because of the dynamic nature of institutions, faculty body at large is in a continual state of change, losing and gaining members; therefore, the need for socialization is always occurring as institutions are modified by the impact of changing faculty employment. "When old members leave, they may take certain ideas and traditions with them. When new members join, they bring new ideas and traditions to their new departments and institutions" (p. 3). In a similar manner, Gardner (2007) stated:

It is the socialization process that allows education to achieve its goals. Through the socialization process the individual acquires the knowledge and skills, the values and attitudes, and the habits and modes of thought of the society to which he belongs. Thus, the socialization process encompasses all learning -- the affective as well as the cognitive. (p. 724)

In other words, this can be considered an ongoing series of developmental stages throughout a degree program. The stages consist of a set of skills and a base of knowledge that students need to acquire in order to become effective college faculty. Referring to Figure 2, Gardner described this process of graduate student socialization, or the systematic series of actions and changes, by referencing theorists' developmental stages as follows: Anticipatory, Formal, Informal, and Personal. 
Figure 2

Developmental Stages of Graduate Student Development

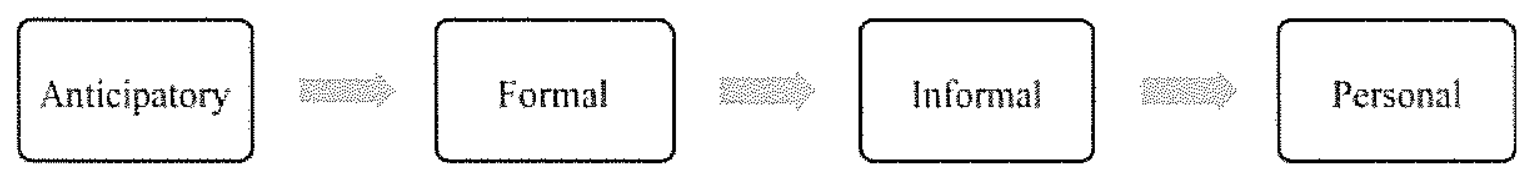

Expanding on this concept briefly, the Anticipatory Stage occurs as a student begins a program of study. His or her expectations of the program adapt to an initiation into the new roles, procedures, and agendas to be followed. The Formal Stage occurs during interactions between faculty and students and observation of older students in order to understand role expectations. The Informal Stage is related to students assimilating the expected behavior of incumbents in a program or department. It is at this stage where students adapt to a more professional level, beyond that of a novice student. Finally, during the Personal Stage, the student develops a unique identity that allows for coexistence in his or her environment. The student accepts the values characteristic of a discipline and is able to distinguish a role transformation allowing him or her to work effectively in the social structure. This series of developments varies based on individual maturity and background, departmental support, and academic program; therefore, the theory is flexible in nature (Gardner, 2007, p. 728). Although linear in design, it is a version of the socialization that can be expanded.

Similar to Gardner's (2010) description of developmental stages, Rosser (2004) discussed the idea that doctoral education at major universities is an intense social experience designed to develop students for careers in scholarship and research. The work is similar with regard to the Anticipatory, Formal, and Informal Stages, noted above; however, Rosser also described a perspective of Organizational Socialization. According to this theory, the Organizational Stage 
occurs during initial entry and during a phase of role continuance. This concept is related to the initial interviewing and hiring process for new faculty and continues throughout the tenure process. Rosser explained, "the tenure process is considered formal, whereas the casual conversations that individuals have on this and other subjects are examples of informal socializing experiences" (p. 29). As a result, it is through various phases of interaction that graduate students are exposed to the norms that affect their socialization. The socialization process also takes place at multiple levels of interaction. Gardner specifically noted three distinct avenues: "(a) the interaction of students with the structures of the educational setting, (b) the interaction among students in the same educational program, and (c) the interaction between students and faculty members" (p. 40). Throughout this collective interactive process, students become engaged in the overall culture inherent in a graduate education. They become accustomed to the norms, habits of mind, and behaviors characteristic of individual programs and disciplines. It is during these interactions that students and career professionals are exposed to interpersonal dynamics, history, and mission that affect members of the program. Students develop bonds between incumbent students and faculty as they experience course materials, selection for advanced programs, exposure to explicit values and role models, internships, and feedback on projects. For the most part, it is the student interactions with faculty's attitudes and behavior that are essential to shaping and transforming the identity of future faculty.

The idea of a student developing a social identity within the scope of the graduate program is more than an institutional force being acted upon, or engrained in, the student. On the contrary, the graduate student actively engages in the process, hence, also affecting the culture itself. For 
instance, Kwan and Lopez-Real (2010) noted three modes of belonging to social learning systems that aid student identity formation. The three modes of formation are:

- Engagement, as in doing things together, talking, producing artifacts, helping colleagues with problems.

- Imagination, as in constructing a self-image, an image of the community and of the world in order to become oriented, to reflect on situations, and to explore possibilities.

- Alignment, as in making sure that local activities are sufficiently aligned with other processes that can be effective beyond an individual's own engagement. (p. 722)

In other words, as graduate students transform during this process, they become more actively engaged in the community of scholars. Kwan and Lopez-Real pointed out that, not only do students and new faculty become socialized to their environment, but also a two-way process of identity construction occurs. Hence, it is stated that a notion of "co-construction" of identities exists as students become active members of a community of practice, resulting in a change in the dynamic of the social community. For example, service to the academic community is a faculty duty during which graduate students and new faculty have the opportunity to impact a departmental identity. In addition, Rosser (2004) pointed out that service and committee work are the faculty's contribution of their time and expertise to a university, scholarly, and community activity. This activity can be part of a learning process for new faculty as they discover and reflect on agendas, debates, and personalities shaping their programs. Furthermore, graduate students and novice faculty might attend and participate in national research meetings and conferences, thereby benefiting from observance of respected researchers and discussions of national debates on issues beyond the confines of their institution. In essence, exposure of 
graduate students and new faculty to experiences that shape their scholarly community will have direct impact on their professional growth and can evolve into complex interactions.

Combining multiple concepts of the socialization process, Weidman, Twale, and Stein (2001) presented a more synergistic approach to those mentioned previously. The diagram, recreated in Figure 3, depicts a process that is more inclusive of the graduate student's environment and emphasizes ongoing development throughout a faculty career. It is presented here to stress the complexity of the socialization process; however, in the interest of brevity, only a summary will be described. To begin, the diagram is structured to indicate the dynamic and continuous nature of the socialization process. The center of this diagram is designed to indicate the core of a graduate student degree program. Weidman et al. stated:

This is the segment of the socialization process over which the academic program in the university has primary control. It is the academic program faculty who establish the norms for teaching, research, and service within the constraints of the larger university community. Faculty shape the curriculum as well as the organization of instruction and social relationships among members of the academic program. (p. 38)

Thus, Weidman et al. believed it is the university program faculty who are most influential in exposing graduate students to teaching norms, research, and service required of career college faculty. In addition, Weidman et al. have indicated in the outer portion of the diagram four additional components influencing the graduate student during his or her development. These shapes are designed to emphasize the non-linearity of the socialization process and suggest the interaction with core elements throughout a student's career. 
Figure 3

Conceptualizing Graduate and Professional Student Socialization

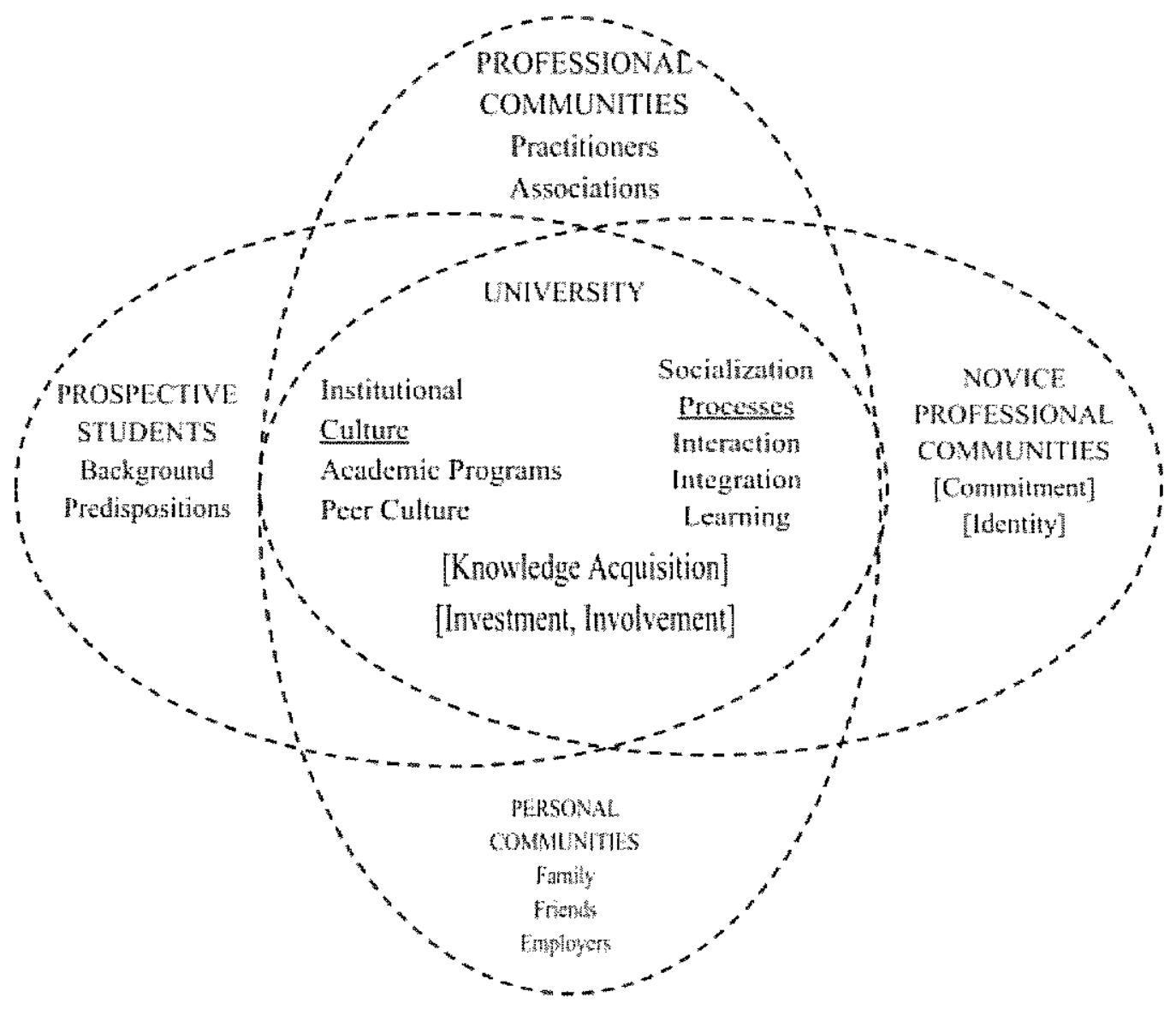

Interactive Stages of Socialization: Anticipatory, Fomal, Intormal, Personat

Figure 3-Conceptualizing graduate and professional student socialization. Adopted from "Socialization of graduate and professional students in higher education: A perilous passage?" Weidman, J. C., Twale, D. J., \& Stein, E. L. (2001), ASHE-ERIC Higher Education Report, Volume 28, Number 3. Jossey-Bass Higher and Adult Education Series. Jossey-Bass, Publishers, Inc., San Francisco, CA. p. 37.

Furthermore, this theory also incorporates the four linear interactive stages at the bottom of the diagram. Inclusion of the Interactive Stages of Socialization, previously described, makes reference to the various stages being applicable to any point in the entire experience of graduate students or novice practitioner socialization. Lastly, ellipses are drawn with broken lines to 
denote flexibility of the student environment and permeability of various stages which allow all stages in the process to have an influence on one another. The shifting boundaries among all the conceptual elements indicate that elements are not independent but rather dependent on one another to varying degrees. Thus, having a better understanding of these socialization processes allows graduate students to have a better understanding of their future professions.

Insightfulness regarding the socialization process provides a general perspective of how new faculty transition to the college teaching profession; however, a closer examination of the schema and sense-making these individuals experience deepens the understanding of this phenomena. Harris (1994) and Mendoza (2008) both described schema in socialization as a dynamic process of cognitive knowledge development where thoughts are formed based on specific topics, entities, and events encountered. These phenomena are conceptualized and organized as subjective theories about how the world operates and guides one's perceptions, memory, and inferences in order to direct information acquisition and processing. Harris highlighted seven functions of schema for socialization which:

- Structure mapping of personal experiences;

- Encode and retrieve information from memory;

- Enhance efficiency and speed of information processing;

- Assist in filling information gaps;

- Speed problem solving using conceptual templates;

- Facilitate evaluation of experiences; and

- Promotes anticipation of future events, goal setting, plans, and execution. 
Utilizing the functional aspects of schema for new faculty during the socialization process, Harris categorized schema for use in an organizational context, which is directly related to new higher education faculty experience. During the transition to new roles with academic institutions, individuals encounter many stimuli and experiences to which they must be perceptive and responsive. Harris summarized his research to categorize five in-organization schemas that "seem to capture the range of knowledge needed for theses sense-making efforts: self, person, organization, object/concept, and event" (p. 312). The descriptions below summarize these categories:

Schema

\section{Category}

Self Individuals' theories and generalizations regarding aspects of themselves in the organizational context such as personality, values, roles, and behaviors. Help direct individuals' reactions to organizational stimuli and decide upon responses consistent with self.

Person Organized memories, impressions, and learned expectations regarding the traits, goals, behaviors, and performance of particular individuals, groups of people, and organizational roles. This helps to shape the reality one is trying to understand. Deals with summarizing beliefs, values, and behaviors of others.

Organization Central to understanding how the culture of an organization is embodied cognitively in individuals. Schema associated with organizational groupings as entities abstracted from the individual members. Corresponds most closely to one's knowledge of his or her organization's culture.

Object/ Refers to knowledge about stimuli which are not inherently Concept social, but are physical and verbal cultural artifacts. These facilitate communication by providing a framework within which verbal terms can be understood. 


Event Captures knowledge about social contexts, situations,
encounters, and events such as departmental parties, firings, and
customer complaints. Serve to guide interpretation of behavioral
artifacts such as ceremonies, meetings, and rituals. Can also be
overlaid on other schema categories for a more specific
in-situation schema. (Harris, p. 313)

Using these categories, administrators garner a broader understanding of schema affecting new faculty socialization. The schemas act in harmony to provide a means of sense-making for the large amount of information being processed during a career transition. Schemas serve as patterns or guides on which to base an individual's perspective of past experience and knowledge while adapting to new and anticipated roles and cultures. In summary, development of schemas during the socialization process allows efficient sense-making of new information by faculty transitioning to higher education.

As newcomers encounter changes to institutional or departmental cultures, the organizational socialization process of schema development affects interpretation of phenomena and stimulates responses in accordance with behaviors derived from individual sense-making. According to Mendoza (2008):

Sense-making is the ongoing thinking process of individuals purporting to create order and make retrospective rational accounts of the situations in which they find themselves. During socialization, newcomers find themselves in an environment with high levels of uncertainty and ambiguity that forces them to engage in cognitive processes to make sense of the new environment at higher rates than other members of the organization. As newcomers gain experience and go through their socialization process, they develop more 
elaborate in-organization schemas, and sense-making for these domains begins to require less conscious effort. (p. 112)

In addition, Mendoza's research determined sense-making to be an ongoing process for creating order and rational scripts, or schema, to predict events and outcomes. When the outcomes deviate from expectations, the sense-making is required to reduce tension that may be created, thus restoring equilibrium and cognitive integrity. It is sense-making during these situations that allow individuals to develop explanations for the unpredicted experiences. To emphasize the difference in the degree and frequency of sense-making for new faculty versus those with experience with the institution, three factors are considered:

- Insiders normally know what to expect, so the level of surprise they encounter is considerably less.

- In the event of surprises, insiders have sufficient history within the setting to interpret the event more accurately.

- Insiders have established a social network within the organization to compare perceptions and interpretations. (p. 111)

In summary, it is during the socialization process that sense-making for new faculty is most challenging and less accurate. With time and experience, they gain a greater understanding of how to interpret actions of institutional members and events specifically related to their new culture. The result of this stage of the socialization process establishes the foundation upon which they become contributing members who shape their discipline, institution, and professional community. 
A final concept related to socialization of graduate students into specific areas of professional academic communities highlights a broader element of professionalism and culture associated with higher education. Thornton (2010) suggested that "each discipline attracts individuals of particular talents and interests, and the experiences of working in each field places its mark on their personalities" (p. 39). With that being said, new faculty members with prior professional careers, in contrast to graduate students, typically embrace their discipline or career field as a primary source of faculty identity and expertise; therefore, their professional culture and ethics are formed prior to employment with an academic institution. As such, these new faculty develop their teaching identities in the context of the postsecondary institutions where they are employed. More specifically, as Gardner (2010) suggested, "the socialization that occurs is also specific to the discipline" (p. 40) in which career professionals and graduate students concentrate their interests. With regard to the various disciplines within higher education, new faculty will find varying levels of consensus, high versus low, for each department of an institution. Depending on the academic discipline, there will be varying levels "of consensus their members show on such factors as theoretical orientation, appropriate research methods, and the importance of various research questions to advancement of the discipline" (Braxton and Berger, 1999, p. 245). To provide an example of the types of disciplines characteristic of high or low consensus, Mendoza (2008) explained that areas in the sciences, such as physics are high consensus fields, and areas in the social sciences, such as education, are low consensus fields. It should be pointed out, however, that various disciplines are found to have a range of attributes, and therefore, these descriptions are generalizations of the wide range of academic fields. To more clearly compare the low and high consensus concept, 
Table 5 is provided to highlight the different factors attributed to the two areas for which new faculty are to be socialized:

Table 5

Comparison of Low and High Consensus Fields

Low Consensus

High Consensus

More ambiguity in making decisions

Less ambiguity in making decisions regarding regarding research topics, methods, and research topics, methods, and curriculum curriculum

More oriented to teaching and service More oriented to research

Higher journal rejection rates, and less Lower journal rejection rates, and greater availability of external funding for research availability of external funding for research

Stress the development of critical thinking skills, employ student-centered teaching, and Emphasis on analytics, project oriented to advance research topics

favor student assessment for teaching improvement

Adapted from "How Disciplinary Consensus Affects Faculty," by Braxton, John M. and Berger, Joseph B., 1999, Faculty in New Jobs, p. 245.

Table 5

Correlating socialization processes with high and low consensus field concepts with various institutional cultures new faculty encounter, Woods (1999) explained that "norms can vary in terms of distribution, degree of conformity, and mode of enforcement. The intensity, consistency, and authoritative source of allocated sanctions all influence how likely individuals are to conform to a norm" (p. 270). The values and norms of a culture exist when the group has a consensus regarding expected behavior, when the majority of the group conforms to expectations, and when there are sanctions employed for nonconformity with the shared beliefs. 
Therefore, it is inherent in the nature of higher education that a consensus of professionalism and ethics be established as a foundation of academic freedom, peer review, and shared governance into which new faculty are socialized.

Hamilton (2006) stated, "faculty professionalism defines the ethical duties required by the social contract for professors as well as for the relevant groups of professional peers" (p. 15). The principles of faculty professionalism are inclusive of correlative duties of academic freedom, ideals, and core values of the academic profession, public service in the area of the discipline's fiduciary responsibility, and faculty member contributions to peer review and shared governance. These peers can be identified as groups internal to the institution and as external groups of professional oversight and leadership, such as accrediting agencies, Association of American Colleges and Universities, the Association of Governing Boards of Universities and Colleges, and the American Association of University Professors. Hamilton noted that it is through a process of professional self-governance that new faculty will be indoctrinated into the culture of higher education. In addition, Hamilton pointed out that "the vast majority of the professoriate receives virtually no formal education on the ethics of the profession. We assume that an osmosis-like diffusion in the apprenticeship model will transmit the principles of the social contract" (p.15). For example, principles ranging from high ethical standards and fiduciary responsibilities, commitment to institutional service, devotion to teaching and advancement of knowledge, and a capacity for both self-scrutiny and moral discourse with colleagues are elements essential to the socialization process. Hence, instilling these values in graduate students is an important aspect of socializing them to their role in higher education and is most effectively conducted during an interaction with incumbent faculty. 
Having presented a progressive explanation of the concept of socialization, the question as to how higher education institutional administrators can affect new faculty during socialization remains to be answered. With this in mind, the role of mentoring as an element of the socialization process cannot be understated and will be discussed at length as it relates to new faculty transition.

\section{Mentoring}

The importance of mentoring graduate students and career professionals transitioning to faculty positions in higher education is essential and deserves a close examination. Mentorship serves as a guide for successfully assimilating the culture of an institution and specific program disciplines. With that said, a description of the concept of mentoring, the mentoring process, role modeling influence, and the impact of mentoring on faculty development will provide greater insight to mentoring and its impact on socialization.

The concept of mentoring has been in use for many centuries. Its value has been sought after as means of guiding a novice successfully to actualizing their full potential in their chosen endeavor. A historical perspective, Dunham-Taylor, Lynn, Moore, McDaniel, and Walker, (2008) noted the association of mentorship with the Homeric poem, The Odyssey:

The term mentor can be traced to the Ithacan noble by this name to whom Ulysses entrusted his son Telemachus while Ulysses was gone fighting the Trojan War. As guardian and surrogate parent to Telemachus, Mentor is meant to embody wisdom and to serve as teacher, protector, and counselor. (p. 339)

More recently, and in relation to higher education, mentoring serves as a means for aspiring professional academics to become effectively socialized into their careers by an experienced 
faculty member. With regard to training of faculty for higher education Kwan and Lopez-Real (2010) stated, "mentoring in the context of initial teacher education is a 'planned or arranged' but sustained relationship between a student-teacher and the experienced teacher-mentor, which is often referred to as a "journey"' (p. 724). The research describes an aspect of duality where mentoring functions as both a relationship and a process. As such, the relationship involves a personal caring and supportive collaboration, while the process focuses on socialization of the student into their role as an academic professional. In Bieber and Worley's (2006) research on graduate student perspectives of academic life, it was found faculty interact with students as advisors and mentors, as well as teachers. "One international student in chemistry said that 'teachers are not just teaching you in the class but they actually know you. So they are more like second parents and I like that" (p.1019). Bieber and Worley determined that by establishing a mentoring relationship faculty guide graduate students by connecting with them in a personal and meaningful way. In effect, in this context, mentorship can be described as a form of planned socialization, with the mentor acting as the socializing agent. Furthermore, mentoring can be designed as an effective means for colleges and universities preparing new faculty for future positions of leadership. Kezar, Lester, Carducci, Gallant, and McGavin (2007) addressed this matter, noting mentors can help newer faculty understand the culture of the institution as a dynamic entity. As such, a mentor can help new faculty understand the elements affecting change, thereby easing transition. Kezar et al. stated, "successful change strategies vary by campus, so "learning the ropes" from experienced individuals who have already created change helps faculty avoid failure, running into roadblocks, and becoming paralyzed by obstacles" (p. 18). From this perspective, mentoring is considered a process that does not cease after a few 
weeks or months, but continues throughout a novice's early career. Dunham-Taylor et al.'s research on mentoring of nursing faculty explained mentoring as "the single most influential way to help in the successful development and retention of new nursing faculty, not only for the initial purpose of filling a vacant position but also for the long-term maturation of the nurse faculty members" (p. 337). Lastly, Bland, Taylor, Shollen, Weber-Main, and Mulcahy (2009) listed three characteristics to describe the professional relationship involved with mentoring new faculty:

1. Mentoring is a relationship with a defined purpose: to help mentees successfully acquire the key competencies and constructive work relationships they need to lead a successful and satisfying career. The specific competencies to be gained are based on the mentee's existing abilities and career goals.

2. Mentoring is a collaborative learning relationship. It is a relationship that, in the traditional model, draws upon the knowledge of suitably experienced faculty as mentors and upon the commitment of mentees to develop their professional abilities.

3. Mentoring is a relationship that develops over time and passes through specific phases. (p. 12)

With these definitions in mind, mentoring should be considered essential for new faculty to thrive in a new environment in an efficient manner.

Understanding mentoring as a collaborative process between the mentor and mentee leads to viewing this relationship as two-sided. To begin this perspective, the descriptions of mentor roles, discussed above, are reiterated by Bode's (1999) research noting four functions of the mentor: "role-specific modeling or teaching, 'encouraging the dream,' organizational 
socialization, and advocating" (p. 120). In addition, Bode pointed out four factors considered as ideal in mentoring relationships: "the friend (providing socioemotional support), the career guide (enhancing professional development), the information source (helping the new faculty member 'learn the ropes'), and the intellectual guide (collaborating in scholarly activities). With this in mind, it is now essential to consider what the mentee is expected to contribute to the relationship. As described in Table 6, Bland et al. (2009) identified seven mentee skills for effective development during the mentoring process:

Table 6

Seven Mentee Skills For Effective Development Mentoring Process

Skill Description

Ask productive Prepare questions, in advance, that produce the information and learning questions you wish to receive during mentoring.

Develop key listening Listen for the central message and feelings in a response to questions. skills

Use trust-building Behaviors such as encouraging, listening, sharing, and cooperating are behaviors trust building, in contrast to behaviors such as putting people down, ignoring, hiding or withholding, and competing.

Overcome the awe A mentor is likely an important person. To overcome being intimidated, factor prepare for meetings, practice speaking with the person, and talk with others who have a relationship with the mentor.

Resolve differences Use "soft" responses, such as, "That is a good suggestion, but it doesn't fit me." Use "I" versus "You" messages, such as, "I understood we were meeting today," rather than "You missed our meeting."

Capture the essence After each meeting, ask yourself, "What was learned? How can I apply of your mentor's help what I learned?" Summarize for your mentor what you learned, listen carefully to feedback, and ask questions to clarify. 
Table 6 Continued

Skill Description

Internalize your

Sort out the learning and find where patterns appear. Review these in mentor's input your mind shortly after they occur. Record the outcome of mentoring sessions to reinforce learning. Discuss the learning with others.

Adapted from "Faculty success through mentoring: a guide for mentors, mentees, and leaders," Bland, C. J., Taylor, A. L., Shollen, S. L., Weber-Main, A. M., \& Mulcahy, P. A., 2009, R\&L Education p. 85.

Table 6

The relationship between these individuals is one that must be established with a level of trust from both sides that each will fulfill role expectations. According to research by Hopkins and Grigoriu (2005):

Mentees describe mentoring as a one-on-one relationship with a mentor who listens and reflects with the mentee on the mentee's experience. They describe mentors who are accessible both with their time and personal support. In the study, mentees who could not establish a trusting relationship reported being unable to proceed with their mentoring. (p. 46)

As explained, the roles of the mentor and mentee are not passive or static in nature. They require focused effort on the part of both sides of the relationship to be successful. Unfortunately this is not always the case.

Because of the time and attention the mentor and mentee must commit to developing a relationship, it is not uncommon for the process to break down; or fail to be initiated at all. For a number of reasons the mentoring process can fail. Huwe and Johnson (2003) cited a survey of 
graduate students, indicating roughly half were mentored, while the others reported found it increasingly difficult to find a traditional primary mentor during their doctoral studies. They also note "concerns about the increased ratio of students to faculty, particularly in professional, non-research oriented programs, has led some to urge more intentional identification with a mentor during graduate education and early career" (p. 42). Furthermore, Bode's research discovered that at the community college level less than half (38\%) of the faculty interviewed had mentors during their transition to higher education careers. Of those who did have a mentor, $60 \%$ of those had a mentor assigned versus $40 \%$ who found their own mentor. Of the faculty who found their own mentor, there was a stronger relationship during the socialization process than those who were assigned mentors. Given these points, two reasons for the low frequency of mentoring were suggested: "only a minority of new faculty find a mentor on their own, and few campuses provide mentoring in a systematic and effective way" (p. 122). In a similar manner, but on the university level, Boyle and Boice (1998) emphasized the evidence of greater graduate student success when mentoring interactions are implemented properly, whereas the study attributes graduate student lack of achievement directly to poor mentoring practices. "Students who did not finish their dissertations list poor working relationships with their advisors or committee as one of the two most frequent reasons for terminating their graduate schooling; the other reason is financial difficulties" (p. 90). Correspondingly, Coleman, Christic, Culver, Erickson, Hunt, Williams, Kinsey, Smith, and Tareilo (2006) found a significant shortage of mentoring programs available for new faculty at the university level to support successful teaching, research, and service to the institution. The research indicated poor working relationships, lack of support for research agendas, and little assistance with teaching as primary 
contributors to new faculty separation from universities. Coleman et al. attributed the failure of faculty retention to the inadequate support of department chair personnel during new faculty socialization. Whereas Menges (1996) suggested two specific causes for the lack of mentoring in higher education: "only a minority of new faculty find a mentor on their own, and few campuses provide mentoring in a systematic and effective way" (p. 122). Likewise, Kezar et al. (2007) discovered that the lack of support by department chairs is a common occurrence and explained their finding as follows:

Chairs are often overwhelmed by bureaucracy, untrained for the role, apathetically waiting out their rotations, lacking in sensitivity, or have forgotten what it was like to be an early career faculty member. Thus, faculty must look to other supportive figures if their department chairs cannot, or choose not to, play this role. Institutions need to examine the structures that inhibit department chairs from playing a role in fostering faculty members as organizational citizens, and to consider the guidance and priorities provided to chairs. (p. 16)

Emphasizing the importance of administrative support for the mentoring process, their research findings noted that almost every successful faculty member from the study had support from a departmental chair or other administrator. In essence, having a supportive administrator for a mentoring program can, in effect, make significant strides in change to an institutional culture for development of highly productive faculty members. Administrators and mentors can meet with faculty on a regular basis to discuss career plans and academic goals, or they can meet informally to provide support and encourage faculty to focus their attention on areas where performance improvements may be necessary. 
Due to varied institutional settings to which new faculty are hired, it should be pointed out that not all mentoring formats are effective for the multitude of higher education scenarios and they should be flexible to adapt to diverse cultures. The research of Braxton and Berger (1999) recommended that faculty hiring committees develop ways to determine the research and teaching abilities of candidates for open positions. Questions to be asked of the candidate should be designed to determine the best fit between the individual's background and the fundamental role expectations of the institution and department. This approach should be supported by the academic administration in order to establish a suitable process for mentoring new faculty. Contrasting this position, however, research conducted by Sabin (2007) explained that administrators often expect new faculty to be at a high level of productivity with little in the way of institutional support systems. According to Sabin:

New faculty often report that the expectations administrators have for them are 'vague, ambiguous, changing, or unrealistic.' As a result, new faculty often felt isolated, uninspired, and unsupported. Graduate school, according to many new faculty, did not prepare them for everyday professional requirements such as student advising, working on thesis committees, sponsoring student clubs, or balancing the conflicting pressures of research and teaching. (p. 9)

Under circumstances such as these, where an institution has little faculty leadership, a mentoring program designed by faculty development committee would be helpful for socializing new faculty. In short, the new program can be based on the candidate's background, academic discipline, and expectations. In addition, the mentoring process can be designed to be administered in either a formal or informal format, or a combination depending on context. For 
instance, research from Holley and Caldwell (2012) concluded that a formal mentoring program must factor in several variables, such as, "the ability of faculty members and students to serve as mentors, the interest of doctoral student participants, and the administrative willingness to coordinate the initiative" $(p, 252)$. With this in mind, mentoring for socializing future faculty is a balance between indoctrination of the mentee into the academic department and the long-term goal of enhancing the mentee's academic and professional development. Correspondingly, Trower (2010) stated, "formal mentoring provides a process whereby protégés are matched with a mentor or team of mentors. Formal mentoring implies an expectation to coach and be coached, to advise and be advised" (p. 28). Again, the benefits of a formal mentoring program are described by Bland et al. (2009), indicating this method is more consistently effective in socializing new faculty than the informal approach. "For example, a study of medical school faculty at the University of Minnesota-Twin Cities found that having or having had for formally designated mentor was the second-best predictor of high research productivity (a passion for research was first)" (p. 32). In fact, Kezar et al. (2007) found that:

Some campuses establish formal networks that include a mentoring function - groups for women faculty in the sciences, for example, or groups for faculty of color, gay and lesbian faculty, and faculty committed to sustainability, etc. In addition, by ensuring that professional development opportunities include both senior and junior faculty, campuses can maximize opportunities for cross-generational mentoring and contact. (p. 17) Extending this further, various types of organized mentoring practices are valuable learning experiences wherein structured guidance affects socialization. Rosser (2004) found that while new faculty transition to the academic workplace, a positive and rigorous formal 
mentoring experience is most effective for professional and academic socialization. For the most part, the formal approach to mentoring must comprise a number of functions such as planning how the mentor and mentee might be connected, specific goals to be accomplished as a result of the mentoring effort, and a feedback system to monitor and evaluate progress of the experience. As a final note on formal mentoring, Lenze (1999) explained:

Regardless of whether a mentor was assigned or chosen, for those new faculty who had a mentor, job satisfaction was positively related to satisfaction with their mentor. It behooves institutional colleagues to pay careful attention to the orientation of mentors and the monitoring of institutionally fostered mentor-protégé pairs. (p. 318)

As described above, the benefits of formally structured mentoring programs can be instrumental for socializing new faculty, however it would be a mistake to ignore the impact informal mentoring has on the transition of individuals transitioning to academic careers. The process of informal mentoring consists of advisors or coaches who are not part of the formal mentoring program. Thus, informal mentoring occurs as new faculty seek counsel from experienced individuals outside the formal process who are willing to guide new faculty.

Mentoring of new faculty is a process that, if structured well, can have significant benefits for the individuals, as well as an institution. Therefore, it is also important that students and new faculty are sure their advisors and mentors are suitable and have personalities that are cohesive enough to establish a working relationship. As Fischer and Zigmond (1998) explained regarding graduate student experience in the mentoring process:

...students need to realize that no one person can satisfy all of their educational needs. For this reason, faculty should encourage and students should seek to build a group of 
mentors who can cumulatively address the needs of the trainee. This tactic may be particularly important for trainees who come from underrepresented populations and are not able to find adequate role models among the individuals in their field. (p. 32) In addition, the research of Bland et al. (2009) highlighted both of these points by noting the importance of quality mentoring relationships for optimal learning and high career satisfaction, and the benefits of multiple mentors for gaining varied perspectives and a variety of support. They emphasized the importance of having a mentor from the new faculty member's department for the most effective acculturation into one's discipline, but commented that new faculty may find some of their best mentors outside of the department. Furthermore, regarding underrepresented populations, Bland et al. found women and minorities have difficulties being adopted by informal mentors. This situation makes it difficult to benefit from a less formal relationship opposed to one based on mutual interests. For this reason, during the spring semester of 2008, the Office of Faculty Development and Diversity (FD\&D) at Harvard began a program on mentoring for Harvard's pre-tenure faculty members, with special attention on issues concerning women and faculty of color. "The goal of the project is to foster active mentoring relationships within an engaged, supportive network of faculty colleagues, meeting a need identified by women and other underrepresented groups of color" (Cariaga-Lo, Dawkins, Enger, Schotter, and Spence, 2010, p. 21). Law, Bottenberg, Brozick, Currie, DiVall, Haines, Rao (2014) commented on the importance of informal mentoring, stating:

It is advisable for new faculty members to meet briefly with all members in their department to see who might be a natural fit as a mentor for them. Often informal mentorship is more fruitful because the relationship is established in a more spontaneous 
and organic way, often developing over time. However, that means an informal mentorship requires more time initially to form a relationship/bond. (p. 3)

Additionally, during the development of an informal mentoring relationship, the interaction between mentor and mentee often requires a balance between leading and imposing a framework, and allowing the future faculty member develop their own social identity. Fischer and Zigmond (1998) pointed out that all too often students are willing to pursue work with a suboptimal advisor on the assumption that they can "tough it out" for their graduate student years. These students need to be aware that relationships with a mentor or an advisor can have a significant influence on their careers well after graduation. Mentors and advisors can be an important asset after graduation for letters of recommendation, endorsements for grants, and references for future promotion. Ultimately, the relationship with the faculty member who is working closely with the graduate student or future faculty member will be instrumental to ensuring appropriate socialization.

A discussion of mentoring for socialization of graduate students and new faculty should not understate the importance faculty members have on influencing the identity development of mentees. Gardner's (2010) research found that the majority of faculty members held no more than a naive conceptualization of their influence in the socialization process and generally considered socialization to be a strictly a formal process, or designed for specific goal accomplishment, as opposed to informal socialization, consisting of unstructured experiences. At the institution Gardner researched, the majority of the faculty did not see the importance student socialization. They believed experiences such as national conferences and guest speakers seminars were designed for such purposes. Correspondingly, Duphily's (2011) study of 
novice nursing faculty found that their training "did not prepare them for the expectations of the position they were pursuing, including teaching, student advising, committee work, and service learning. Once hired, they had to learn on-the-job, making them feel ill prepared and unsure of themselves" (p. 126). Duphily's study also determined that mentorship can be critical to successful career development and retention of novice educators. The contrast of these findings exemplify the importance mentors have in socializing graduate students into a community of scholars. The interactions between mentors and mentees, in cases such as these, become mutually dependent for affecting socialization. In addition, O'Meara (2016) noted the importance of doctoral student advisors for providing more information and advice to graduating doctorate holders on the faculty job market. Referring to the higher education context, O'Meara stated:

Given that the majority of graduate student are educated at research universities, but most will hold faculty appointments at other types of institutions, it is important for graduate programs to offer workshops on different institutional types and the economic and political constraints on institutional missions and operations. (p. 291) Therefore, mentors and advisors should understand that graduate students require socialization into higher education careers where institutions are markedly diverse and organizational cultures fluctuate. To summarize, just as faculty need to understand their impact on students in the formal and informal mentoring process, graduate students should understand their role in the socialization process. They should seek advisor relationships based on factors such as a mentor's commitment to the mentorship process, research interests, support for professional affiliations, awareness of the dynamic and diverse nature of higher education, guidance in the dissertation 
process, and amount of time in research and teaching. Through mentor role modeling, during the formal and informal socialization process, successful development of graduate student identity can thrive; therefore a closer examination of the process itself is useful.

A mentoring process that establishes supportive climate for new faculty can be critical to development of scholars at all stages of an academic career. Cariaga-Lo et al. (2010) described mentoring programs as unique for the particular environments in which faculty engage, reflecting the values and traditions of each of the many schools within an institution. As such, mentoring programs adapting to differences in gender, race, ethnicity, culture, and generational levels can determine how well the mentoring process affect the socialization of new faculty. Dunham-Taylor et al. (2008) explained how mentoring functions as a socializing aspect of new faculty orientation when viewed as a form of planned socialization process. The research discussed mentoring new faculty in a nursing program being studied, as a flexible developmental process consisting of a continuum of four phases: Initiation, Cultivation, Separation, and Redefinition. Each of the phases is briefly described as follows:

\section{Initiation Engagement Phase:}

Begins when the mentor and mentee meet and determine necessary goals. Repeated reciprocal interactions are key to this phase.

Cultivation Active Phase:

Ensues as the new faculty member learns all the details. This phase is the "meat and potatoes" portion of the process because a majority of the mentee growth as nurse educator occurs here.

Separation Ending Phase:

Involves a dyad reaching the mutually agreed upon goals from the initiation phase and agreeing to conclude the mentoring relationship. The mentee is ready for independence in most functions as a new educator 
Redefinition Collegiality or Friendship Phase:

The former mentor and mentee decide whether or not their relationship transforms into one that is collegial and/or friendship focused. (p. 340)

The implementation of these stages during the mentoring process allows new faculty to make adaptations with the support of an experienced individual. Mentoring according to this process precludes new faculty "sense of isolation, as well as uncertainty, frustration, and lack of satisfaction with the position of educator," ( $\mathrm{p} 345$ ) with the expectation of retaining more qualified academic professionals. In a similar manner, Bland et al. (2009) explained an effective mentoring program addresses importance of two critical factors:

- Work productivity based on career development activities

- Work satisfaction based on relationship development activities

It is believed that by focusing on the primary factors of mentoring process and mentoring outcomes these critical factors can be addressed, resulting in a more satisfied faculty member remaining with the institution. For clarification, the effects of the mentoring process are indicated by the mentoring outcomes in Table 7 as follows:

Table 7

Effect of Mentoring Process on Mentoring Outcomes

Mentoring Process

Career development activities are implemented, tailored to fit the mentee's individual competency needs
Effective mentoring relationship is developed and routinely attended to 


\begin{tabular}{|c|c|c|}
\hline \multicolumn{3}{|c|}{ Mentoring Process } \\
\hline $\begin{array}{l}\text { Retention and success are } \\
\text { increased }\end{array}$ & $\begin{array}{l}\text { Productivity and satisfaction } \\
\text { are enhanced }\end{array}$ & $\begin{array}{l}\text { Career competencies } \\
\text { and constructive work } \\
\text { relationships are } \\
\text { developed and maintained }\end{array}$ \\
\hline \multicolumn{3}{|c|}{$\begin{array}{l}\text { Adapted from "Faculty success through mentoring: a guide for mentors, mentees, and leaders," } \\
\text { Bland, C. J., Taylor, A. L., Shollen, S. L., Weber-Main, A. M., \& Mulcahy, P. A., 2009, R\&L } \\
\text { Education p. } 7 \text {. }\end{array}$} \\
\hline
\end{tabular}

Table 7

As shown above, it is important that the interaction between mentors and their protégés be one that establishes a relationship focused on career development if both faculty and institutional expectations are to be achieved. In summary, the implementation of a mentoring program for socializing new faculty member can aid him or her in navigating their experience with the institution on a positive trajectory. To support a position for the importance of the socialization process, an explanation of the results to be expected from endeavoring to socialization new faculty members to an academic institution is necessary.

\section{Results of Socialization}

Having a greater awareness of socialization concepts and understanding the importance of socialization in shaping graduate students, and career professionals, for future faculty positions in higher education is essential for faculty development. The question as to how mentees come to know and become transformed through engagement in the process is pivotal. This is a matter addressed by many great educators, Cady (1973) pointed out that one can provide a long list of scholars who had a "problem with communicating with the young adult 
mind - Socrates, Loyola, Alcuin, and others" (p. 12). Consequently, four questions presented by Cady are directly adaptable to the socialization process:

- What are the objectives of the endeavor?

- What behaviors and knowledge will indicate socialization objectives are being met?

- What socialization processes will yield behavioral and knowledge development most effectively?

- What methods of evaluation will provide feedback regarding student and process performance in meeting socialization objectives? (p. 12)

These questions are general in nature and modified to examine most developmental programs. In a like manner, a focus on how mentees acquire knowledge during the socialization process and results of student mentoring need to be explored fully appreciate the effect of this process.

As students transition from undergraduate studies, or from professional careers, into their years as graduate students, they will encounter a new perspective of the educational process from being users, or consumers, of knowledge to a level of scholarship where they assume a role of creators of knowledge. Fischer and Zigmond (1998) explained graduate students need to realize that to become successful professionals they must begin to set their own goals and objectives for acquiring knowledge (p. 31). A schema for achieving success in graduate school is significantly different from their undergraduate mindset. To examine the concept of how graduate students acquire knowledge during the socialization process of graduate school, two perspectives will be discussed. To begin, Bieber and Worley (2006) discovered, during a study of graduate students, that they make graduate school career choices in a very relaxed and casual manner. It was found that students gathered information about the role of higher education professionalism from three 
main sources; (a) they literally saw and watched what faculty do; (b) they reported having snatches and tidbits of conversations with faculty as an undergraduate, sometimes during scheduled meetings and/or chance meeting outside of the classroom; and (c) they did the work of faculty in graduate school, most typically as a teaching assistant and occasionally as a research assistant. Because they did not actively engage in a process of systematic data gathering regarding the profession, the schema shaped by their undergraduate identity warranted socialization to the tensions, pressures, and satisfaction of creating knowledge at a higher level. As a result of misinformation and erroneous schema development of graduate students preparing for faculty positions, a lack of congruence between the students' future academic role and the socialization process taking place during graduate school is being created. Research by Bieber and Worley (2006) found survey respondents indicating a disjuncture between the values held by recent graduates and the values they believe employing institutions prioritize. Based on this research, it was determined that of the socialization activities implemented by their graduate school, the highest rated activities were those related to research, not teaching. Bieber and Worley's additional findings are as follows:

Graduate students (and newly minted Ph.D.) have very strong interests in and commitments to teaching. The new hires, had however, learn enough to know that their personal priorities (their personal ideal script of a faculty life?) did not correlate with the perceived priorities of a research institution. That is, the socialization that took place seemed to be on the order of a lesson learned -- how to be successful at a research university -- rather than a fundamental adoption, internalization, and commitment to the norms, values, and attitudes associated with a research university. (p.1029) 
Based on these findings, they conclude the doctoral education model in use at this institution did not take into account the student's personal interests and commitments to teaching into account, nor did it take into consideration future academic employment possibility for their students at institutions beyond those of doctoral universities.

There appear to be no clear benchmarks for determining when a new faculty member is considered competent and adequately socialized to his or her academic role. On the other hand, the impact current socialization practices are having on future higher education faculty is not very successful. According to Chao, O'Leary-Kelly, Wolf, Klein, and Gardner (1994), "it is still unclear which criteria...can be used to judge the success of organizational socialization, and what the contingencies are on which the completion of the socialization process depends" (p. 731). With that said, research indicates many graduate students are not being adequately socialized for their roles as academic professionals. Menges' (1996) conducted a study of job expectations for new faculty from several institutions, based on interviews of faculty during the initial second and third years of employment. The interviewees were asked about the clarity of expectations for their work (on a scale of 1 to 10 ). Although the results were highly variable, based on the subjective nature of the question, "on average, faculty reported that expectations were no more clear in year three than they were in year two" (p. 176). Perhaps, due to the autonomy inherent in many faculty positions, self-evaluation of one's level of socialization can be a difficult undertaking. Based on Cady's (1973) study, he described the predicament new faculty contend with when evaluating their performance on the job:

Although he is only one variable, he is a major one because he determines what the objectives will be, what will be learned to achieve those objectives, and what the 
procedures will be that will influence and even determine student behaviors and achievements. There are methods by which one can analyze his own teaching...but few of us are encouraged to use such techniques on ourselves, whether we teach undergraduates or prepare college teachers. (p. 16)

Without support for applying techniques for self-analysis regarding achievement of role expectations, new faculty become subjected to assessment by means they may not be accustomed to when initially socialized. As Jensen, Rabe, Runde, and Wee (2006) pointed out:

It might take some time for one to be at peace with the idea that you are evaluated for events like third-year review and tenure and promotion by people who may never have worked with you or seen you teach. (p. 8) Inadequate socialization processes do not prepare new faculty for the undertaking of promotion and tenure evaluation by the array of institutional personnel on review committees, including department colleagues, faculty outside the department, deans, administrators, and Board of Regents. Often these individuals will know little about the faculty member's performance or discipline, yet they are in a position to make decisions about the career of new faculty. Likewise, many are surprised to discover the influence student evaluation can have on their careers. As Jensen et al. stated, "It is a sobering realization that the comments 18- and 20year olds are part of your employment evaluation, which can make you wonder its appropriateness and validity at times" (p. 8). In summary, without socialization of new faculty providing clear role expectations for the various types of academic institutions to which graduate students and career professional transition into, they will be ill prepared to become fully productive in a timely manner. 
The research information regarding the deficiency of universities to prepare new academic professionals is well documented. To begin, Gaff (2002) documented two conclusions in reference to a survey of doctoral students in 11 arts and sciences disciplines at 27 universities:

The data from this study show that in today's doctoral programs, there is a three-way mismatch between student goals, training, and actual careers...Doctoral students persist in pursuing careers as faculty members, and graduate programs persist in preparing them for careers at research universities, despite the well-publicized paucity of academic jobs and efforts to diversify the options available for doctorate-holders. The result: Students are not well prepared to assume the faculty positions that are available, nor do they have a clear concept of their suitability for work outside of research. (p. 7)

In a like manner, Lenze (1999) described a lack of clear expectations expressed by departmental and institutional administrators of higher education. It was found that new faculty received mixed messages and a lack of clarity from administrators, department chairs, and senior faculty. New faculty was unsure of what was expected of them and found even new faculty in the same departments had different understandings of expectations. The study suggests that, "when the role expectations of the institution are not made clear at the outset, faculty may suffer the consequences of feeling as though they do not fit the role expectations that the institution holds for them" (p. 313). Similarly, Dinham's (1999) study noted a disconnection between what graduate students experience during doctoral studies and career reality. It is claimed that the preparation for faculty life during graduate school can actually deceive aspiring faculty into expectations of a faculty role that are not accurate. 
Research universities are the gatekeepers for most doctoral preparation; however, the predominant placement of new academic professional occurs at colleges and universities where research expectations are less central to their careers than teaching. Dinham (1999) claimed "the junior faculty member expecting a life of research pursuits punctuated by teaching responsibilities is surprised to become enmeshed in a life dominated by teaching and punctuated by occasional opportunities for research" (p. 3). For that matter, Dinham stated that the array of research experiences provides little guarantee graduate students will be adequately prepared for that role either. "One new doctorate holder might have participated in no research other than the dissertation, while the next doctorate holder might have been involved in many research projects throughout graduate school" (p. 2). Furthermore, based on research of 4,000 doctoral students in 11 disciplines at 26 universities, Golde (2004) found:

Surprisingly, comparing the students at each stage of graduate study does not reveal differences between them in either the level of interest or the level of perceived preparation for various tasks of faculty work. The big exception is preparation to conduct research; in this case, student interest and preparation both rise over time in a linear way. Perhaps what is most important here is the contrast with teaching, advising, and service. This finding reinforces the perception that attention to preparation for teaching, advising, service, and governance is at best sporadic and haphazard. By contrast, research is an activity in which students gain increased proficiency over the course of their time in graduate school. (p. 4)

Not only are there deficiencies in the emphasis of what role future faculty are being prepared, but also the level of proficiency for teaching in higher education is questionable. 
Dinham (1999) found graduate students gaining teaching experience only while employed as teaching assistants during graduate school. The research commented on the fact that teaching assistantship duties and responsibilities vary widely in relation to determining level of preparedness to assume a faculty role. It is pointed out that these differences can vary in the extent and quality of faculty supervision, role played while interacting with other faculty and knowledge developed about teaching and learning. Specifically, Dinham stated, "A year of a teaching assistantship, or even several years, then, provides no guarantee of preparation for the teaching responsibility of a faculty member. Typically, a teaching assistantship provides no experience with teaching responsibilities outside of the classroom" (p. 341). On the whole, statements made by Bieber and Worley (2006), regarding the preparations for future faculty, provides an adequate summary of graduate student socialization:

...the programs seem neither to have been able to dislodge earlier schema nor to illuminate the full range of faculty responsibilities for our respondents. They did not indicate that they fully appreciate the myriad complexities of faculty life, which include the core position of research. Thus, graduate students find themselves in the unenviable position of being fully served neither by their graduate faculty mentors nor by their institutions' efforts at preparing them to assume faculty roles, in all of their complexities, at a variety of institutions. Extant mentoring and other institutional efforts to socialize graduate students do not appear to counter successfully the powerful influence of the schema that graduate students bring with them to graduate school. (p. 1030) Given these points, socialization of new faculty is faced with many challenges, both from within the institutions preparing graduate students for academic careers and within the hiring 
institutions of higher education to which the graduate students must learn to become productive members.

In order to develop a new mindset for the graduate studies community, Kwan and Lopez-Real (2010) proposed the following three qualities for "healthy" socialization during the transition: connectedness, expansiveness, and effectiveness. In more detail, connectedness involves a deep connection with others through shared histories and experiences, reciprocity, affection, and mutual commitments. Whereas, expansiveness consists of developing an identity not exclusively locally defined but involves engagement in multiple memberships and crosses multiple boundaries. Lastly, effectiveness establishes an identity for participating in the social world of higher education that is empowering rather than marginalizing (p. 723). Overall, the elements for developing a healthy identity in a community of scholars can enhance graduate student knowledge during the socialization process.

Similar to the knowledge and identity developed in the example above, Weidman, Twale, and Stein (2001) described a concept of role acquisition that occurs during the socialization of graduate students and new faculty beginning careers in higher education. The research presents knowledge acquisition, investment, and involvement as core elements leading to identification with and commitment to a professional role. In this case knowledge development applies to socialization in two ways: (a) Novices must acquire sufficient cognitive knowledge and skills for effective professional role formation; and (b) novices must acquire affective knowledge such as awareness of normative expectations associated with the professional role being sought, a realistic assessment of personal ability to perform the demands of professional role successfully, and awareness of the confidence others have in the novice's capacity to practice professional 
roles successfully. Hence, it is during the socialization process that knowledge shifts from being general to being specialized and complex.

The second element, noted as "investment", refers to the commitment of something valued that is personal, such as time, alternative career choices, self-esteem, social status, or reputation to a professional role or preparation for it. Furthermore, as Weidman et al. explained, professional socialization depends to a great extent on the student's goals, level of commitment to those goals, commitment to the program and discipline being studied, level of investment given to the program of money, time, and psychic energy, and personal pride in previous accomplishments and future expectations.

The last element of "involvement" is considered the participation in some aspect of the professional role or in preparation for it. According to Weidman et al., social participation is the action by which students acquire and internalize an occupational identity, develop an interest in a profession's problems, and take pride in perfecting technical skills. It is believed involvement in the role and thinking about the personal meaning of participation in that role that brings about professional role identification. The opportunity for graduate students to benefit from these elements can occur during either formal or informal socialization activities. Mentorship during these stages allows students to mature through this process and reflection on their experiences provides potential for mentees to progress beyond their relationship with mentors to create their unique social role and identity.

The knowledge and behavior acquired by students will be, in large part, determined by their areas of interest and career focus. This can create complexities for institutions establishing socialization programs to accommodate students with aspirations to study and seek careers in the 
diverse types of programs, colleges, and universities. Hence, it becomes difficult to determine what methods of evaluation to provide feedback concerning student and process performance in meeting socialization objectives. It also remains unclear as to a determination of knowledge gained from mentorship and socialization be measured. Fischer (1998) noted that depending on what position the graduate student eventually hopes to obtain, development of certain additional skills may be essential. Students can develop skills in teaching by providing an occasional lecture or running a course at their institution, community college, or other such venue. In a like manner, the development of grant writing can begin upon entry to graduate school, and later they might assist a faculty member writing an actual research grant application. Furthermore, supervisory skills can be developed starting with the supervision of a high school or undergraduate student researcher, work-study students, or laboratory aides. Areas such as these can be monitored and evaluated by a mentor, faculty member, or advisor to determine knowledge and experience acquired. With this in mind, Rosser (2004) pointed out that preparation of future faculty is a process requiring diligent study.

Although a new PhD may have the skills and capacity to become a professor, earning a doctorate does not automatically "prepare" the student to become a professor at an institution of higher education. Becoming a successful professor takes careful preparation, socialization, and mentoring. With this in mind, and considering the importance of instructional aspects dominating the role of higher education faculty, particularly at community and technical colleges, further examination of an emphasis on socialization related to teaching is indispensable. 


\section{Emphasis on Teaching}

The need for addressing teacher training of graduate students entering college faculty positions is an important mission if research universities are to prepare and socialize the next generation of college faculty effectively. Regarding preparation of future faculty, Meacham (2002) posited, that if research university programs do not adequately prepare their graduates for their role as new faculty, then these universities are failing not only their own students but the generation of students and families relying on new faculty to be effective teachers. Thus post-secondary institutions are the providers of a large number of teachers beginning career in higher education classrooms. One of the difficulties associated with developing future college faculty arises due to the significant differences in higher education institutional missions; contrasting that of community colleges, liberal arts colleges, and master's degree institutions to that of major research universities. To describe the diversity in institutional missions found in the various higher education venues, Meacham stated:

At the former (community colleges), teaching and being a teacher are highly valued, teaching is student-centered and requires a rich repertoire of teaching skills, and the role of faculty is to be the change agents with their students and for the institution and the larger community. In the research university, teaching is the same as lecturing, and it is course specific and content-centered; the role of the faculty is to complement each other's research expertise and fit comfortably among other's personalities. (p. 25) In relation to Meacham's findings regarding the dilemma associated in preparing higher education faculty, Cady (1973) described a myth in the form of a syllogism, that perpetuates the resistance for resolving this situation; "scholars know their subject matter, teachers know their 
subject matter, therefore, scholars are teachers" (p. 7). The paradox is reflected in the notion that to acquire a faculty position at the college and university level a student must become a scholar of subject matter to an advanced level, however, in order to teach the subject matter emphasis on teaching is also important; it is the pedagogical knowledge that is lacking. More to the point, Thornton's (2010) research on the transition of career professionals into technical college teaching roles described the difference in preparation for students seeking academic careers at universities versus community colleges. The research claimed those transitioning from industry careers may find the experience more difficult than those transitioning to other institutions. In most cases graduate training prepares new faculty to anticipate some aspects of teaching, the training was not, however, typically a sufficient background for most vocational technical faculty. Thornton's finding supported the relevance of socialization of four-year students for improving their capability to acquire the norms and culture associated with their higher education careers. (p.8) However, Thornton argued that for teaching in the community and technical college system, the preparation received in graduate schools is inadequate. Compounding this predicament faced by community colleges, Thornton explained that many of the community college teachers with technical expertise, from successful industry careers, have not been socialized to understand the expectations of vocational technical college instructors. Most faculty are directly recruited from professional careers, with no higher education degrees and often have little or no formal pedagogical training prior to entering the classroom. (p. 8) The assertion is made that during the socialization process, pedagogical aspects of teaching and student learning should be emphasized, as well as the skills and expertise of the discipline taught. Consequently, there is a dilemma faced by community college institutions recruiting faculty 
socialized in both their discipline and pedagogical aspects of teaching because the research found the later to be deficient.

Turning attention to university socialization of higher education faculty, Cady (1973) argued "graduate schools train researchers, not teachers; and effective teaching requires sufficient knowledge of both the discipline and pedagogy" (p. 8). Similarly, it may be argued that the goal of doctoral education is to prepare excellent researchers and scholars, not necessarily skill-based career centered graduates. Although this may be true, universities socializing future faculty should not overlook the application aspect of knowledge created by researchers. Information created by researchers must be communicated in various settings to become useful, for example, with students in classrooms and laboratories, colleagues internal and external to the university, and with administrators and policy makers. With this in mind, Golde (2004) emphasized the goal of improving socialization of future teachers by noting that "teaching, whether in an article, classroom, or grant proposal, is an integral part of investigation and scholarship. Researchers must be able to contextualize their work, both within their discipline and the world, and to explain its importance to others" (p. 26).

Related to this, the research of Parker, Ashe, Boersma, Hicks, and Bennett (2015) described the pedagogical training being incorporated to the orientation programs of some graduate program teaching assistants. Institutions relying on voluntary orientation including content-based training lacked the effectiveness in meeting the pedagogical knowledge needed for training graduate students to teach their discipline. In addition, some mandatory orientation programs focus the training related to "university policies and procedures, as well as individually selected topics regarding teaching methodologies, student learning styles, and instructional 
design" (p. 88). This type of training was found to be discipline specific, and often focused on transitioning the student's mind from student to teacher. Overall, there is a perspective that socializing future faculty, focusing on the important attributes of teaching, is gaining momentum, albeit slowly.

Depending on the institution, and specific discipline of study, there is recognition that socialization in the teaching aspects of graduate students will better prepare them for academic careers. The research by Cady (1973) pointed out that teaching in higher education is more complex today than merely repeating the methods of previous generations of college professors. The knowledge of learning is much greater today and the questions to be asked about learning can be answered through more resources, intensity, and justification. Cady stated: "Those intensely-asked questions are directed at why we teach what we do teach, what we expect of our students, how we help our students learn, and how we know that we have done our part well" (p. 16). With this in mind, there is still a dramatic variance in this endeavor depending on field of study, leaving room for improvement. For example, a study by Golde (2004) revealed disciplines such as English (79\%), Mathematics (58\%), and Sociology (60\%) were offering courses on pedagogy lasting for one term; whereas, departments teaching Chemistry $(28 \%)$, Biology (30\%), and Art History (33\%) were not socializing their students' pedagogical practices (p. 3). This exemplifies the striking differences in the way graduate students and future faculty are being prepared and socialized to enter the academic workplace. While some are receiving quality doctoral experiences, mentoring, and socialization, others are lacking the training that will make them effective early in their careers. Meacham (2002) described blunt testimonial to 
the reason for some institutions' lack of interest in preparing doctoral student for teaching roles, by stating:

From having raised this question on several campuses, I know that the doctoral program faculty and administrators believe that it is not their responsibility to prepare their graduates to be effective teachers. Their reasons include numerous concerns; for example, the potential for drawing time and effort away from students' research endeavors and the perceived threat to these programs' National Research Council and similar rankings. However, I believe that the core concern is that most faculty in doctoral research programs don't know how to instill a passion and commitment for teaching in their doctoral students, or how to mentor novice teachers to be student-centered and to acquire a repertoire of teaching skills beyond lecturing, or how to prepare their graduates to be change agents for their students, their institutions, and their communities. (p. 25) A contrasting view of graduate assistantship impact was pointed out in Parker's et al. (2015) research. It was determined that graduate students with teaching assistantships rated their experiences more meaningful, and "that the assistantships prepared them for a career in academia by helping them cultivate their teaching skills" (p. 87). Graduate students with assistantships become socialized into areas of lesson planning, discussion leadership, employment of teaching techniques, and methods of classroom management. Moreover, Rosser (2004) suggested that teaching should also combine a commitment to and a sense of responsibility for student learning. A high standard of training and preparation of future educators should be maintained during graduate school. Rosser stated: 
Therefore, it is critical to seek answers to the question, 'How should doctoral students prepare themselves to become exemplary teachers?' The responsibility lies in our commitment: to the public, to our students, and to our own desire to better ourselves as educators. (p. 30)

All things considered, the emphasis on socializing graduate students and new faculty, in all disciplines, cannot be overlooked if universities are to prepare doctoral students for professional careers in higher education effectively.

As a means for facilitating socialization, some institutions at least provide orientation sessions to introduce graduate students to what will be expected as they begin their college teaching careers. Addressing this from a more historical perspective, research by Wetzler (1954), determined all universities in the study of School of Education involved in college teacher preparation, agreed an orientation should be provided for candidates planning to teach in higher education, however the definition of "orientation" was not specific. Nevertheless, given the overall support for this training, Wetzler found only $47 \%$ of the universities surveyed stated that a positive program of orientation was being provided. In addition, there was complete agreement by study participants that all perspective have a broad general education background. However, in actual practice, Wetzler discovered that no more than:

$\ldots 45 \%$ of the universities require a broad, general education training for college teacher candidates. Twenty-five percent of the institutions do not have any general education requirement, and the rest of the universities make little or no demands in this area. (p. 11) 
The results of data such as this is reflected in the feedback received from Golde's survey of graduate students who consider themselves ill-prepared to begin faculty roles. The data found: ...the conception of "preparation" held by doctoral programs is quite narrow. The proportion of students who report that their program has helped to prepare them for these various tasks and roles is disappointingly low. For nearly every role or task performed by a faculty member, there is a significant gap between the proportion of students reporting interest and the proportion reporting preparation. The gap is small for conducting research, but much larger for many teaching service roles. (p. 2)

This deficiency puts new faculty in the unenviable position of attempting to meet institutional expectations with a socialization handicap. As a result of this lack of preparation the new teaching role can be a daunting task. As Jensen, Rabe, Runde, and Wee (2006) described, "the first semester can be grueling for first-time teachers given the class preparations, office hours, assignments and exams to develop and grade, departmental and faculty meetings, and other responsibilities" (p. 5). Moreover, new faculty find themselves on their own with less classroom support than expected. The opportunity for having the assistance of a mentor or instructional development program at this stage are two of the potential resources available to resolve this lack of preparation. Understanding the benefits resulting from a new faculty socialization and mentoring program is the initial step for beginning such a program at an institution. Referencing information regarding programs currently being implemented at other colleges and universities provides a framework for new program development. A description of socialization programs instituted at colleges and universities is beneficial for gaining an insight regarding what is working for other institutions. 


\section{Programs for Enhancing Socialization}

Due to concerns with traditional practices in doctoral education and the need for improvements in the way faculty members are being prepared, programs have been initiated to address this issue. Examples of programs leading to improvements in socialization of graduate students primarily consist of ongoing efforts to enhance the quality of teaching assistantships and, on a broader scale, there are organizations leading major faculty reform initiatives; in particular, the Preparing Future Faculty movement.

In many of the programs currently being implemented, graduate students are being tasked with teaching roles to enhance instructional experiences. Parker, Ashe, Boersma, Hicks, and Bennett (2015) stated:

Traditionally, the role of a graduate teaching assistant is largely to provide instructional support by teaching undergraduate students, or performing administrative duties, and this position often serves as the initial stage in the career of an aspiring professor. Some graduate teaching assistants are more likely to teach in a classroom for the entire school year or semester, while other assistants are more likely to teach a limited time in a classroom; while attending to laboratories, grading papers, or proctoring examinations. (p. 86)

In addition, Parker et al. (2015) commented on the value graduate assistants gain from the pedagogical training that benefits the entire department. An example describes the Teaching Assistant Institute at University of North Carolina Wilmington, in which 275 out of 1,500 graduate students work closely with faculty as teaching assistants. They participate in a university teaching assistant orientation, providing a foundation for learning about campus 
resources and support services, and best practices for teaching and learning. In this case, the institution appears to be guided by the benefits socialization and mentoring may provide their graduates. (p. 93)

Beyond socializing and mentoring graduate students and future faculty in pedagogical development as teaching assistants, there are initiatives being taken on a broader scale by the Preparing Future Faculty (PFF) movement. This program originated jointly in 1989 by the Association of American Colleges and Universities and the Council of Graduate School. The mission of both organizations is to assist graduate education programs in more closely aligning curriculum with the work graduates will perform. Schneider (2002) noted the importance of PFF for inspiring long-term expansion of its initiative to hundreds of institutions and thousands of supporters for a change in the American academy. Essentially, the PFF movement is working to bridge the divide that research believes exists between doctoral student knowledge acquired at universities and what they will encounter as professional academics. Meacham (2002) stated: PFF has played an important role in linking doctoral students with the teaching strengths and opportunities of nearby community and liberal arts colleges and master's institutions. Components of Preparing Future Faculty programs with the greatest impact have included being mentored by one or several faculty at cluster institution, spending time following cluster faculty through a typical day on campus, participating in high-level graduate seminars on teaching and faculty life, preparing a course syllabus and having it critiqued, being supervised in teaching by excellent teachers, engaging in self-assessment and self-reflection as a teacher and potential faculty member, and assembling a teaching portfolio that includes a statement of teaching philosophy. (p. 26) 
Finally, as Gaff (2002) pointed out, when considering research acquired from perspectives of university graduate students, new faculty, or incumbent faculty, PFF is addressing a widely perceived need for improving socialization of future faculty. Graduate students and future faculty, institutions where they research and teach, and the students they engage with, all benefit from future faculty receiving additional education directed at the socialization of teaching and learning.

Regarding programs for socializing and mentoring new faculty, an argument may be made for the need for this developmental experience for improving the transition from graduate student, or career professional, to a new academic role. With that said, an overview of program traits scholars find important for mentoring and socialization will guide further examination of programs in place, and establish goals for new programs being considered. This discussion begins with consideration of institutional and departmental orientations for future faculty. The research of Boyle and Boice (1998) determined "departments that excel at enculturating graduate students supplement the general orientation with departmentally sponsored orientation. These departments realize that it is the departmental culture, not necessarily the university culture, to which their incoming students will need to adjust" (p. 88). In addition to orientations, Parker et al. (2015) emphasizes the importance of consistent input from mentors, multiple workshops during the semester, and observation of the graduate students and protégés engaging in the classroom and laboratory. Building on these ideas leads to further consideration of mentoring as a means of socialization. With an assumption that the objective of mentoring is strong socialization, the foundation of mentoring program development is a solid understanding of what constitutes good socialization. For example, the research of Sabin (2007) identified points as 
component of good socialization processes and suggests the teaching outcomes to be derived from the processes as follows:

- Good socialization process will use:

o Collective socialization methods, bringing together all new entrants

o "Formal" systems, including "sequential events," for socialization

o Designated mentors to act as the official spokesperson for the organization, thereby eliminating "noise" from other sources

- Good socialization processes will teach:

o The formal structure of the organization

o The role of the particular individual university in the higher education world

o Institutional values (p. 10)

To achieve these objectives, and a high level of commitment by participants, Savin, West, and Purcell (2006) explained the importance for programs to have clear, formal, but not rigid guidelines. The expectations, established by either a committee or an administration, covers topics such as documentation, level of commitment, and evaluation of the mentoring progress. Savin et al. commented about one case in which "participants were expected to document their partnership by signing a contract. This practice had been highly encouraged at the departmental workshop to help both parties clearly establish expectations for the relationship" (p. 21).

Moreover, the inclusion of written evaluations for program activities was found to be instrumental for determining the program components needing improvement. In support of this formal mentoring and its associated documentation, Savin et al. referred to data indicating the reluctance of new faculty to initiate interactions with senior faculty. Correspondingly, Hopkins 
and Grigoriu (2005), found mentees preferring formal programs offering strong, visible-but non-intrusive institutional support for informal mentoring. They continued by stating:

Strong institutional support is defined collectively by mentees as a formal mentoring program with informal structural components that provide resources and materials without prescribing how they are used and that offer voluntary informational meetings without mandating attendance. Mentees prefer formal support for mentoring that is informal in nature so they can choose how best to develop their relationships and address their individual needs. (p. 41)

Given these points, it appears successful mentoring depends less on who the mentors are, as long as a productive relationship exists, versus what occurs during the mentoring process. Research by Bode (1999) determined topics important to discuss during mentoring included teaching and scholarly productivity; review, tenure, and promotion packages; collegiality; balance between professional and personal roles. On a more informal basis the pairs developing the closest relationships filled in gaps with small talk; building a friendship that motivates a desire to continue meeting at intervals. As a result, the mentor functions as friend, career guide, information source, and intellectual guide. "In other words, proteges can receive emotional support, advice and professional promotion, information about their organizational system, and/or enter into professional collaborative relationships through mentoring" (Savin et al., 2006, p. 19). Overall, the continuation of meeting on a consistent basis was essential, indicating success seemed to depend on structure, getting pairs involved in the relationship, and evaluations. 
The formation of the relationship during mentoring and socialization is often critical to the success of a graduate student or new faculty member. With that said, Sabin (2007) found a number of factors leading to successful mentoring relationships:

- Mentors had three to five years of experience on campus and were generally happy with their departments and schools.

- Successful mentors were those with the interpersonal skills to foster personal relationships with new faculty.

- Mentoring relationships that were officially established through an organizational program worked better than relationships that occurred without intervention. (p. 11) These relationships often provide a foundation upon which proteges can base their faculty identity and future academic success. For example, Huwe and Johnson (2003) reported "research bearing on the benefits of mentor relationships during the past two decades leads to the conclusion that this developmental relationship can positively and powerfully influence graduate students' personal and professional development" (p. 42). They express numerous intermediate and long-term benefits of mentoring relationships as follows:

- Development of professional skills and identity

- Procurement of internship and training opportunities

- Enhanced satisfaction with doctoral training

- Higher salaries

- More rapid promotion rates

- Greater career satisfaction (p. 42) 
Consequently, the benefits of mentoring and socialization programs appear advantageous for mentor, mentees, and the institution. This overview of socialization programs provides a glimpse of the design components and the expectations determining program effectiveness. The variety of programs and the implementation methods present at various higher education institutions provides an opportunity for further study. 


\section{Chapter Three}

\section{Methodology}

This chapter describes the case study method used to investigate the socialization and mentoring of faculty in community and technical college. The author offers a rationale for choosing the case study method and presents the theoretical framework upon which this study is based, methodology for this study, a description of participant samples, the role of the researcher, and issues of study validity. Lastly, a description of the data collection tools, method of data analysis, and trustworthiness and limitations are included.

The primary purpose of this case study research is to examine and present the perceptions of socialization and mentoring of new college faculty transitioning from career professional roles into academic teaching roles during their first years as faculty members, focusing on new faculty with three to five years of service. The study addresses the following questions:

\section{Research Questions}

1. What are the unique structures and processes in place at the institution being perceived as aiding socialization, mentorship, and transition of new faculty from professional careers to the Applied Technology college teaching profession?

2. How do new faculty perceive that socialization and mentorship programs provide content and pedagogical knowledge during the transition from career professional to higher education professional careers and support integration to the norms and culture of community college institutions? 
3. How do new faculty perceive the effectiveness of socialization and mentorship processes, structures, and strategies on pedagogy and student learning in the Applied Technology college environment?

\section{Research Design}

The qualitative paradigm used in this study is based on the concepts of a constructionist epistemology. An understanding of the importance of socialization and mentoring in development of community and technical college faculty is rooted in the experiences of faculty who are new to higher education teaching practices and are able to communicate their experiences for the benefit of others. The pursuit of meaning and understanding derived from a case study of new faculty is guided by the position that: "There is no objective truth waiting for us to discover it. Truth, or meaning, comes into existence in and out of or engagement with the realities of our world" (Crotty, 2012, p. 8). Case study, and the perceptions of novice faculty, allow the researcher and the participants of the research to account for a derived understanding of the impact of socialization and mentoring. Yin (2013) stated:

A case study involves an inference every time an event cannot be directly observed. An investigator will 'infer' that a particular event resulted from some earlier occurrence, based on interview and documentary evidence collected as part of the case study. (p. 47) Based on the lack of prior research literature related to socialization and mentoring at community and technical institutions, justification of this case study design is based on the unique findings to result analyzing relevant perceptions of new faculty regarding this issue. Furthermore, a descriptive category of case study is utilized based on Yin's definition of case types as "...used to describe an intervention or phenomenon and the real-life context in which it 
occurred" (Baxter \& Jack, 2008, p. 258). Finally, the results of this dissertation provides a foundation for future studies of multiple institutions and an increased number of faculties whereby a survey method of data gathering will be more effective.

The constructivism paradigm is based on the idea that reality is a product of one's own creation as it relates to experiences. Each individual sees and interprets the world, and his or her experiences, through his or her personal belief systems. Constructivism is an underlying philosophy or way of seeing the world. As such, it is based on the way of seeing the world that includes notions about:

The nature of reality (mental representations have "real" ontological status just as the "world out there" does). The nature of knowledge (It is individually constructed; it is inside people's minds, not "out there"). The nature of human interaction (we rely on shared or "negotiated" meanings, better thought of as cooperative, than authoritative or manipulative in nature). The nature of science (it is a meaning-making activity with the biases and filters accompanying any human activity). (Cakir, 2008, p. 197)

Through application of case study research, constructed meaning is examined from individuals based on their experiences and their systems of beliefs; participants' attitudes, values, and ideas combine to bring clarity to broad perspective of socialization occurring at the institution. It is through case study research of the experiences and perspective of new faculty that meaning can be transmitted for the benefit of research knowledge.

The research questions are what influence the choice of research method, which in this case is to gain an understanding and derive meaning as to the impact of socialization and 
mentoring of new faculty in a community and technical college. For clarification, Yin (2013) defined case study research as follows:

- A case study is an empirical inquiry that, (a) investigates a contemporary phenomenon in depth and within its real-world context, especially when, (b) the boundaries between phenomenon and context may not be clearly evident. In other words, you would want to do case study research because you want to understand a real-world case and assume that such an understanding is likely to involve important contextual conditions pertinent to your case. (p. 16)

- A case study inquiry, (a) copes with the technically distinctive situation in which there will be many more variables of interest than data points, and as one result, (b) relies on multiple sources of evidence, with data needing to converge in a triangulating fashion, and as another result, (c) benefits from the prior development of theoretical propositions to guide data collection and analysis. (p. 16)

By researching the perceptions and experiences of new faculty of a community and technical college during the socialization process, knowledge was gained regarding the transition of individuals from beginning stage of their college teaching careers through their development into veteran faculty status.

\section{Assumptions in Qualitative Research}

The objective of this research is to derive meaning and understanding from perceptions of new community and technical college faculty so the experiences might be influential to the development of others striving for improved socialization of their college teaching role. Using case study research, the perceptions of instructors have been collected as a means of 
understanding experience as lived and told, through interviews, research, and literature. To understand the value of case study research as it relates to this dissertation, it is important to distinguish its traits as a qualitative research methodology in pursuit of understanding.

This qualitative research study is utilized to gain an understanding of common traits and characteristics developed by instructors based on their experience with the socialization and mentoring of new faculty. In addition, the conclusions are communicated for the benefit of the academic community seeking knowledge concerning the topic. The ability of qualitative data to more fully describe this type of phenomena is an important consideration not only from the researcher's perspective, but also from the reader's perspective as well. This qualitative research is based on the following rationales:

1. Qualitative research uses the natural setting as the source of data. The researcher attempts to observe, describe and interpret settings as they are.

2. The researcher acts as the "human instrument" of data collection.

3. Qualitative researchers predominantly use inductive data analysis.

4. Qualitative research reports are descriptive, incorporating expressive language and the "presence of voice in the text."

5. Qualitative research has an interpretive character, aimed at discovering the meaning events have for the individuals who experience them and the interpretations of those meanings by the researcher.

6. Qualitative researchers pay attention to the idiosyncratic as well as the pervasive, seeking the uniqueness of each case. 
7. Qualitative research has an emergent design, and researchers focus on this emerging process as well as the outcomes or product of the research.

8. Qualitative research is judged using special criteria for trustworthiness. (Hoepfl, 1977, p. 3)

\section{Site Selection}

The site for this research was a community and technical college, also termed applied technology institution located in the Mid-Atlantic Region. For the purpose of this dissertation a pseudonym, Mid-Atlantic Community and Technical College, is used to identify the site of this research.

For the purpose of this dissertation, a typical mission statement, derived from a compilation of community and technical colleges is as follows: Mid-Atlantic Community and Technical College is to provide opportunities for learning, training, and further education that enrich the lives of individuals and promote the economic growth of our service region and state. Mid-Atlantic Community and Technical College strives to enhance the quality of life for people of the Mid-Atlantic Region through accessible, affordable, comprehensive, responsive, workforce-related training, and quality higher education opportunities.

While Mid-Atlantic Community and Technical College is headquartered in a city within the central Mid-Atlantic Region, nearly half of the college's students take classes at sites outside of the central campus. Regional Academics campuses and educational centers are located throughout the college's 13-county service region. Mid-Atlantic Community and Technical College shares a beautiful 120-acre campus with an affiliated four-year university. Mid-Atlantic Community and Technical College is part of the region's growing high technology corridor with 
a metro area of about 50,000 residents. During the Fall 2015 semester the college had an enrollment of more than 2,100 students, to which the institution offered a combination of more than 40 Associate of Arts, Associate of Applied Science, Certificate of Applied Science degree programs, Advanced Skill Sets, and Skill Sets. Based on this description, Mid-Atlantic Community and Technical College is an ideal representative sample of what the American Association of Community Colleges [AACC] professes for their affiliated institutions. As the AACC states:

In simplest terms, the mission of the community college is to provide education for individuals, many of whom are adults, in its service region. Most community college missions have basic commitments to:

- Serve all segments of society through an open-access admissions policy that offers equal and fair treatment to all students,

- A comprehensive educational program,

- Serve its community and community-based institution of higher education,

- Teaching,

- Lifelong learning (“About Community Colleges,” 2010)

Furthermore, Mid-Atlantic Community and Technical College is one of the 1,167 community colleges serving undergraduate students in the United States. The institution is representative of those community colleges fulfilling the institutional objective described by the Department of Homeland Security [DHS]:

To ensure students have adequate preparation for jobs that require higher education or workforce training, community college officials are working with employers to develop flexible, 
affordable and relevant training programs that meet business and regional economic needs. The partnership between businesses and community colleges can maximize workforce development strategies, job training programs, and ultimately, job placement. ("What is Community College", 2012)

For the purpose of this dissertation a bounded system, or unit of analysis, is the faculty member perceptions of socialization and mentoring at Mid-Atlantic Community and Technical College. Multiple institutions were not considered for this research in order to provide an element of control regarding perceptions of faculty members reflecting on experiences from an individual representative college. The goal of this study was a focus on the depth of experiences and nuances of several new faculty transitioning from professional careers to academic careers at an individual college. Yin (2013) supported the use of case study for this research stating, "A case study is a form of inquiry that does not depend solely on ethnographic or participant-observer data" (p. 21). In contrast, researching multiple institutions related to this topic was considered more suitable to survey type methods necessitating a separate study, yielding data beyond the scope of this dissertation. Final justification for this case study research versus statistical probabilities was described by Yin stating, "...in doing case study research, your goal will be to expand and generalize theories (analytical generalizations) and not to extrapolate probabilities (statistical generalization)" (p. 2l). For this dissertation the objective paid specific attention to the interviewee's personal perceptions of the socialization and mentoring process he or she experienced at Mid-Atlantic Community and Technical College. In this research the sense of meaning based on the interviewee's perceptions are the data to be understood. 


\section{Sample Participants}

Having established the unit of analysis for this research purposeful sampling was conducted to gather the richest data from faculty members having transitioned from professional careers to academic teaching roles at Mid-Atlantic Community and Technical College. The site and sample justification was identified as both a typical sample and a convenience sample of the community college system in the United States. Most importantly for purposeful sampling, Merriam and Tisdell (2016) claimed "the site is specifically selected because it is not in any major way atypical, extreme, deviant, or intensely unusual" (p. 97). Secondarily, this purposeful sample was selected with consideration of Merriam and Tisdell's convenience sampling criteria "based on time, money, location, availability of sites or respondents" (p. 98). Due to the researcher's proximity and access to the selected site and sample faculty members the reasoning was logical. Five faculty members with approximately two years of experience and less than five years' experience constitute the sample group for the case study interviews. To gather the most recent institutional data, if more than five interview candidates existed with three to five years experience, the most recent faculty member hired in a program established the basis for in interview request. With that said, in order to gather a broad institutional perspective, every effort was made to avoid multiple interview samples from the same program of study. This research considered Merriam and Tisdell's recommendation of establishing a sample size "based on expected reasonable coverage of the phenomenon give the purpose of the study" (p. 102). This timeframe stipulation was based on the reasoning that faculty within this range had enough time in service to clearly reflect upon the socialization experience during his or her transition process. The rationale for this purposeful sample was the expectation that new faculty members with less 
than two years' experience had not been fully transitioned to the institution and completed the socialization process to enable the gathering of rich data. For faculty members with more than five years of service at the institution the expectation was that those perspectives of the transition experience were outside the scope of rich data relative to the research objective of studying new faculty entering the institutional ranks. This research was guided by the purpose of gathering new faculty member perspectives who have recently undergone the socialization process and were within proximity of time to enable him or her to clearly reflect on the new faculty experience. This research was designed to gather the perceptions of new faculty members who had been recently socialized to the institution, by interviewing five individuals meeting these criteria a thorough amount of data leading to rich analysis. The size sample number (five) was based on a belief that less than five interviews do not provide an adequate range of perspectives for the size of this institution. This decision was also based on the Mid-Atlantic Community and Technical College website current list of 36 full-time faculty teaching in a variety of programs offered within the four major curriculum divisions of the college. Also, according to the website for Mid-Atlantic Community and Technical College, there were currently ten faculty members who had three to five years of new teaching experience. The primary objective was to interview (five) half the population of current faculty meeting the proposed selection criteria. This sample group was selected with an emphasis on those new faculty with previous professional career experience prior to their transition to an academic career. Furthermore, to establish a broad range of institutional data, a concerted effort was made to select only one sample from an individual program of study. Each of the interview samples was granted pseudonyms for identification, along with providing anonymity for privacy. In an effort to promote objectivity, 
each member sample was employed at the same institution as this researcher; however, none of the sample members were employed in same department as the researcher. Finally, to provide additional objectivity it should be noted, the researcher was located at a remote facility of the institution's campus from which sample members was selected.

In addition to personal interviews of faculty members from the purposeful sample, a focus group interview was conducted combining all faculty participant sample members for a session of group discussion regarding socialization and mentoring experiences. Given the constructivist perspective as the basis for this research, the socially constructed data from a group discussion was valuable. Merriam and Tisdell's (2016) supported the use of focus group interview stating:

Perhaps the most unique characteristic of focus group research is the interactive discussion through which data are generated, which leads to a different type of data not accessible through individual interviews. During the group discussion participants share their views, hear the view of others, and perhaps refine their own views in light of what they have heard. (p. 114)

The collaborative focus group interview was essential for generating additional data not gathered during personal interviews. This was an expectation predicated on the expectation that additional reflection was facilitated by a group setting and discussion. The focus group process called for gathering interviewees to convene in a small group and utilize an interview discussion to corroborate findings from individual interviews and captured additional data from individual reflections stimulated by group members' perceptions. Finally, it should be noted that interviews with administrators and mentors were not conducted, since their perceptions were considered to 
be outside the scope of this research. The possibility of gathering perspectives from those members of the institution should serve as basis for additional study at a future date.

\section{Data Collection}

Prior to the data collection phase for this study an Institutional Review Board (IRB) approval was necessary. Once the necessary approvals were in place, the personal interviews and focus group commenced. An invitation was sent out to all prospective participants at Mid-Atlantic Community and Technical College for voluntary participation in the study. From the targeted sample group, five novice faculty members were confirmed for inclusion in the study. A sample faculty member from each major institutional program and with the most recent hire date, between approximately three to five years of service, was the criteria goal for selection.

Data gathering consisted of two methods: Firstly, open-ended questions and dialogue with participant interviews and focus group discussion to garner first-hand perceptions of experiences during the early years of higher education employment; and secondly, reflective analysis and interpretation of participant stories related to their experiences. Each of the individual interviews and the focus group interview provided ample tape recorded data subsequently converted to manuscript format. A professional transcriptionist was contracted for transferring taped interview data to written format. The authenticity and accuracy of the transcribed data was verified by both the researcher and the participants.

Written documentation available for reference regarding Mid-Atlantic Community and Technical College socialization and mentoring programs were researched. Yin (2013) stated: "Because of their overall value, documents play an explicit role in any data collection in doing case study research. Systematic searches for relevant documents are important in any data 
collection plan" (p. 107). The institutional Faculty Handbook, Faculty Welfare Committee records, and personal records of participant were instrumental for supporting and corroborating interview data. Understanding the institution's written data prepared and published for purposes other than this case study was taken into consideration during the analysis phase of the study to avoid erroneous conclusions.

\section{Individual Interview Questions}

Each of the interviews was conducted in the private offices of the individual participants. For consistency, all participants were asked the same series of questions and were provided ample opportunity to elaborate on their recollection of their experiences. For reference, the individual interview questions are provided below and a table of questions and responses is located in Appendix 1. For clarification, the questions have been labeled for reference to topic areas related to foundational background information, Research Question 1, Research Question 2, and Research Question 3:

As a background: Will you describe for me your professional career prior to beginning your teaching career?

1. Foundational: When you reflect on the time when you were in college or in your professional training programs, how did those experiences influence your impression of teaching in a college level program?

2. Foundational: At what stage in your educational journey did you begin to think seriously about pursuing a career in college teaching in tandem with your professional career?

3. Foundational: Based on your past experiences during your years of education and professional training or employment, how would you describe the traits or teaching philosophies of teachers, you consider mentors, that have been most influential in your own teaching strategies. 
4. Foundational: Given your professional education and experience, will you describe the training or education you have that has been specifically beneficial for classroom instruction, both before becoming a college teacher and after beginning your college teaching career?

5. Foundational: Based on your initial impression of what college teaching roles entail prior to transitioning into your teaching career, how do you perceive the roles differently today, since beginning an academic career?

6. Research Question 1: What is your perception of the transition process from a career professional to your early stages of a college teaching role? When you made the decision to begin your college teaching career, what were your expectations regarding the career change?

7. Research Question 1: When you recall the initial job interviews, the hiring, and the first semester of college teaching, will you describe for me the processes and/or programs you experienced whereby the institution provided a means for you to socialize and acclimate into your new teaching career?

8. Research Question 2: When you began teaching at this institution, to aid your transition and socialization, were you assigned a faculty mentor? If so, how was that that mentor selected for you? If not, how would you perceive a mentor would have benefited you during your transition?

Was there a formal mentoring process? Will you describe your perception about what that entailed and how that experience help your transition to the norms and culture of higher education?

If not, how would you perceive a mentor would have benefited you during your transition?

9. Research Question 2: Were there informal mentors to whom you gravitated to and associated with? Will you describe your perception about what that entailed and how that experience help your transition?

10. Research Question 2: Were there any situations you experienced during your transition that you think would have made you more effective as a college teacher early in your college teaching career if you had been informed during a socialization process? 
Will you describe any programs provided by the institution that aided your pedagogical and collegial expertise for teaching your specific content matter and actively engaging in service to the institution?

11. Research Question 3: Will you describe your perception of how socialization and mentoring at the institution has helped (or could have helped you) to be effective in the classroom and enhance student learning?

12. Research Question 3: What recommendations do you have for improving the institutional socialization and mentoring processes for transitioning from career professional to college teaching professional?

\section{Focus Group Questions}

The focus group interview was conducted in a private conference room located at the main facility of Mid-Atlantic Community and Technical College. A survey was sent to all participants to determine the most compatible time for maximum participation. It should be noted that due to scheduling conflicts, as a result of professional and personal commitments, a fifth participant was unable to contribute to the focus group discussion. The following question established a framework for leading the focus group discussion:

Engagement Question: Introduce participants to the topic or subject

1. Thinking back to the first days you began pursuing a teaching career at the college, what were your impressions of how the beginning of your teaching role would evolve? How accurate was the preconception?

2. What is a phase of the socialization process that was most memorable during your transition to your college teaching career? Good or Bad.

Exploration Question: Designed to get to the heart of the discussion and typically open-ended.

1. Thinking back over the past few years, what are some things or events you perceive as being advantageous during the socialization process at this institution? 
2. What do you perceive as areas of weakness related to aspects of the socialization process at this institution?

3. How do you perceive the effectiveness of the mentoring process you experienced at this institution for socialization to your new teaching career?

4. What would you suggest for socializing new faculty transitioning from a professional career into a new community college teaching career?

5. Suppose that you had an opportunity to speak candidly with the college President about socialization and mentoring, or any perceptions you have about this topic, what would you say?

Exit Questions: Designed to see if any angle was missed during the discussion.

1. Is there anything else you would like to say about socialization or mentoring that your perceive to be relevant to your experiences or that you would have changed during the transition period?

2. Reviewing the purpose of this study, which is to examine new faculty perceptions of the socialization and mentoring process, and perceived impact of the process on instruction and student learning, have we missed anything?

\section{Analysis of Data}

Qualitative analysis requires some creative and interpretive technique, because the challenge is to place the raw data into logical, meaningful categories, examine them in a holistic fashion, and to find a way to communicate this interpretation to others (Hoepfl, 1977, p. 8). The goal of organizing this data was to gain a clear focus of the research question and separate irrelevant or redundant information from that which were analyzed. The strategy for analyzing this study focused on the content and the context of the text data derived from the open-ended questions presented during interviews to participants of the research process. The goal of this 
content analysis was to provide knowledge and understanding from the collective perceptions and experiences of participants. For this research, "qualitative analysis is defined as a research method for the subjective interpretation of the content of text data through the systematic classification process of coding and identifying themes or patterns" (Hsieh \& Shannon, 2005, p. 1278). In addition, as it was of primary interest to gain meaning and understanding from the study of new faculty member's experiences with socialization and mentoring at Mid-Atlantic Community and Technical colleges, the conventional content approach for data analysis was most suitable.

Conventional content analysis was used in this study to describe the perceptions and experiences, discovered during case study of participants. The choice of this method was based on the fact that there was limited theoretical or research literature available on the phenomenon of new faculty socialization and mentoring related to new community and technical college faculty. This inductive process of analysis and coding allowed for categories and names for categories developed as information flowed from interview transcripts because preconceived categories did not yet exist. Given the lack of prior research in this area of study it was important to develop a thorough understanding of the context, to ensure identification of pertinent categories. In an effort to organize and compare responses from the interviewees information was organized in a manner similar to that shown in Table 8 below and provided in its completed form in Appendix 1 : 


\begin{tabular}{|l|l|l|l|l|l|}
\hline Table 8 \\
Interview Response Chart & Interviewee \#1 & Interviewee \#2 & Interviewee \#3 & Interviewee \#4 & Interviewee \#5 \\
\hline & & & & & \\
\hline Question \#1 & & & & & \\
\hline Question \#2 & & & & & \\
\hline Question \#3 & & & & & \\
\hline Question \#4 & & & & & \\
\hline
\end{tabular}

Table 8

To begin the analysis repeated reading of interview data was required for complete familiarity and a sense of the whole. The data then required word by word reading to determine codes that capture key thoughts and concepts. A constant comparative method was utilized for determining a theory that is based on the data. Boeije (2002) referred to comparison as the main intellectual process for grounding a theory, stating:

The main intellectual tool is comparison. The method of comparing and contrasting is used for practically all intellectual tasks during analysis: forming categories, establishing the boundaries of categories, assigning the segments to categories, summarizing the content of each category, and finding negative evidence, etc. The goal is to discern conceptual similarities, to refine the discriminative power of categories and to discover patterns. (p. 392)

To prepare for reporting the findings of the research, codes and categories were identified from the interview data (Hsieh \& Shannon, 2005, p. 1279). The coded data, categorized for organization into meaningful clusters and subcategories, reflect a prioritization of frequency and 
importance. Prior to final analysis, "all the information about the case should (was) be brought together - interview logs or transcripts, field notes, reports, records, the investigator's own documents, physical traces, and reflective memos" (Merriam \& Tísdell, 2015, p. 233). Based on the collective data, analytic generalizations were derived. As explained by Yin (2013), this analysis was an "opportunity to shed empirical light about some theoretical concepts or principles, not unlike the motive of a laboratory investigator in conceiving of and then conducting a new experiment" (p. 40). Thus, the accuracy and completeness of analysis was invaluable to the trustworthiness and validation of the knowledge gained for "reinterpreting the results of existing studies of other concrete situations (that is, other cases or experiments) or to define new research focusing on yet additional concrete situations (that is, new cases or experiments)" (Yin, p. 41).

\section{Validity of Research}

The compilation and validation of various sources of research data support the research findings. Validation for trustworthiness of the claims being made was a critical issue. "“Trustworthiness' not 'truth' is a key semantic difference: The latter assumes an objective reality, whereas the former moves the process into the social world" (Riessman, 1993, p. 65). Of the various means of ensuring trustworthiness, Riessman (1993) describes four ways of approaching validation:

1. Persuasiveness; greatest when theoretical claims are supported with evidence from informants accounts and when alternate interpretations of data are considered. Success will depend on a capacity to invite, compel, stimulate or delight an audience. 
2. Correspondence; taking work back to the individuals or groups who participated in the study to ensure the accuracy of the researcher's interpretations.

3. Coherence; whereby researchers must continually modify initial hypothesis about a speaker's beliefs and goals (global coherence) in light of the structure of particular case studies (local coherence) and recurrent themes that unify the text (theme coherence). The interpretation of meaning is constrained by the text, offering a check on ad hoc theorizing.

4. Pragmatic Use; involves the extent to which a particular study becomes the basis for others' work. This will include descriptions of how interpretations and perceptions are produced, making visible what was accomplished, and making primary data available to other researchers. (p. 65-68)

The validity of construct described by Yin (2013) was met by applying three tactics. First the use of "multiple sources of evidence" was fulfilled by gathering interview data from five separate open-ended interviews and by means of a focus group interview. Secondly, a "chain of evidence" was established during the data collection process. This case study, with its multiple data points and its analysis technique, provided the researcher a means of triangulation supporting the resultant research findings and conclusions.

Strategies for increased credibility consisted of member checking, an audit trail, and a peer audit. Member checking consisted of data verification and accuracy of category analysis. The interview and focus group participants were requested to review documents prior to publication of a final draft; interpretations, finding, and conclusions were reviewed with participants to ensure reliability. This allowed participants an opportunity to make corrections 
to erroneous interpretations of perceptions prior to formal presentation. In addition, an audit trail recording the management of data sources and interpretations are addressed with appropriate rigor. "This record provides evidence that recorded raw data have gone through a process of analysis, reduction, and synthesis. (Wolf, 2003, p. 178)" Most importantly interview transcriptions of open-ended questions, field notes based on observations, description of document analysis process, and personal notes provide a record attesting to the logic used for research findings. Finally, peer audits were conducted to review and comment on the draft document rigor and accuracy. Commentary on scholarly writing and format, critique of methodology, and authenticity of work were invaluable of dissertation credibility.

\section{Research Positionality}

For the past 25 years I have been teaching at Mid-Atlantic Community and Technical College. During my early years as a new faculty member essentially no training or education in the application of pedagogical concepts related to teaching and classroom management was provided. The pedagogic expertise applied during my early academic career was assimilated by me as a student during my undergraduate and graduate studies, and what I learned from trial and error while conducting my classroom and laboratory presentations with my students.

Prior to my professional academic career, I spent time working as a machine operator at an Allis-Chalmers manufacturing facility, fabricating and machining engine parts. It was during this employment that I became aware of the importance of education as an avenue to improve my opportunities for a more fulfilling occupation. I choose to begin my academic career at Southern Illinois University as a student of aviation technology. My studies ultimately allowed me to be begin a 10 year career as an aircraft technician with some of the world's largest 
airlines, at some of the busiest airports in the world. Today, as a Doctoral Candidate in Curriculum and Instruction, at West Virginia University, I feel compelled to help new faculty transitioning from professional technical careers to academic careers as instructors at community and technical colleges.

By researching the socialization and mentoring of new faculty members at Mid-Atlantic Community and Technical College, it was my desire to examine the perceptions of new faculty during their early years in higher education. Although economic and industrial issues that drive the need for a trained workforce are important criteria for measuring the need for a collegiate program, the socialization and mentoring of new faculty should not be overlooked when implementing programs designed to improve the knowledge and quality of life for students.

During my 25 year career as an aviation technology educator I have had the opportunity to mentor several new faculty in the department. In fact, four of the five faculty members in the Aviation Technology Program were students in my classes and were under my mentorship early in their teaching careers. Given these circumstances, no aviation technology faculty participated in this study, in order to prevent preconceived perceptions during the interview process. My intent focused on the importance of having a balance of participants from various departments at Mid-Atlantic Community and Technical College. With this objective, I conducted my research into the perceptions of the socialization and mentoring process for new faculty members at the community and technical college institutional level. 


\section{Findings}

\section{Chapter 4}

This dissertation is designed to examine the perceptions of faculty experiencing mentoring and socialization in applied technology disciplines at the community college level. The impetus for this research is derived from existing literature which predominantly focuses on the socialization processes whereby four-year colleges and universities develop graduate students for advancement to higher education teaching and research careers. There is, however, a significant amount of higher education occurring at the community and technical college level, where faculty are being recruited from career professional ranks, yet a dearth of research literature exists related to this topic. To fill this gap in the research literature, this dissertation examines the mentoring and socialization structures within the context of community college Applied Technology disciplines. Specifically, this case study design utilizes five individual interviews and a four person focus group interview to investigate the mentorship and socialization process implemented for Applied Technology faculty during the first few years of transitioning faculty academic careers.

\section{Research Questions}

This research will be guided by the following questions:

1. What are the unique structures and processes in place at the institution being perceived as aiding socialization, mentorship, and transition of new faculty from professional careers to the Applied Technology college teaching profession?

2. How do new faculty perceive that socialization and mentorship programs provide content and pedagogical knowledge during the transition from career professional to higher 
education professional careers and support integration to the norms and culture of community college institutions?

3. How do new faculty perceive the effectiveness of socialization and mentorship processes, structures, and strategies on pedagogy and student learning in the Applied Technology college environment?

\section{Purpose}

The purpose of this chapter is to present an analysis of new college faculty perceptions of institutional socialization and mentoring during the transition from career professional roles into academic teaching. Emphasis is placed on the first years of the career change process, focusing on new faculty with three to five years of service. The findings derived from both individual interviews and a focus group interview are presented below. The chapter begins with the five background interview questions presented to each participant of the study. The remaining questions are designed to solicit perceptions of participants as they relate directly to the three research questions. Summarized responses to interview questions are presented, followed by related focus group discussion comments, as a main body of findings.

To establish a broad range of institutional data, a concerted effort was made to select only one sample from an individual program of study. Each of the interview samples was granted a pseudonym for identification, along with providing anonymity. In addition, to promote objectivity, although each participant of the case study is employed at the same institution as this researcher, none of the sample members are employed in same department as the researcher. Finally, to provide further objectivity, it should be noted, the researcher is located at a remote facility of the institution's campus from which each participant was selected. 
Data gathering consisted of two methods: first, open-ended questions and dialogue with participant interviews and focus group discussion to garner first-hand perceptions of experiences during the early years of higher education employment; and secondly, reflective analysis and interpretation of participant stories related to experiences. Each of the individual interviews and the focus group interview relied on taped conversations from participants identified in Table 9 , subsequently converted to manuscript format. A professional transcriptionist was contracted for transferring taped interview data to written format. Appendix 1, provides an "Interview Response Table" for a summary and comparison of feedback from each of the individual interviews. The authenticity and accuracy of the transcribed data was verified by both the researcher and the participants. Where available, institutional written documentation addressing faculty positions and background has been used to corroborate participant information. However, no institutional data was available related to faculty socialization and mentoring programs.

\begin{tabular}{|c|c|c|c|c|}
\hline \multicolumn{5}{|c|}{$\begin{array}{l}\text { Table } 9 \\
\text { Participant Descriptions }\end{array}$} \\
\hline Participant & $\begin{array}{l}\text { Professional } \\
\text { Career }\end{array}$ & Education & $\begin{array}{l}\text { Approx. } \\
\text { Age }\end{array}$ & Current Title \\
\hline Collin & $\begin{array}{l}\text { Lineman for power } \\
\text { company }\end{array}$ & $\begin{array}{l}\text { BS Degree } \\
\text { Electrical } \\
\text { Technology }\end{array}$ & 55 & $\begin{array}{l}\text { Program Coordinator } \\
\text { Electrical Utility } \\
\text { Technology }\end{array}$ \\
\hline Mary & $\begin{array}{l}\text { Managerial } \\
\text { Accountant natural } \\
\text { gas company }\end{array}$ & $\begin{array}{l}\text { MBA and } \\
\text { Certified Public } \\
\text { Accountant }\end{array}$ & 60 & $\begin{array}{l}\text { Program Coordinator of } \\
\text { Business Management }\end{array}$ \\
\hline Diane & Physical Therapist & $\begin{array}{l}\text { Master's Degree } \\
\text { Physical Therapy }\end{array}$ & 35 & $\begin{array}{l}\text { Program Coordinator of } \\
\text { Physical Therapy } \\
\text { Assistant }\end{array}$ \\
\hline
\end{tabular}




\begin{tabular}{|l|l|l|l|l|}
\hline Table 9 Continued \\
\hline Participant & $\begin{array}{l}\text { Professional } \\
\text { Career }\end{array}$ & Education & $\begin{array}{l}\text { Approx. } \\
\text { Age }\end{array}$ & Current Title \\
\hline William* & $\begin{array}{l}\text { Firefighter and } \\
\text { Emergency Medical } \\
\text { Service }\end{array}$ & $\begin{array}{l}\text { BS Degree } \\
\text { Occupational } \\
\text { Safety and Health }\end{array}$ & 35 & $\begin{array}{l}\text { Program Coordinator of } \\
\text { Emergency Medical } \\
\text { Services }\end{array}$ \\
\hline Patricia & $\begin{array}{l}\text { Medical Laboratory } \\
\text { Technician }\end{array}$ & $\begin{array}{l}\text { BS Degree } \\
\text { Medical } \\
\text { Laboratory } \\
\text { Science }\end{array}$ & 50 & $\begin{array}{l}\text { Instructor/Assistant } \\
\text { Professor Medical } \\
\text { Laboratory Technology }\end{array}$ \\
\hline W William did not participate in the focus group due to unexpected personal obligation and \\
schedule conflict.
\end{tabular}

Table 9

\section{Participant Biographies}

The first research participant, named Collin, began a professional career as a Lineman, working on utility poles for electric companies. His career in industry lasted more than 30 years, working for various companies, "up and down the pole." The career for this first interviewee, encompassed both the electrical power trade and experience with the communication trades, in both cable television and telephone. In addition, the technical career included contract work that involved travel up and down the east coast repairing storm damage. The career required an extensive amount of "hands-on" work, in all types of weather and at all times of the day and week. Unfortunately, in 2003, an accident occurred prohibiting the continuation of this career. At the age of 47 , having little previous college, participant \#1 returned to higher education to complete a four-year Bachelor's Degree in Electrical Technology. 
Collin is a male, approximately 55 years old, who was hired as an instructor by the institution during the fall of 2015. Currently he is the Program Coordinator of Electric Utility Technology and Power System Institute, which is a division of the institution's School of Workforce Development. The curriculum provides students with a variety of educational activities and experiences that will prepare them for mid-level positions in the electric utility industry as line workers or substation electricians. Collin teaches all classes and labs, such as Electrical Machinery, Mechanics 1, Industrial Safety, and Electrical Utility Practices, at the institution's main facility.

The second research participant, named Mary, has a Master's Degree in Business Administration and is a Certified Public Accountant. These credentials established a foundation for pursuing a 31 -year career, with two different companies, in the gas transmission industry. This career allowed for experiences in various departments from tax accountant to revenue accountant, general ledger accountant, and taxes. Throughout this career, time was spent at the divisional level of the parent company, where a broad managerial accounting career provided insight to corporate accounting from beginning to end. Due to the relocation of the corporate headquarters, a decision was made to separate from the professional accounting career and consider a college teaching career, after 31 years as a professional accountant.

Mary is a female, approximately 60 years old, who was hired as an instructor by the institution during the fall of 2014. She is currently the Program Coordinator of Business within the School of Business, Aviation and Technology. This degree program helps to address the educational needs for trained human resources in the service area of the institution and gives 
graduates the necessary skills to function professionally in today's business environment. Mary teaches all classes and labs, such as Introduction to Business, Corporate Communications, Legal Aspects of Business, Principles of Management, and Introduction to Financial Management, at the institution's main facility.

The third research participant, named Diane, graduated from physical therapy school, with a Master's in Physical Therapy in 2000. Her professional career started with six years working primarily in an outpatient care facility and six months in a nursing home facility. The career entailed aspects of workers' compensation, running a whole workers' compensation program and return to work program. Outpatient and orthopedic physical therapy, however, was her primary focus. After relocating for personal reasons, six more years were spent running the outpatient division of a smaller clinic. It was at this clinic where local college students interned as practitioners from a physical therapist assistant college program. Diane applied at local college as an adjunct instructor to teach their neuroscience course, focusing on neurophysiology of the central nervous system, as a lab assistant and began her initial college teaching career.

Diane is female, approximately 35 years old, who was hired as an instructor by the institution during the fall of 2013. She is currently an Assistant Professor of Physical Therapy and Program Coordinator of the Physical Therapist Assistant Program in the School of Health Careers. The Physical Therapist Assistant program is designed to educate and prepare students to work under the supervision of a physical therapist to provide therapeutic treatments to patients who have lost functional ability because of illness or injury. The program prepares students to sit for a state licensing exam and graduates must pass this exam to work as a Physical Therapist 
Assistant. Diane teaches all classes and labs, such as Introduction to Patient Care, Kinesiology, Therapeutic Exercise, Orthopedics, and Neurology, at the institution's off-campus facility.

The fourth research participant, named William, graduated with a Bachelor's Degree in Occupational Safety and Health with a concentration in Fire Science. William's post-secondary education began at UVU-Tech to study engineering, a path through Marshall University to study Safety, and finishing the Bachelor's degree online through Columbia Southern University in Safety and Fire Science. William is currently working in both professional and academic career roles. A career as an emergency services professional began in 2007 , working as a volunteer firefighter, and began as a full-time firefighter in 2011. While working as a full-time firefighter he was taking courses to expand professional credentials to include an additional Associate Degree in Paramedic Services at the local community college. While engaged in a professional emergency services career, an opportunity to conduct in-house training became available as a Cardiopulmonary Resuscitation instructor; a position he held for the past eight years. Upon graduation from the Paramedic program at the local college, an adjunct faculty position was secured, soon followed by an offer to become the Program Director.

William is a male, approximately 35 years old, who was hired as an instructor by the institution during the fall of 2015. He is currently an Instructor and Program Coordinator of Emergency Medical Services within the School of Human Services. The primary goal of the program is to produce entry-level basic, intermediate, and advanced Emergency Medical Technicians who are competent to work in career and volunteer positions within West Virginia's health care system. Students completing the EMS Associate in Applied Science may also 
complete the EMS Certificate in Applied Science during their time in the program. William teaches all classes and labs, such as Introduction to Emergency Medical Services, Emergency Medical Technician - Basic, Trauma Life Support - Basic, Airway Management and Advanced Patient Assessment, Pathophysiology and Shock Trauma Resuscitation, and Emergency Medical Service Cardiology, at the institution's off-campus facility.

The fifth research participant, named Patricia, participated in a local college's two-year Medical Lab Technology program before transferring to another in-state college to study for a four-year degree in 1988. Upon graduation, Patricia began a professional career as a hospital lab technician on a full-time basis, with occasional part-time employment. This professional career as lab technician, as well as lab assistant manager, and as lab manager at various hospitals, spans a period of 25-years. Most of the professional duties such as preparation of culture tissue samples, establishing and monitoring programs that ensure data accuracy, chemical analysis of blood and urine, and operation and calibration of test equipment, until she began her academic teaching career.

Patricia is a female, approximately 50 years old, who was hired as an instructor by the institution during the fall of 2013. She is currently an Instructor/Assistant Professor of Medical Laboratory Technology within the School of Health Careers. The Medical Laboratory Technology program provides education and training for students to become Medical Laboratory Technicians (MLTs). MLTs perform a variety of laboratory tests in blood banking, chemistry, hematology, immunology, microbiology and urinalysis. In addition to offering general studies and a laboratory based general science curriculum, the program is also designed to provide 
students with 43 credit hours of required MLT lecture and laboratory courses, which are integrated with a hospital or clinic-based practicum experience. Patricia teaches classes and labs, such as Clinical Immunology, Clinical Chemistry Techniques, Clinical Microbiology, Urinalysis and Body Fluids, and Hematology, currently being taught at the institution's main facility.

\section{Interview Analysis}

A brief summary of the interview analysis will serve to describe categories of information that emerged from the research process. After multiple readings of the transcribed interviews, phrases and sections were assigned codes for reference and relevance to the research topic. Codes were collated to generate the categories from the interview data as shown in Table 10 , which is based on frequency of data points attributed to the category ranging from high to low. Based on the categories of information, a process of organizing and connection of related topics was undertaken to establish relevance to the research questions of this study, which are discussed in the following sections.

\begin{tabular}{|l|l|c|l|}
\hline \multicolumn{2}{|l|}{ Table 10} & 10 & Job Change to Academia \\
\hline 1 & Institutional Mentoring and Socialization & 11 & Initial Hiring Into Teaching Position \\
\hline 2 & Preconceptions of Teaching Role & 12 & $\begin{array}{l}\text { Individual Departmental and In-Program } \\
\text { Mentoring }\end{array}$ \\
\hline 3 & Biography Before Teaching & 13 & Educational Background \\
\hline 4 & Traits of Past Teachers Emulated & 14 & Initial Interest in Teaching \\
\hline 5 & Training For Teaching Role & 15 & Processes to Improve Student Learning \\
\hline 6 & Recommendations to Improve Transition &
\end{tabular}




\begin{tabular}{|c|l|c|l|}
\hline \multicolumn{2}{|l|}{ Table 10 Continued } \\
\hline 7 & Career Change Trigger & 16 & Professional Development \\
\hline 8 & Informal Mentoring & 17 & Formal Mentoring \\
\hline 9 & Duties Beyond the Classroom & 18 & Advantages of Socialization \\
\hline
\end{tabular}

Table 10

\section{Background Questions}

During the interview stage each participant was asked the same semi-structured questions related to the overall research questions. Five background questions were asked to establish an individual context for the participants' perceptions of how their experiences influenced their impression of teaching at the college level. The questions addressed the following topics: at what stage of their career did they begin to consider a college teaching profession, past experiences that influence their teaching philosophies, how they perceive their experiences as benefiting them in the classroom, and how their initial impressions of college teaching was affected since beginning their teaching career. The responses to each of these questions is summarized below, along with supporting feedback from responses to similar focus group questions.

Participants were asked: When you reflect on the time you were in college or in your professional training programs, how did those experiences influence your impression of teaching in a college level program? Four of the five participants responded that they had not considered a teaching career while in college or during their professional careers. Circumstances in their lives 
such as professional career retirements, injuries necessitating career change, and relocation of a spouse's career precipitated an interest in pursuing their current teaching careers. Only one participant considered teaching while in the process of studying for a college degree. Collin stated that during the time he was taking classes he did not consider teaching as a career possibility. He was going to school, wanted to get a degree, but did not know where that was going to lead. He stated, "here is your degree, good luck, find a job. Never thought of teaching." Today, Collin draws lessons from his experience as an undergraduate student to use in the classroom. In addition, he derives his teaching philosophy from "past instructors having, and not having, industry experience and tries to distinguish a difference between the two styles when teaching." Similarly, Mary did not consider a college teaching career until she retired from her professional career with a regional gas transmission corporation. She also derives her teaching philosophy and practices from experiences with past college teachers. Mary stated that the professors who had the greatest influence on her were the ones that motivated her and worked with her one-on-one over the rougher courses. She said, "they went out of their way and did not cut us any breaks, but gave us all the opportunity to succeed. I felt I had a personal relationship, and they were very professional, something I would have aspired to be." The third interview participant, Diane, described having gone to a large university for undergraduate studies and never having talked to a professor until her senior year. She stated, "I never thought I would be a teacher, ever. When you say, what was my perception of it. It never crossed my mind, even going through Physical Therapy school." Diane's lack of engagement with college faculty compares to the experiences of William, the fourth participant in the case study. Although he interacted with his college advisors, it was the negative experience he encountered that 
influenced his current dedication to teaching. During the first semester as a college student, William had an advisor who was not fluent in English and a relationship never developed. He felt like he was merely a number: "Here is your schedule. Follow this. See you later." This situation did not improve for William, consequently he entered his senior year lacking some classes for graduation. According to William, there was no communication with instructors. Because of his disappointing experiences during college, his interactions with students are based on a philosophy of ensuring they do not encounter similar hardships. He sympathizes with students when they say they are lost and frustrated. William stated:

We implemented an orientation process where everybody has to come in, sit down with me one-on-one. We talk about life, where they are at in their personal lives, how they can balance college life and everything else, because most of our students are nontraditional. They are working adults and they come in so we can get them a game plan.

Lastly, Patricia, did not originally consider a teaching career during her undergraduate studies. Regarding her perception of teaching during college and her professional career, Patricia was noted that she thought it was mostly teaching, and a lot less of everything else. In her words, "I think you really underestimate, even the preparation for courses, even if you know what you're teaching, even if you taught it every year since you've been here, we constantly fine tune it, and that was underestimated by me." Patricia admits she grossly underestimated committee work, and all the other responsibilities, involved with teaching at the college level of which students are unaware. 
The second background question sought to determine at what point in their educational journey did they begin to think seriously about pursuing a career in college teaching in tandem with their professional career. Collin mentioned that he had no thought about teaching during his educational journey. Becoming a college teacher was coincidental due to another faculty member asking him about teaching as an adjunct faculty member after completing his undergraduate degree. In a similar manner, having completed his four-year degree, William was taking classes at Mid-Atlantic Community and Technical College to earn an Associate Degree in Emergency Medical Services. He explained that he thoroughly enjoyed the program and thought he had found his niche. He described his enthusiasm for the career field and noted that he expressed his interest in teaching to the faculty. In his words, he told the program coordinator, "if you need help in the future, l'd love to come back and help future students, just because I am such an advocate of the program." When Mary discussed her goal of teaching at a college as a means of helping students, she explained that "throughout my career in industry I never felt like I ever had the opportunity to help anybody, nothing, zero. I feels like teaching fulfills that need. Related to this, Mary stated, "when I retired from industry I thought, 'Ok, this chapter has ended and here is what I'm missing that I'd like to do.' Now I'm helping somebody else achieve their goal." Somewhat different circumstances influenced Diane's career change. She explains that it was definitely not until much later in her career that she thought she would go into any sort of teaching. "There was an opportunity where I worked, where we kept having students, the door opened, and I went through it. Even in my early career of having students in the clinic, I enjoyed it, but never tied it to classroom teaching." Finally, Patricia discussed that when she was first out of college she thought about teaching, then after beginning a professional career she did not 
consider it again. She had always worked at places that had students come to her hospital for clinical training, so that was enough teaching for her at the time. It was much later in her professional career that Patricia considered teaching at the college level as a full-time career.

A third foundational question asked participants to reflect on their past experiences during their years of education and professional training or employment, how would they describe the traits or teaching philosophies of teachers they consider mentors, who have been most influential in their own teaching strategies? The comments from participants describe teaching philosophies derived from faculty who inspired students to keep learning. They provided an interactive approach to learning and kept students engaged.

For example, Collin pointedly stated, "30 years of experience. You can't fake that." From his perspective, he is teaching to ensure students learn course material they need to know for a successful career. They need to learn the basics of the discipline, and to go on from there. His objective is to give them a desire to learn. Collin thinks encouraging students to keep learning is a challenging aspect of teaching. He stated:

We can challenge our students to the point that they just cannot pass. All of us can just make it impossible to pass our course. We are here to ensure that they learn what they need to know. They learn the knowledge. They learn the basics of the knowledge, and to go on from there. To give they that desire. This is the difficult part; to keep learning.

Whereas in Mary's case, she described the accounting profession as very hands on, and "you do not just pick it up by sitting there watching the instructor." Her instructors said, "you do 
it and bring back what you've done. I want to see the work." Regarding her teaching philosophy, Mary said, "I try not to just lecture, I use an interactive approach. That is how I learned the best, keeping students engaged." Likewise, Diane's influence was imparted on her during her first job, where her supervisor was very good at helping her and always used positive reinforcement. She also benefited from her past program coordinator, who was very clear about directing her and "would always explain the importance of what was being asked." Similarly, William was most impressed with past instructors who were passionate and who he believed were reputable as teachers. He stated, "I think I just tried to pick little pieces from every instructor I've ever had of what's great and what's not. Just try to mold them into myself." Lastly, Patricia reflected on a graduate level molecular biology course and recalled a discussion with her professor; "I'm gonna have problems, my bar is really low in this." He said, "It really doesn't matter where your bar is as long as it comes up." She used that as her motivation through graduate school, and believes that kind of outlook is what we need for students.

The fourth foundational question asked, "Given your professional education and experience, will you describe the training or education you had that has been specifically beneficial for classroom instruction, both before becoming a college teacher and after beginning your college teaching career?" Three of the five participants responded with feedback related to both their personal life and industry experience, whereas the other two referred to conferences and workshop as their means of gaining expertise for classroom instruction. Patricia referenced experience as a parent for being able to communicate better with students, while Collin and Mary both commented that industry experience was essential for developing their knowledge and experience in areas that are not typically expressed in textbooks. Collin stated, "They know I 
know, and so when I tell them, in this book what I'm trying to teach you, is also just as important as the physical skills. They tend to listen a little more and agree with me." Lastly, the two participants emphasizing academic training described conferences and workshops as a benefit for gaining new ideas for engaging students, improving delivery methods, educational technology, and educational theories regarding Bloom's taxonomy as it relates to learning objectives and learning outcomes. The biggest part for William is to never stop educating yourself about instruction and your discipline. He believes, if you ever let your students know you have not continued to improve your training or any self-development, you are just falling behind the current level of technology. "If you're not trying to better yourself, how do you tell your students education is important."

The fifth foundational question examines perceptions of participants' initial impression of what college teaching roles entail prior to transitioning into their teaching career, how do they perceive the roles differently today, since beginning an academic career? Interestingly, with this question there appear to be common threads related to the unperceived workload encountered beyond the classroom.

Collin: The background scene behind the classroom can be almost overwhelming.

Mary: I didn't realize how hard I'd have to work when I' $m$ in front of them.

Diane: I didn't realize how much time and thinking goes into teaching.

Patricia: It's a lot harder than I thought it was.

William: A very small portion of what faculty does is teach.

For example, Collin's original perception was that the instructor "gets up in front of everyone and instructs. He gives tests, he gives homework assignments, and grades papers." He 
has since discovered that the background scene behind the classroom can be almost overwhelming. "The activities (advising, course preparation, recruiting, committees, and coordinating with industry stakeholders) out of class are time-consuming and more than anyone would think." Similar to this, Diane commented, that the job seems to never end. "I mean, you're always thinking about how I could do this, I could do that. The preparation for one hour of lecture, I had no idea that it would be so much. It takes a lot of time." Whereas, Mary provides a perception that reflects an impression of college teaching, by stating the following: I visualized I would walk in and teach what I knew, and spend my time in front of the class, working with students one-on-one after classes. I really didn't think about the relations that you develop. I never realized how you blend into their lives too. You have to get their attention and engage them. When I walked in class the first time I was afraid of them, terrified. I didn't realize how hard I'd have to work when I'm up in front of them, thought they would be the workers, in a lot of ways. I wondered "you need this course, so why aren't you meeting me halfway to learn."

\section{Research Question One}

To address research question one, participants were asked: What is your perception of the transition process from a career professional to your early stages of a college teaching role? When you made the decision to begin your college teaching career, what were your expectations regarding the career change? These responses were somewhat similar because there was a pervasive sense of unease related to workload expectations, comfort with academic culture, understanding the pace of course delivery, curriculum planning, and scheduling course 
objectives. Based on the consensus of responses, it can be surmised there was very little being offered regarding institutional socialization processes and mentoring, and there are participants of this study who emphatically acknowledge this failing. It is important to note, however, that there are participants who have experienced some exceptions, and they have expressed their positive feedback for the importance of the experiences during their transition.

With regard to perceptions of their transition, participants noted they did not understand the effort necessary to arrange their workload and did not anticipate the administrative aspects of teaching at the college level, such as advising, committee work, recruiting, and coordinating with employers. Comments from Collin revealed he "understood about test, midterms, finals, assignments, and grades to give." In contrast, however, he "didn't understand the work necessary to arrange all that, how to plan, schedule and pace workloads, and then follow-up. Didn't consider administrative aspects of teaching." Related to this, Patricia described the freedom she was allowed in academia that she had not encountered in professional career. This was, however, disconcerning as she explained, "I remember coming in and sitting at my desk and thinking, 'Okay, where am I supposed to be,' I didn't even know how to pace the course, or all the work that it entails." Her perception was that as an institution "there was no real set up, like yeah, we had faculty development week, but honestly if you're new faculty, how much effect on a development week can you even use." Patricia felt, even though a faculty development week existed, as an institution, "the ball was dropped as far as mentoring new faculty." From another perspective, Diane and William, expressed their experiences from the context of instruction and relationships with students in the classroom. Both related the sense of being challenged by having a high comfort level with their professional knowledge and expertise, but unease with 
their ability to deliver course material and transfer their knowledge in a way students can best learn. Diane stated:

Things I had been doing for so long that I forgot how to explain it and I thought they should just know because to me it's so easy, why would this be hard. Also, I didn't expect the relationship of the students and myself to be different than my patients and me. I didn't realize with students, you have to put a wall up because you can't get that relationship to that level of what you would with a patient. If you have to fail someone, that is hard.

In a like manner, William found a challenge in figuring out how to explain and engage course content, especially material that students need to know, but they find less exciting. "It's hard to deliver. If you're exceptionally motivated and passionate about what you do, trying to convey that to the students, so they get to be passionate and motivated about their education is difficult." In contrast, Mary's response was based on her impression of the institutional transition. Having recently retired from a competitive corporate culture, Mary described being scared not knowing what to expect in academia. The atmosphere was hard for her, because she came from an atmosphere of distrust. It was a very competitive mode in the gas transmission industry, where everybody was trying to secure their job, trying to "out perform" colleagues, always looking over your shoulder. Mary stated, “when I started here I felt like everybody seemed nice, but I didn't want to trust anyone. I kept watching for a threat, so I'd know where my enemies were coming from. It never happened, I'm still waiting." It was an entirely different culture for her to adjust to after a lengthy professional career. 
Related to research question one, the focus group participants were asked to think of their first days of pursuing teaching careers at the college, and describe their impressions of how they perceived the beginning of their teaching role, and how accurate were the preconceptions of that time? Coming into the new college teaching career, what did they think they would be doing? Also, were they surprised at some of the things they encountered once they got their feet on the ground? These responses were somewhat similar, focusing on topics relating to the amount of work associated with teaching and related administrative responsibilities at the community college level, and the amount of energy expended engaging with students to help them learn course material. When Collin became familiar with the workload of colleagues, he was "surprised how little time they are teaching, relative to the other duties related to their faculty role." He thought most of his time would be "preparing material for courses and really, you're in there for your class time, but I had to do course preparation during off time, because of all the other things that came up through the day." Other participants' perceptions centered on the amount of effort put forth in the classroom engaging with students in the educational delivery process. Diane recalled coming to realize how they thought once they taught the material that students would actually "get it." She thought, having spent so much time preparing for delivering the material, that students would do their part by reading and being ready for class; she was surprised at the students' lack of effort. Two participants reflected on first realizing that while in the classroom how much effort is required, with one noting they had to give " 120 percent, and you've got to put forth that extreme amount of effort engaging students, to keep everybody on the same page, to be entertaining to pull the material together." Collin stated, "if you cannot entertain and keep your students' attention you will lose them. I never stop, I never 
get idle, I dance in class." Patricia made reference to the unexpected amount of time they would be in the classroom instructing on a given day. She noted that her teaching blocks are two hours and fifteen minutes long. There are no 50-minute classes like they expected. Also commenting that having two of those teaching blocks in a day accounts for almost six hours of classroom instruction. Further emphasizing that, "if you get two of the blocks back to back, like you can here, with a 10-minute break in between, it is exhausting."

Individual participants were also asked to reflect on the hiring process, the initial job interviews, and their first semester of college teaching. They were then asked to recall and describe the process and programs they experienced, whereby the institution provided a means for them to socialize and acclimate to the academic environment. The findings indicate Mid-Atlantic Community and Technical College has essentially no institutional process whereby new faculty are socialized into an academic career after working in professional careers. Each of the participants in this study clearly expressed the lack of institutional support during the transition from professional careers to a classroom teaching career. This perspective, however, is directly contrasted by the support provided by individuals were provided within their respective departments. Although there appears to be no institutional structure or program, there were program-level offerings for socialization and mentoring, to a limited degree, that is tacitly endorsed by the administration. The comments from all participants, however, reveal a consensus that the institution was woefully lacking in providing support for the new faculty transitioning from their professional careers to a new academic career as a college teacher. Each participant seemed to recall their the experience. Collin's impression was that there was not any institutional socialization and acclimation process. "I was handed a file and a book, was told 
'see you Monday.' I was observed after a couple of weeks and told 'you will be fine."' Mary said she thought it was odd, they brought her down and showed her the office and she was given a desk. She stated, "they didn't even have books, they hadn't ordered the textbooks. Classes were starting in a couple weeks and I didn't have anything. There was no model of what whoever did this before me did." Diane explained that the institution did "nothing" to assist with the transition process. She described in detail a hectic interview process and her unease surrounding the event. Diane stated:

I never had an interview like that before, it was like a board and they were asking me all types of questions about diversity, and I was moving from Chicago. It was very intimidating, so much of it just thrown at you, here you go, like, mark and set, go.

In addition, William experienced similar circumstances. He was optimistic when he expressed his view that a mentor would have been very helpful. In theory, when the past program director was leaving, he was supposed to shadow her for a few months. "Due to her schedule changes and relocating, it just never worked out. She was available for phone calls to answer questions, but it was pretty much thrown in my lap. "Here's your office." By comparison, related to efforts put forth by individual program deans and coordinators, Patricia described an example of her positive socialization experience. She describes her impression of departmental meetings relative to faculty development week as follows:

I think school meetings and things were the most helpful, because you don't really do committee work that first little bit, so you don't really know what's 
going on with that. I think there's a little bit of a disconnect. She (the dean) had agendas, they'd go out before meetings, there was very lively discussion in those too. And there were always follow-ups, so I think our school meetings were very good. I understand the purpose of faculty development week, but, it just stresses me more than it enlightens me.

When this topic was discussed during the focus group interview, participants were asked: "How do you perceive the effectiveness of the mentoring process you experienced at the institution for socialization into the new career? Some of you mentioned you had mentors." Responses were provided by only two participants. Collin noted that from his perspective, regarding the institutional program, "I don't think they have a mentoring program. I think it's non-existent. I think they need to do something. I really do. I think they have a horrible adjunct policy, if they even have one." Similarly, Patricia's perspective was also not very positive:

On the institutional side, I went into-and I don't think it's there now, they used to have a program, I guess. I don't know. There used to be a mentorship. You were assigned a mentor. They were somebody in your school. Here I was, waiting for my mentorship. Yeah, I know, right? All the time, I found I'm thinking, hey, nobody's coming in assigned as mentor."

\section{Research Question Two}

Addressing research question two, participants were asked: Was there a formal mentoring process? Will you describe your perception about what that entailed and how that experience helped your transition to the norms and culture of higher education? If not, how would you 
perceive a mentor would have benefited you during your transition? All participants stated emphatically that there was no formal mentoring and socialization process provided by the institution. Throughout the group there was a sense of disappointment regarding the lack structured orientation and initiation, organized by the institution, as they transitioned into their career as college instructors. It is important to note, however, in most cases, it was a program coordinator, a dean, or colleagues assuming an informal mentoring role to aid the new faculty during their transition, versus an institutional initiative or process being implemented. To varying degrees, four of the five participants were to be mentored by their program coordinators. Due to a lack of a structured mentoring process and program coordinators terminating their employment with the institution the intended socialization and mentoring of participants did not come to fruition as expected.

Each of the participants' perspectives of their mentoring experience is summarized as follows: Collin was clear to point out that there was not any mentoring program made available by the institution. Other faculty would informally see concern on his face and offer assistance. "My mentoring comes from people just because I could talk to them, and I was social, and I was wanting to learn." He commented that he did not think an assigned mentor would have been beneficial due to personalities. He felt the assigned mentoring would become a job for somebody already overworked and underpaid. From Collin's perspective, it would be better to allow new faculty to gravitate to an informal mentor willing to provide guidance. Next, Mary described her former program coordinator as the best mentor she had in her whole life. As an informal mentor, the program coordinator was energetic, positive, upbeat, knowledgeable, and amazingly hardworking. The institution did not assign a formal mentor for Mary. As a 
commentary related to mentoring and the institution, she stated, "I really do struggle with the mentality of these institutions. (coming from a corporate background) I feel like sometimes I speak French and they speak Spanish." Similarly, Diane had a program coordinator who assumed the role of mentor. Because the program in which she teaches is located off campus, she thought it would have been nice to also have somebody outside her program assisting with the transition process. She mentioned, "here we are isolated, we're here by ourselves. In my case it was one person that did it all, so my interaction with the rest of the institution was not there." As a fourth example, William's situation involved mentorship from a fellow faculty member. He did not directly have an institutional mentor, because his program coordinator retired shortly after his arrival. In William's case another full-time faculty in his program, who had several years experience, served as his mentor and provided guidance during his transition. He commented that having graduated from the program it really helped" and his colleague acted unofficially as his mentor. Lastly, Patricia said, she did not know if anyone was specifically assigned to her as a mentor; she never saw it on paper. For classroom teaching the program coordinator was assigned to keep her on pace. She expressed her gratitude for other faculty who she "relied on for committee work and promotion portfolios, things you don't get day to day."

During the focus group session, related to this topic, Patricia was the primary conversant and described her experience. To provide a context to the comments, it should be noted that the venue for the participant's program had recently (within the past year) relocated to a new facility. It should also be noted, due to similar experiences, there was a consensus and support among group participants regarding the following comment: 
I think that good socialization, I never-I always felt very welcomed by the people in my program and in my school. I mean the School of Health Careers. I mean, not that I didn't feel then, but where we were then, we weren't even at this one building. We were spread out. My office is, like I said, was not even where the classes were that I taught. I got to meet a wide range--they were very welcoming. The other part that I just felt-I was okay with it, because like you said, I think having a long professional career, that you become, you succeed, you're self-motivated, and that kind of thing. I felt like, man, this could be bad. Somebody should be watching me. Not that I was doing anything wrong, but just like, don't they care that how much time--there's no accountability, maybe, it just was assumed. That worked for me, but I saw other people, and I don't, not point fingers, but with that lack of accountability ended up being very little input to what their job should be. It's just a different atmosphere, but 1 think that would, had to do with a different-very different social atmosphere than I was (used to) . When you work in a lab (there is accountability).

To address the topic of informal mentoring, all participants were asked: Were there informal mentors to whom you gravitated to and associated with? Will you describe your perception about what that entailed and how that experience helped your transition? In response to these questions, all participants expressed affirmative answers. Informal departmental mentoring was found to be the primary means of socializing new faculty into the norms of their programs and the institution. Although none of the programs provide structured mentoring, new faculty relied on senior faculty and coordinators for guidance during their first years of transition 
to an academic career. Focus group responses to inquiry identified both ends of the spectrum related to the topic of informal mentoring in participants' programs. Patricia discussed the informal mentoring she experienced usually occurring at times "when you're about to cry, because you're so stressed out from something." Whereas Mary expressed her perspective as feeling blessed to have the mentor in their program helping her transition into her teaching role. She described her positive experience as follows:

I had a mentor that came in recently from industry, that could talk my language, but tell me what I needed to know here to survive. He understood my perspective first, and then was able to translate how to get where I needed to be.

As a follow-up, a second interview question addressing research question two, focused on institutional programs to support pedagogical development for new faculty. Participants were asked, "were there any situations you experienced during your transition that you think would have made you more effective as a college teacher early in your college teaching career if you had been informed during a socialization process? The responses were diverse, ranging from a need for administrative support, student services support, individual program initiatives, and recognition by the administration that a learning curve exists allowing for new faculty transition. It is apparent, however, that none of the participants described any specific programs provided by the institution that aided their pedagogical and collegial expertise for teaching specific content matter, or actively engaging in service to the institution. Collin expressed:

It would have been helpful to have a better understanding of administrative processes, regarding who, and when, to contact administrative personnel about various issues related to their program and the institution. As coordinator I need help, where do I find that? 
There is no processing place to tell us where to go, and who does what. It would help a lot.

Related to this, Mary reflected that they would have benefitted from knowing how to detect warning signs of students when they are in jeopardy and "how to direct students to the help they need. Where is Disability Services? Are there any financial solutions for the students? I feel like I wasn't given the tools to direct the students where they may need to go." Diane described being able to discuss issues with her coordinator when assistance was needed. When speaking of her coordinator, Diane commented that "she made herself available but was not assigned. We would have lunch and because she wanted to retire, she would train me." In contrast to these impressions, William and Patricia described different perspectives related to their development. From William's viewpoint, he believed administrators knew that he was not going to come in off the street as a former field person and just be an expert at teaching course material in a classroom. His comment was that, "there's a grace period, and the college does faculty development once a semester to try to help some of the other people; there was a learning curve to come in." Likewise, Patricia acknowledged that since she was hired, her program coordinator now has a whole book put together for new faculty and has an all-day faculty orientation for her department. Furthermore she enthusiastically said, "they now have monthly peer lunches that are helpful, I didn't have that. I think we need to focus on new faculty during faculty development week, so they have their own day."

A final interview question addressing research question two, focused on institutional programs to support pedagogical aspect of new faculty. Participants were asked, "Will you describe any programs provided by the institution that aided your pedagogical and collegial 
expertise for teaching your specific content matter and actively engaging in service to the institution?" Two of the participants emphatically stated the institution provided no assistance related to this topic, whereas the three other participants described various workshops that were helpful. The significance of this contrast should not be overlooked nor understated. This finding clearly distinguishes a disconnect among program level initiatives for socialization and mentoring of new faculty versus institutional initiatives to plan, organize, and implement processes for transitioning career professionals in to academic instructional roles.

Perspectives of the institution providing no assistance were found in Collin's reflection; "the institution did not plan anything out." Following-up his recollection with the comment, "call that a sorry state-of-affairs, but they simply did not (plan anything out)." He emphasized that the administrators knew he had never taught before. "The conversation never came up, or the question never arose. I draw on all the different teaching methods I was fortunate to remember and use bits and parts." As in Collin's situation, Mary is a participant experiencing similar circumstances, saying that "the institution did not provide help with learning how to teach." She learned through networking with other people and through lunchtime discussions with experienced faculty members in the program. She learned about teaching through the informal network of asking questions of other instructors that have been here longer. "As far as anything besides the faculty handbook, I can't think of anything else provided." By comparison, the other three participants reflected on workshops they attended for improving their pedagogical and collegial expertise for teaching. The workshops these participants attended included a writing workshop, a national accreditation workshop, a fundamental teaching workshop, and involvement on a qualitative literacy team during a conference, all taking place during their first 
year of employment at the college. For example, Diane described a writing workshop she attended during her first year that she thought was very good. "As a group we helped to rewrite directions to assignments, and then we looked at our rubrics and helped to rewrite the rubrics to better fit the assignments. It was great." In a similar manner, William stated that the college sent him to workshops for his program's national accreditation and some other fundamental educational events. He found it very helpful and pointed out, "the first year I was here, I went to three or four pretty big workshops, and symposiums, and events." Finally, Patricia experienced a range of workshop for which she was pleased to attend:

For the institution, I was on the quantitative literacy team that went to a conference, and we heard an outside speaker on assessment, who is on quantitative literacy, and work with other colleges. That was a good experience. There was a Quality Matters course, but I didn't have time for it. We also go to the clinical laboratory education conference and the national conference, that the institution supports.

In relation to this topic, the focus group was asked: Thinking about the past few years, what are some of the things or events you perceive as being advantageous during socialization? What was helpful for you, to help you become more indoctrinated into the college system? The discussion among participants again emphasized experiences involving writing workshops and quantitative literacy workshop that were helpful for acclimating to college teaching during their transition. The participants attending the writing workshop, Diane and Patricia, explained to the group that it was the best thing they ever did, because it taught them about rubrics. In addition, it taught them how to write assignments to match the rubric, along with relating the assignment to 
Bloom's taxonomy. Diane reiterated this sentiment by sharing her experience with a quantitative literacy workshop. They described the skills acquired during the workshop for doing rubrics for assignments while also networking with faculty from other community colleges.

\section{Research Question Three}

Regarding research question three, participants were asked: Will you describe your perception of how socialization and mentoring at the institution has helped (or could have helped you) to be effective in the classroom and enhance student learning? The responses to this question once again centered on what is being done at the individual program level versus what the institution is doing to engage new faculty in classroom and student learning initiatives. Four of the participants described their perspective of communication and networking within their programs and another mentioned the benefits of workshops. Providing a perspective of the lack of institutional involvement in the socialization and mentoring to improve student learning in the classroom, Mary noticed that "at the institution everybody stays within their own school, their own little group. Everyone is friendly, but they stay in their own clique. They don't withhold things, but there's not always sharing of information." Contrasting this comment, William found it beneficial to talk with other educators in the field running similar programs. He stated, "with a "hands-on" program, I couldn't go to an educator in the English department and say, "I need help trying...with delivery methods," because it's apples and oranges." In addition, Collin reflected on his perspective of communication within his program. He found that in the world of academia there is more involvement and more open discussion on how processes should evolve. Collin felt more inclined to have input to the process and that he had a sense his perspective has more value to it. Next, Patricia noted her perception about program activities benefiting new 
faculty during her transition. She stated, "we are working on things, to maybe see each other in the classroom and that will be a big help. We are very open. There is no wrong way, just different ways to do things." Lastly, Diane again emphasized program support of the writing workshop and Quality Matter course that were helpful for understanding rubrics and for learning about Bloom's taxonomy for teaching to the level they focus on for student learning in various assignments. She stated:

That rubric example, definitely helped because I could go back to other assignments and say, 'Why am I getting students only writing one paragraph?'

Then I could apply the concepts to change my directions because it was not clear and students did not understand that I was looking for more than one paragraph. That was great, because then I could apply what I learned to all the other assignments.

The final interview question, related to research question three, asked participants: What recommendations do you have for improving the institutional socialization and mentoring processes for transitioning from career professional to college teaching professional? The responses expressed various versions of improving institutional socialization and mentoring in the areas of administrative knowledge, awareness, and communication, along with mentoring from people in different departments. Collin recommended that, "there should be a process or program to train new faculty in Felix and Blackboard computer based administration programs, training for adjuncts in basic computer techniques, and administrative assistance; there are none currently." Likewise, William thought administrative issues were the greatest concern. He recommended the administration arrange an orientation, and some sort of faculty map of 
contacts. A handbook of who you should call in the event you need things. More information about who to contact. Just like Diane, William's program is also located away from the college main campus.

We are at a remote site, so out of sight out of mind making it difficult to answer student questions administratively. Being a new educator, when students have questions and the instructor is clueless, that looks bad. Students get discouraged, making it harder for them to learn.

William continued to voice his impression regarding the education side, because he thought new faculty should shadow educators with good reputations for teaching, to see how they conduct themselves both inside and outside of the classroom. Additionally, Patricia suggested the school have orientation day, introductions, and then regular institutional faculty lunch meetings. Furthermore, Mary recommended the administration post a series of online training or information that could be watched as time permits, and some face-to-face group meetings; who does what and where to go whenever you have questions? The following comment from Mary expressed some of her perceived frustration the lack of training provided:

After three semesters, I was the Program Coordinator and had no Banner Training. Just to get a question answered is difficult. Nobody seems know protocol or procedures, very little responsiveness to questions. I've never been somewhere where customer service isn't high priority, because, in industry, customers are all of us.

Diane re-emphasized her thoughts of having a faculty mentor from outside the new instructor's program . Her program is located at a remote site from main campus, and her 
perception is that, "we are left out a lot because nobody thinks of us, or automatically excludes based on location. Technology should be used to include remote sites in main campus meetings. They talk about inclusiveness, but we have yet to see it."

As a final topic of discussion for the focus group, they were asked to reflect and discuss the questions: Suppose that you had an opportunity to speak candidly with the college President about socialization and mentoring, or any perceptions you have about this topic, what would you say? The participants in the group keyed in on two related topics related to relationships within the institutional programs and administration, and the recently initiated Mid-Atlantic College Leadership Institute group workshop. Participants discussed the idea that to have teamwork, faculty members need to have relationships. To have relationships, you need to know somebody outside of your classroom and outside of just the two faculty members in your program. You need to know people from different programs, then you have the same value and you begin to share the same purpose. If faculty and staff know that there is an entire institution beyond their individual program, and there is an understanding that other parts of the school are having similar issues, it becomes a more unified effort toward making improvements. Secondly, Diane had recently participated in the newly created Mid-Atlantic College Leadership Institute group workshop, supported the endeavor, and encouraged other faculty in the focus group to become involved. She explained that someone from each school, and student services was involved in the workshop, which contributed to the group diversity. Diane described the workshop as one of the best things she participated in since starting their career at the institution. She stated that, "it was a group of people who--everybody had their own problems, but not, nobody was going to 
come and talk about it. It was probably the best team-building things that I've done since at-being at Mid-Atlantic Community and Technical College." 


\section{Chapter 5}

\section{Conclusion}

The purpose of this research was to expand knowledge in the area of socialization and mentoring of new community and technical faculty transitioning from professional careers to college teaching careers. There currently exists a preponderance of literature identifying the socialization and mentoring occurring at universities, where graduate students are prepared to transition into roles as four-year college and university teachers and researchers. This dissertation, however, addressed more specifically the perceptions of faculty experiencing mentoring and socialization in Applied Technology disciplines at the community college level. This case study examined the institutional resources in place for Applied Technology faculty socialization and mentoring, their processes, and the perceptions of affected faculty as to the effectiveness of the processes for aiding their transition to become successful teachers. This chapter is about analyzing the participants' perceptions and formulating conclusions that afford furtherance of knowledge related to the career development process in the community college applied technology teaching career field.

As stated in the literature review, enrollments at community and technical colleges grew considerably over the past several decades. Kasper (2002) described the growing contribution of community colleges to higher education as follows:

Enrollments at community colleges leaped 413 percent from 1965 to 1999 , increasing from about 1 million to about 5.3 million, while those at public 4-year institutions increased 104 percent, from about 2.9 million to about 6 million during the same period. 
The growth of community college enrollments is expected to continue outpacing increases in enrollments at public 4- year baccalaureate colleges and universities. (p. 19) Increasing demand for technical education and training has two year colleges frequently relying on career professionals with no experience in the classroom or understanding of higher education culture. The culture into which transitioning faculty become indoctrinated is different from the four-year colleges, which they attended as students, resulting in a disconnect between their perceived schema of college teaching roles versus the actual culture they enter. This is evidenced by participants' comments concerning the amount of work they expected to encounter in the role as a college teacher. Each participant alluded to their lack of understanding of how hard they would be required to work outside of the classroom. They expressed a lack of foreknowledge as to how much time and planning is necessary for teaching, along with how challenging it can be to motivate students. Participants also described how difficult it can be to communicate information in the classroom, so that students gain an understanding of the concepts being conveyed. In addition, the job responsibilities beyond the classroom duties inherent in a college faculty career were also a surprise to the participants. Not only did the participants lack a clear understanding of the institutional expectations for advising, service to the college and stakeholders, and scholarly endeavors, they were often frustrated by the limited amount of guidance and administrative support during the transition period of their career.

Referring to the Conceptual Framework, previously described in Chapter 1 and reproduced in Figure 4 below, the basis for conclusions are related to the transition process, beginning at the initiation of the career change and hiring stage. 
Figure 4

Conceptual Framework Revisited

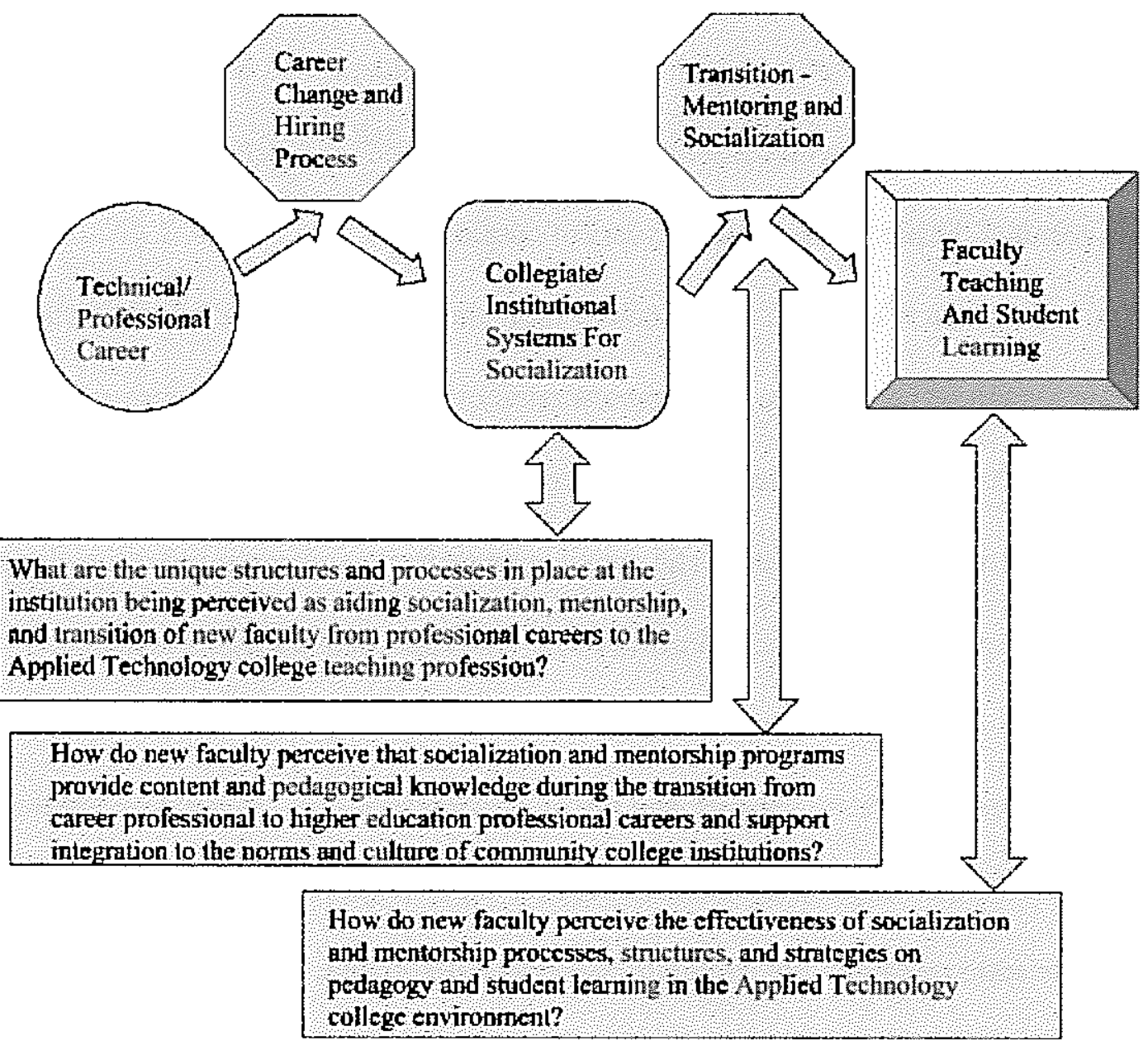

To address each stage of the conceptual framework for this research, the participants of this study were drawn from a group of newly hired (three to five years experience) faculty having many years of prior professional experience. The participants had varied professional careers ranging from emergency medical services, business management, physical therapy, electrical power distribution, and medical laboratory technology. None of these new faculty pursued their college education with a preconceived goal of securing a career as a community and technical college 
faculty member. In fact, three of the five participants each had more than 20 years of experience in their respective professional careers and began teaching as a second career option. As discovered during the interviews, four of the five participants never considered becoming a college teacher, and only two of the five had experience as students at a community college. Given the lack of experience with community and technical college teaching, there was a cultural adaptation required during the transitional years of employment.

The importance of addressing the socialization and mentoring issue of new faculty transitioning to college faculty careers is demonstrated by participants' comments related to being unaware of the teaching duties required beyond classroom instruction, administrative responsibilities concerning committees and course management, and communication channels for effectively supporting student enrollment issues. Participants expressed frustrations regarding the lack of socialization in areas such as student advising, stakeholder networking, committee work, administrative support, and instructional technology. In addition, participants in this study reflected on experiences with student cultural characteristics indicative of that described in existing research. For example, Jenkens (2017) stated, "many unprepared students will continue pursuing higher education to chase the American dream. And most of them will end up at two-year colleges, and because two-year institutions are about the only ones actively recruiting remedial students these days" (p. 2). Most students are either recent high school graduates or non-traditional students seeking a two-year degree, certificate, trade skills, or transfer credits for advancing their employment opportunities or furtherance of their education by transferring to a four-year college. The level of participants understanding the characteristics of this demographic was reflected by comments related to difficulties trying to engage with 
students and motivate them in the classroom and laboratory. The participants' strong commitment for teaching and student learning blends well with the primary mission of community and technical college faculty emphasis on teaching versus research activities, attributed to university faculty. It is also reflected by the empathy they describe when reflecting on their desire to help students learn and understand course concepts necessary for successful completion of their programs.

The study regarding participants' career change decisions and the institutional hiring process reveals multiple personal reasons for pursuing a college teaching career, along with varied scenarios encountered during the hiring process. A common theme of the participants' decision process for pursuing college teaching careers is that they never seriously considered teaching as an option while pursuing their college education. Each of the participants' pursuit of a college teaching position was one of fortunate circumstances, being in the right place at the right time, or having the necessary career preparation when the opportunity happened to appear. Participants support as follows: Mary stated, "I never thought about being a teacher", whereas Collin claimed, "after graduation they asked me to teach", and Patricia commented, "it was just a coincidence that the position was open when considering a career change." These statements reflect the lack of advanced career planning and preparation for a teaching position with a community and technical college. This scenario is directly associated with Sabin's (2007) research findings noted in Chapter two, "New faculty are in need of socialization, so they can know what the expectations are, and how to meet those expectations. Unfortunately, because many schools do not make a concerted effort to socialize new faculty..." (p. 8). This limited forethought concerning a college teaching career establishes real-time examples of existing 
literature describing post-professionals finding themselves in a culture much different from which they experienced during careers in industry. Referring to the literature from Chapter 2 , , Dunham-Taylor, Lynn, Moore, McDaniel, and Walker (2008) research on mentoring of nursing faculty explained mentoring and socialization as "the single most influential way to help in the successful development and retention of new nursing faculty, not only for the initial purpose of filling a vacant position but also for the long-term maturation of the nurse faculty members" (p. 337). With this in mind, the demands for teaching, opportunities for advancement, and scholarship are all areas where socialization would benefit new faculty transitioning to academia.

To develop a perspective of the initial transition to higher education, the findings highlight the lack of structure or formal steps typically encountered with a professional career hiring process. Based on participants' comments, the informal nature, short notice, and varied structure inherent in the hiring processes for participants appears to exemplify the need for socialization at the institution even before the new faculty position is secured. From a broader and long term perspective, it is disconcerting to discover not only the lack of socialization during the initial hiring stage, but the rapidity by which most of the participants were thrust into program coordinator positions in short time frames. Each of the participants, except Patricia, assumed Program Coordinator positions with the institution within the first two years of their transition to academia. This calls into question the consistency, quality of instruction, and long-term stability of the institutional culture when new faculty with very little exposure to the norms of the college are placed in departmental leadership roles. Given this critique however, these findings are somewhat indicative of the research that describes the dynamic nature of academic institutions' faculty body as typically being in a continual state of change, losing and 
gaining members in need of socialization. The findings indicate the participants' anticipatory schema regarding expectations of a college teaching career as being disjointed from what is actually encountered during their transition into the new academic career. The findings in this case establish evidence that the institution is not prioritizing the importance for socialization of new faculty for learning and transferring the attitudes, actions, and values inherent in their discipline of study to students.

Addressing professional academic socialization, as a specific focus of organizational socialization, Figure 5 (recreated from Chapter 2) depicts a process that is more inclusive of the new faculty members' and graduate students' environment and emphasizes ongoing development throughout a faculty career. The structure of the diagram is indicative of the dynamic and continuous nature of the academic faculty socialization process. The center of this diagram is designed to indicate the core areas of socialization that institutional administers can have the most influence. Weidman, Twale, and Stein (2001) claimed aspect of the academic socialization process is an area over which administrators in the university have fundamental control. Furthermore, they stated:

It is the academic program faculty who establish the norms for teaching, research, and service within the constraints of the larger university community. Faculty shape the curriculum as well as the organization of instruction and social relationships among members of the academic program. (p. 38)

Coupled with the core aspects of academic faculty socialization influenced by administrators, Weidman et al. have indicated in the outer portion of the diagram four additional components influencing new faculty transitioning to college teaching careers. These shapes are designed to 
emphasize the non-linearity of the socialization process and suggest the interaction with core elements throughout faculty development period.

Figure 5

Conceptualizing Graduate and Professional Student Socialization Revisited

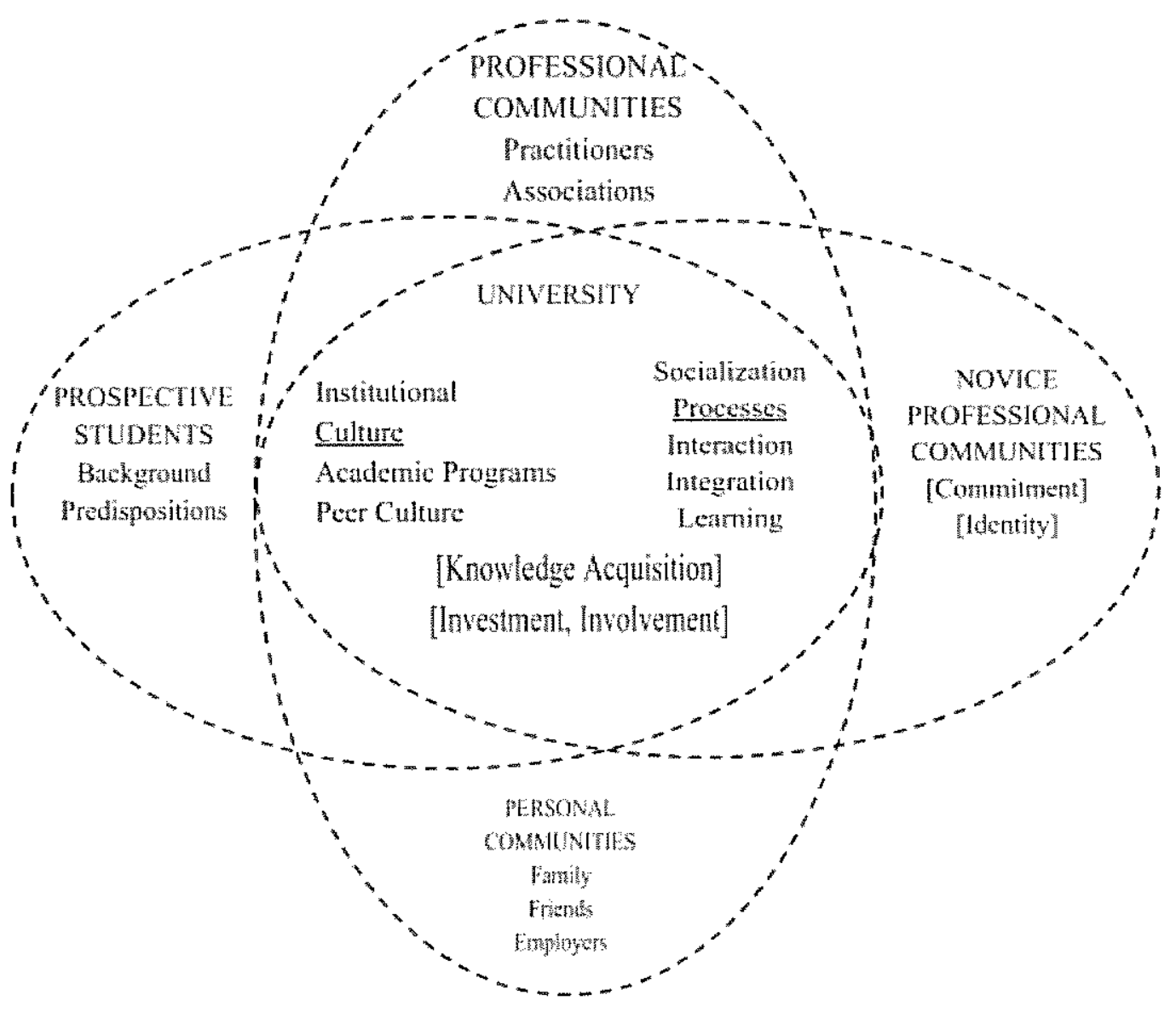

Interaclive Suges of Socialization: Anticipatory, Formal, Informa, personal

Figure 5 - Conceptualizing graduate and professional student socialization. Adopted from "Socialization of graduate and professional students in higher education: A perilous passage?" Weidman, J. C., Twale, D. J., \& Stein, E. L. (2001), ASHE-ERIC Higher Education Report, Volume 28, Number 3. Jossey-Bass Higher and Adult Education Series. Jossey-Bass, Publishers, Inc., San Francisco, CA. p. 37.

Returning to a discussion of the hiring and new faculty socialization process, depicted in the conceptual framework, further analysis of participant interviews and focus group findings 
raises three issues that institutional administrators should address for improving socialization of new faculty and relate directly to each of the three research questions:

1. Lack of any structured institutional socialization program.

2. Contrast between new faculty attending workshops and those not attending.

3. Rapidity of new faculty assuming coordinator positions given lack of socialization.

First, the lack of any structured socialization and mentoring program at the institutional level is readily apparent, in spite of the efforts made by program deans and program coordinators. This conclusion directly addresses the question as to why each of the various departments either had, or did not have, their own unique structures and processes in place for socialization, mentorship, and transition of new faculty from professional careers to the college teaching profession. Based on comments from William, Diane, and Patricia, it is evident the program deans and program coordinators have attempted to place an emphasis on providing some socialization and mentoring. In fact, Patricia specifically mentions that the program coordinator has recently taken initiative to create a new faculty handbook and is coordinating regular lunch sessions as a means for new faculty to communicate departmentally. This contrasts with the lack of action taken by the program deans and program coordinators for Collin and Mary. This disparity between departments for socialization is indicative of the lack of overall institutional direction and oversight for transitioning new faculty to the academic culture. The lack of an institutional socialization process presents a situation whereby the various departments have new faculty "learning the ropes" in a disjointed fashion, depending on which department the faculty member is hired to teach. This is contrary to the importance of socialization for new faculty for assimilating the values, abilities, expected behaviors, and social knowledge to become 
participating members of the institution. The lack of structured socialization and mentoring at the institution indicates Mid-Atlantic Community and Technical College would be a prime candidate for improvements provided by programs described in literature review.

Secondly, the disparity between participants who acknowledged having attended workshops and courses during the initial years of an academic career is apparent upon review of responses. Collin and Mary experienced the least amount of training, versus responses from William and Diane, who expressed the benefits of workshops attended. Perhaps what is not readily apparent in the text addressing this topic was the level of frustration some participants expressed concerning the lack of training and socialization for a new academic role. Those with little or no workshop attendance and administrative guidance, Mary for example, clearly recall the level of unease experienced during their initial transition to the academic role. In comparison, those participants having the good fortune to have attended some training seem to reflect on the experience in a positive manner and recall the training as helpful for bridging the cultural divide between the professional and academic careers. For example, the department to which William was hired provided opportunities for attendance at several nationally sponsored workshops related to his discipline and a senior faculty member was available for support. On the contrary, Collin's opportunities for similar endeavors in his department were not presented. Likewise, Patricia and Diane discussed the benefits of having been exposed to workshops organized by the college, which were beneficial for their course management skill-set, versus Mary who relied heavily on an informal mentor during the short time her mentor remained in the department. These findings present a perspective that participants were not pleased with the lack of perceived new faculty socialization and mentorship programs provided. Finally, the 
perspectives of participants expressed a sense of surprise that there was little, if any, pedagogical training and support for integration to the norms and culture of community college institutions during the transition from career professional to higher education professional careers.

Another conclusion related to the contrasting experiences of participants' exposure to training workshops is the discovery that none of those interviewed commented on this topic from a perspective of comparing one department to another. The discussions related to this topic only addressed what the participants themselves experienced within their program versus socialization practices occurring in other departments. With that being said, there was no apparent sense of angst or envy exhibited during any of the interviews, toward other departmental workshop activities. Based on this observation, there are two questions from which a conclusion might be drawn: (1) What is the likelihood, and explanation, that participants were aware of other departmental workshop training opportunities being provided, yet none of the five participants would express dissatisfaction for not having similar opportunities available? (2) Based on what is known about the socialization process at the institution, what is the likelihood, and explanation, that participants were unaware of other departmental workshop training opportunities being provided? During the individual interviews and focus group meeting, this question was never asked directly; however, it is being inferred here that the various participants were unaware of workshop training opportunities being made available in the various departments. Based on this inference, and other information gathered from the interviews, it becomes evident that the institution lacks any clearly defined objective for helping new faculty transition into new college teaching careers. It is apparent that various departments are undertaking socialization and mentoring activities in a heterogeneous manner. Consequently, the 
college administration's role is so fragmented that individual departments and programs have little or no knowledge of socialization and mentoring practices taking place within the various departments across campus.

It is recommended that administrators become cognizant of this fragmentation between departments to reduce the tendency of organizational boundaries, or silos, from developing within the institution. The geographical distances between the institution's campuses, physical spaces housing the various departments, and managerial differences between discipline administrators all exist at the college and create an environment for a silo mentality to exist. When asked during the focus group interview, what recommendations participants would make to the president of the institution about socialization and mentoring, Collin voiced the following while discussing cross-department mentoring at the institution:

To have teamwork, you have to have relationships. To have relationships, you have to know somebody outside of your classroom and outside of just your two other faculty that are in your program. You need to know people from different programs, then you have the same value, you have the same aim and purpose. If I know that there is a whole institution out there, if I have somebody else -- and sometimes just hearing it, than some other school has the same problems you do -- I mean I hate to say misery loves company. I mean, you get -- you realize, well, hey, we really can work on this, because it is not just me.

Although individual faculty members working in the various institutional facilities and programs may not work together on a regular basis, department administrators should be meeting regularly to keep everyone informed. Various means of communication such as video conferencing, email, 
newsletters, telephone, and personal contact can all be utilized to enhance socialization and improve awareness of departmental practices being used to socialize and mentor new faculty. Given these points, understanding the complexities of organizational barriers, or silos, is beyond the scope of this study, however, this research serves to establish recognition of situational issues resulting from a lack of socialization and mentoring processes that can create a foundation from which silos can result.

Third, the rapidity by which new faculty are assigned to program coordinator positions, given the limited experience in the college teaching profession and lack of faculty development, may be cause for examination. In the cases of Collin and William, program coordinator positions were offered after teaching only one semester at the college. Collin said:

While I was adjunct teaching, the dean came in and sat at one of my classes. I'm sure there was probably some background conversation going on. I didn't know why or anything. It was just a couple days later, and he asked me if I wanted this program coordinator position, and I simply said yes.

William's experience is almost identical, his statement is as follows:

Right after I became a paramedic, they (the college program at Mid-Atlantic Community and Technical College) brought me back (to the college) to work as adjunct to help teach some lower-level EMS classes. Then, it was just a couple months into that process, and then they asked me, well, kind of told me that they were going to assign me as the program director since the current program director was leaving.

In a similar manner, in the cases of Mary and Diane, program coordinator positions were offered after teaching three semesters. Mary was surprised at the rapidity of the assignment, saying 
"when the coordinator left, it was like he just left. Here you go Mary, now you're the coordinator." Although each of these faculty were well qualified in their technical disciplines, considering the lack of training provided by the institution regarding administrative processes and procedures for new faculty, two academic issues come into question. One, administrators might question why there appears to be a high rate of openings for program coordinator positions and the impact this situation has on program efficiencies. Two, given the rapidity of promoting new faculty to program coordinator positions and the lack of training for preparedness, what impact is the situation having on both the faculty classroom expertise and the student learning environment? This predicament is evidenced by the preponderance of interviewee responses citing frustrations with classroom administrative issues due to lack of knowledge and training during initial transition into the classroom. In fact, Collin and William specifically discuss the importance of being able to motivate students in the classroom being a significant challenge due to limited experience with administrative processes. Similarly, Mary admitted being terrified when first walking into the classroom and surprised by how difficult it was to motivate students to become engaged with the course work. These scenarios exemplify contradictions to administrators' desires to hire and promote faculty members who are aware of institutional expectations and can contribute to the welfare of their discipline and institution. As Meacham (2002) stated:

The faculty they would like to hire would understand what it means to be in a community of scholars day in and day out, help make departments run smoothly, understand the institution and be committed to institution building, be good colleagues, contribute to advising, to faculty governance, and to the campus community, bring out the best in their 
colleagues and empower them to be better, be agents of change right away and not wait until after tenure, have a sense that what they do -- and what the institution does -- makes a difference in the community, and would be comfortable juggling a lot of balls at once. (p. 24)

Using this research as a basis for reflection, administrative awareness is essential for understanding and assisting new faculty not only transition to new faculty positions, but to support those who are also taking on added responsibilities as program coordinators. Expecting new faculty to assume coordinator responsibilities will require administrators to provide guidance beyond the technical career expertise and pedagogical training of these individuals. Community and technical college faculty are typically hired to teach courses based on their professional experience and knowledge, but gaps may exist where coordinators must manage conflict between students and other faculty, communicating with other departments and stakeholders, motivating fellow faculty, dealing with accreditation, and staff training and development. The development of academic coordinator and leadership skills is a topic that administrators can reference in many other documents and is beyond the scope of this research. It is highlighted here, however, to bring the issue to the forefront as a matter of importance for developing socialization and mentoring programs at an academic institution.

\section{Conceptual Contribution of Research}

It appears to be conclusive that these experiences further exemplify how new faculty might benefit from a program that is coordinated by the institution, engages new faculty in socialization and mentorship processes, orients them to administrative operations, and presents strategies on pedagogy and student learning in the Applied Technology college environment. 
These findings further support the literature previously stated by Thornton (2010) that for teaching in the community and technical college system, the preparation received in graduate schools is inadequate. Compounding this predicament faced by community colleges, Thornton explained that many of the community college teachers with technical expertise, from successful industry careers, have not been socialized to understand the expectations of vocational teclinical college instructors. Most faculty are directly recruited from professional careers, with no higher education degrees and often have little or no formal pedagogical training prior to entering the classroom. (p. 8) The assertion is made that during the socialization process, pedagogical aspects of teaching and student learning should be emphasized, as well as the skills and expertise of the discipline taught. Referencing the conceptual framework designed for this research and existing research, a practical theory for a progressive developmental process for transitioning career professionals into the culture of higher education is as follows:

\section{career change and hiring process.}

Clarification of the new faculty member's preconceived expectations and schema related to community and technical college teaching should be addressed. As stated by Harris (1994), previously detailed in Chapter 2 , the schema in socialization is a dynamic process of cognitive knowledge development where thoughts are formed based on specific topics, entities, and events encountered. These phenomena are conceptualized and organized as subjective theories about how the world operates and guides one's perceptions, memory, and inferences in order to direct information acquisition and processing. Utilizing the aspects of schema development for new faculty during the socialization process, Harris categorized schema for use in an organizational context, which is directly related to new higher education faculty experience (p. 312). During 
the transition to new roles with academic institutions, individuals encounter many stimuli and experiences to which they must be perceptive and responsive. Relating this existing research to the findings of this study, the new faculty should have a clear understanding of the institutional mission relative to workload, commitments to stakeholders, promotion standards, student culture, research in the discipline, and service to the institution for successful advancement as a new faculty member.

\section{collegiate/institutional system for socialization.}

Administrators should develop and implement a structured program designed to aid new faculty transition socially and functionally to the academic culture of the institution. The findings of this research parallel the literature from Gardner (2007) addressing the socialization process being vital for advancement of institutional goals. As Gardner stated, it is "through the socialization process the individual acquires the knowledge and skills, the values and attitudes, and the habits and modes of thought of the society to which he belongs" (p. 724).

Administrators should encourage new faculty to become involved in departmental and institutional faculty meetings and events, introduce them to community/industry stakeholders associated with the discipline, and support them in efforts to engage with local, regional, and national organizations advocating advancement of the discipline.

\section{transition - mentoring and socialization.}

Administrators should develop a system whereby the institutional and departmental faculty, who are willing to mentor new faculty, will be trained and provided a structured format for mentoring new faculty both formally and informally. This recommendation is based on the findings of this research and correlates with the research of Lenze (1999). As noted in chapter 
two, Lenze stated:

Regardless of whether a mentor was assigned or chosen, for those new faculty who had a mentor, job satisfaction was positively related to satisfaction with their mentor. It behooves institutional colleagues to pay careful attention to the orientation of mentors and the monitoring of institutionally fostered mentor-protégé pairs. (p. 318)

Thus, during the first year of transition, arrangements for mentoring should be coordinated between institutional and departmental administrators, mentors, and new faculty members, to establish clearly defined goals and benchmarks for follow-up of progress. During the second and third year the guidance and mentoring should become more informal, with the goal of relationships becoming more peer oriented.

\section{faculty teaching and student learning.}

Administrators should develop programs of instruction for guiding new faculty in pedagogical practices related to course planning, delivery techniques, teaching technologies, testing methodology, andragogical theory, laboratory organization, and classroom management. Addressing these areas of instruction is essential due to the inexperience of new faculty in the academia and because of the diverse nature of the community college student demographic. As Bragg (2001) stated, community college students are typically older, more often women and members of racial or ethnic groups, not attending full-time due to job requirements or family responsibilities, and likely the first family member to attend higher education, compared to the 4-year student body. Bragg claimed, "student populations of community colleges have been much more diverse than populations of 4-year colleges" (p. 95). Furthermore, community 
colleges are challenged with adapting quickly to technological factors affecting demographic, economic, and academic demands. Those entering the labor force are increasingly in need of added skill sets provided by community and technical colleges. Kasper (2002) claimed, "as higher education evolves, it increasingly emphasizes the value of credentialed and non-credentialed knowledge and skill" (p. 21). Thus, community colleges continue to focus on curriculum flexibility while adapting to changing educational and training needs for which trained faculty are required to teach. To provide guidance for engaging academically with the diversity of community and technical college students, periodic assessment of new faculty performance, by departmental administrators or mentors, will facilitate the progress of developing teaching skills during the new faculty transition period.

\section{Limitations of Research}

The findings of this study are limited to the specific institution at which the interview participants are employed. In addition, it is bound by the number of students enrolled, geographic location, faculty demographics, and types of programs by which the college is characterized. It should also be noted that in an effort to avoid any bias in this study, faculty members associated with this researcher's department of employment were not considered for participation. Also, it should be made clear that the number of participants for this study were limited to five in order to establish a manageable sample group for the amount of time and resources available. Finally, this study addresses only those new faculty having three to five years of experience with Mid-Atlantic Community and Technical College, allowing for participants who have completely transitioned to the institutional culture and a timeframe that allows for current recall of experiences. 


\section{Problems Arising During the Research}

In retrospect, there were very few problems with the gathering of research data. During individual interview sessions, two audio recording devices were used to ensure successful collection of information being discussed with participants. The online service hired to transcribe the audio recordings provided a very easy to operate computer software tool that allowed for timely and accurate written documentation of all interview sessions. In addition, an online computer software tool was utilized for efficient coding and analysis of all transcribed data gathered during both individual interviews and the focus group interview session.

With that said, the use of a video recording, together with an audio recording of the focus group session, would have expedited the identification of speakers while coding and analyzing the transcribed documentation. There were several areas in the transcription data that necessitated repeated audio review in order to identify the speakers. Having a video may have reduced time spent listening to multiple areas for review. In addition, body language, gestures, and interaction between focus group members would have been captured using video and audio recording technology, thus providing a more profound understanding of messages being conveyed.

\section{Recommendations For Research and Practice}

One possible area for further research into socialization and mentoring of new technical and community college faculty transitioning from professional careers is to expand the study to multiple institutions within an individual state or region. Doing so would provide a broader perspective of the dynamics occurring at community and technical colleges. Due to the number of additional institutions and faculty being studied, a mixed methods research design would be 
very effective. Survey questionnaires would allow data gathering from many faculty in the target area for quantitative analysis. In addition, focus group sessions at various institutions would provide qualitative narrative data for the study. Based on an extensive literature review undertaken for this study, no regional or statewide, mixed methods research of this nature has been discovered.

A second recommendation for further study of this subject, more long-term in nature, would be a comparative case study between two separate institutions during a three to four year duration. For this study a socialization and mentoring program would be established and implemented at control group institution (College A) and the second institution would continue to transition new faculty by means of their normal processes. After completion of the socialization and mentoring program at College A, an analysis of the program's impact would be conducted by comparing feedback from both institutions. The research questions would be similar to the ones used for this study and the impact of the socialization and mentoring program could be examined.

With regard to policy considerations for Mid-Atlantic Community and Technical College, it is being recommended here that administrators embrace the information presented in this study to plan and implement a socialization and mentoring program institution-wide. Working in conjunction with members of the faculty body committee groups (Faculty Senate, Faculty Welfare Committee, and Faculty Personnel Committee) and the various departmental administrators, an institution-wide program should be developed for socialization and mentoring new faculty. Voluntary mentors from each department may be identified and a formal structure 
should be developed to address issues identified as problematic for the participants of this study, thus reducing the potential for newly hired faculty to experience similar difficulties.

The use of this research for initiating changes to the socialization and mentoring of new faculty at Mid-Atlantic Community and Technical College can provide a foundation for a more structured process for assisting career professionals transitioning to a college teaching role. It would be incumbent on the provost of the institution to coordinate with all departmental administrators' goals and strategies for developing a mentoring program that will indoctrinate the new faculty into the culture and norms which the school prioritizes.

\section{Contribution to Research}

This study provides contribution in three areas: (1) This research fills the gap in literature addressing the socialization needs of new faculty entering the profession of community and technical college teaching. The preponderance of existing research is highly skewed to graduate students preparing for advanced degrees at research universities. This study specifically focuses on individuals with professional careers and no prior college teaching experience, making a transition to college teaching. (2) This study provides administrators supporting documentation for justifying resources to be allocated for the implementation of socialization and mentoring programs at the community and technical college level. This study addresses the concerns and frustrations faced by new faculty at a community and technical college and serves as a template for developing duplicate study of faculty perceptions at similar types of institutions. Administrators will gain an understanding of the socialization principles, aspects of mentoring practices, and the impact these programs can have on the teaching environment in higher education. (3) This study will contribute to the support of new faculty 
transitioning to higher education as a second career. For the individuals hired into a department or institution having no socialization and mentoring program, this document will provide a foundation for initiating change to the college. In addition, for those new faculty reluctant to make administrators aware of the information provided in this document, it will serve as a basis of knowledge for understanding that the difficulties experienced transitioning to a college teaching career are common. 


\section{References}

About Community Colleges, (2017). American Association of Community Colleges. Retrieved from http://www.aacc.nche.edu/AboutCC/Pages/default.aspx

Altbach, P. G. (2006, Fall). Whither the professoriate? [Review of the book The American Faculty: The Restructuring of Academic Work and Careers, by Philip Altbach]. The NEA Higher Education Journal, 159-162. Retrieved from http://www.nea.org/assets/img/PubThoughtAndAction/TAA_06_15.pdf

Austin, A. E. (1990). Faculty cultures, faculty values. New Directions for Institutional Research, $1990(68), 61-74$.

Bieber, J. P., \& Worley, L. K. (2006). Conceptualizing the academic life: Graduate students' perspectives. The Journal of Higher Education, 77(6), 1009-1035.

Bland, C. J., Taylor, A. L., Shollen, S. L., Weber-Main, A. M., \& Mulcahy, P. A. (2009). Faculty success through mentoring: a guide for mentors, mentees, and leaders. R\&L Education.

Bode, R. K. (1999). Mentoring and collegiality. In R. J. Menges (Ed.), Faculty in New Jobs, (pp. 118-144). San Francisco, CA: Josey-Bass Inc.

Boyle, P., \& Boice, B. (1998). Best practices for enculturation: Collegiality, mentoring, and structure. New Directions for Higher Education, (101), 87-94.

Bragg, D. D. (2001). Community college access, mission, and outcomes: Considering intriguing intersections and challenges. Peabody Journal of Education, 76(1), 93-116.

Baxter, P., \& Jack, S. (2008). Qualitative case study methodology: Study design and implementation for novice researchers. The Qualitative Report, 13(4), 544-559.

Boeije, H. (2002). A purposeful approach to the constant comparative method in the analysis of 
qualitative interviews. Quality \& Quantity, 36(4), 391-409.

Braxton, J. M. \& Berger, J. B. (1999). How disciplinary consensus affects faculty. Faculty in New Jobs. San Francisco, CA: Jossey-Bass, 243-267.

Cady, H. L.. (1973). The preparation of college teachers. College Music Symposium, 13, 7-17. Retrieved from http://www.jstor.org/stable/40373754.

Cakir, M. (2008). Constructivist approaches to learning in science and their implications for science pedagogy: A Literature Review. International Journal of Environmental \& Science Education, 3 (4), 193-206.

Calhoun, C. (Ed.). (2002). Dictionary of the social sciences. Oxford University Press. Retrieved from http://www.oxfordreference.com.ezproxy.fairmontstate.edu DOI: 10.1093/acref/9780195123715.001.0001.

Cariaga-Lo, L., Dawkins, P. W., Enger, R., Schotter, A., \& Spence, C. (2010). Supporting the development of the professoriate. Peer Review, 12(3), 19.

Chao, G. T., O'Leary-Kelly, A. M., Wolf, S., Klein, H. J., \& Gardner, P. D. (1994). Organizational socialization: Its content and consequences. Joumal of Applied psychology, $79(5), 730$.

Coleman, J. C., Christie, E., Culver, M., Erickson, D., Hunt, J., Williams, F. (2006). The transition from practitioner to professor: The struggle of new faculty to find their place in the world of academia. International Journal of Educational Leadership Preparation, $l(2), 2$.

Crotty, M. (2012). The Foundations of Social Research. Thousand Oaks, California: SAGE Publications, Ltd. 
Dinham, S. M. (1999). Being a newcomer. Faculty In New Jobs: A Guide To Setting In, Becoming Established, and Building Institutional Support, (1), 1-15.

Dunham-Taylor, J., Lynn, C. W., Moore, P., McDaniel, S., \& Walker, J. K. (2008). What goes around comes around: Improving faculty retention through more effective mentoring. Journal of Professional Nursing, 24(6), 337-346.

Duphily, N. H. (2011). The experience of novice nurse faculty in an associate degree education program. Teaching and Learning in Nursing 6(3), 124-130.

Fincher, C. (1996). The Influence of British and German Universities on the Historical Development of American Universities. Paper presented at the Annual Forum of the European Association for Institutional Research, Germany. Retrieved from http:/files.eric.ed.gov/fulltex/ED443301.pdf

Finkelstein, M. J., \& Schuster, J. H. (2011). A new higher education: The "next model" takes shape. Advancing Higher Education. Retrieved from https://www.tiaainstitute.org

Fischer, B. A., \& Zigmond, M. J. (1998). Survival skills for graduate school and beyond. New Directions for Higher Education, 1998(101), 29-40.

Fugate, A. L. \& Amey, M. J. (2000). Career stages of community college faculty: A qualitative analysis of their career paths, roles, and development. Community College Review, 28(1), 1-22.

Gaff, J. G. (2002). The disconnect between graduate education \& faculty realities. Liberal Education, $88(3), 6-13$. Retrieved from https:/ezproxy.fairmontstate.edu

Golde, C. M. (2004). The responsibility of doctoral programs for the career preparation of future faculty, Peer Review, 6(3), 26. 
Gardner, S. K. (2007). "I heard it through the grapevine": Doctoral student socialization in chemistry and history. Higher Education, 54(5), 723-740.

Gardner, Susan K. (2010). Faculty perspectives on doctoral student socialization in five disciplines. International Joumal of Doctoral Studies (5), 39-53.

Golde, C. M. (2004). The responsibility of doctoral programs for the career preparation of future faculty. Peer Review 6(3), 26.

Hamilton, N. (2006). Faculty professionalism: Failures of socialization and the road to loss of professional autonomy. Liberal Education, 92(4), 14-21.

Hanford, E. (2014). "The Harris, S. G. (1994). Organizational culture and individual sensemaking: A schema-based perspective. Organization Science, 5(3), 309-321.

Heery, E. \& Noon, M. (Eds.). (2008). A Dictionary of human resource management (2 rev. ed.). Oxford University Press. Retrieved from http://www.oxfordreference.com.ezproxy.fairmontstate.edu

History of American Higher Education. (n.d.). Retrieved from http://www.randomhistory.com/1-50/039degree.html

Hoepfl, M. C. (1977). Choosing qualitative research: A primer for technology education researchers. (M. Sanders, Ed.) Journal of Technology Education, 9 (1), 1-13.

Holley, K. A., \& Caldwell, M. L. (2012). The challenges of designing and implementing a doctoral student mentoring program. Innovative Higher Education, 37(3), 243-253.

Hopkins, R. A., \& Grigoriu, E. (2005). Mentoring community college faculty and staff: Balancing contradictions of informal program components and formal program structure. Community College Review, 32(4), 40. 
Hsieh, H.F., \& Shannon, S. (2005). Three approaches to qualitative content analysis. Qualitative Health Research, 15, 1277-1288.

Huwe, J. M., \& Johnson, W. B. (2003). On being an excellent protégé: What graduate students need to know. Journal Of College Student Psychotherapy, 17(3), 41-57.

Jensen, J., Rabe, C., Runde, S., \& Wee, L. C. (2006). Transition from industry to academia: Reflections of three new faculty members. Director, 07.

Jenkins, R. (2013). What about community colleges? The Chronicle of Higher Education. Retrieved from http://www.chronicle.com/article/What-About-Community-Colleges-/136671

Jurgens, J. C. (2010). The evolution of community colleges. College Student Affairs Journal, $28(2), 251$

Kane, T. J., \& Rouse, C. E. (1999). The community college: Educating students at the margin between college and work. The Journal of Economic Perspectives, 13(1), 63-84.

Kasper, H. T. (2002). The Changing role of community college. Occupational Outlook Quarterly, Winter 2002-03, Retrieved from https:/www.bls.gov/careeroutlook/2002/winter/art02.pdf

Kezar, A., Lester, J., Carducci, R., Gallant, T. B., \& McGavin, M. C. (2007). Where are the faculty leaders?: Strategies and advice for reversing current trends. Liberal Education, 93(4), 14-21.

Kwan, T., \& Lopez-Real, F. (2010). Identity formation of teacher-mentors: An analysis of contrasting experiences using a Wengerian matrix framework. Teaching and Teacher Education, 26(3), 722-731. 
Lenze, L. F. (1999). Accountability for faculty welfare.In R. J. Menges (Ed.), Faculty in New Jobs, (pp. 310-327). San Francisco, CA.

Lindholm, J. A. (2004). Pathways to the professoriate: The role of self, others, and environment in shaping academic career aspirations. The Journal of Higher Education, 75(6), 603-635.

McCormick, A. C., \& Zhao, C. (2005). Rethinking and reframing the Carnegie classification. (Cover story). Change, 37(5), 50-57.

Meacham, J. (2002). Our Doctoral programs are failing our undergraduate students. Liberal Education, 88(3), 22-27.

Mendoza, P. (2008). Socialization to the academic culture: A framework of inquiry. Revista de Estudios Sociales, (31), 104-117.

Menges, R. J. (1996). Experiences of newly hired faculty. In L. Richlin (Ed.), To Improve the Academy, Vol. 15 (pp. 169-182). Stillwater, OK: New Forums Press and the Professional and Organizational Development Network in Higher Education.

Merriam, S. B. \& Tisdell, E. J. (2015). Qualitative research: A guide to design and implementation. San Francisco, CA: Jossey-Bass.

O'Meara, K., Bennett, J. C., \& Neihaus, E. (2016). Left unsaid: The role of work expectations and psychological contracts in faculty careers and departure. The Review of Higher Education, 39(2), 269-297.

Palmer, J. C. (2002). Disciplinary variations in the work of full-time faculty members. New Directions for Community Colleges, 2002(118), 9-20.

Parker, M. A., Ashe, D., Boersma, J., Hicks, R., \& Bennett, V. (2015). Good teaching starts 
here: Applied learning at the graduate teaching assistant institute. Canadian Journal of Higher Education, 45(3), 84-110.

Riessman, C. K. (1993). Narrative Analysis. Newbury Park, California: Sage Publications, Inc. Rosser, V. J. (2004). The socialization and mentoring of doctoral students: A faculty's imperative. Educational Perspectives. 37(2), 28-33.

Sabin, B. (2007). Socialization of new college faculty: Mentoring and beyond. Retrieved from http:/www.brucesabin.com/pdf files/socialization_of new faculty.pdf

Savin, M. C., West, Charles P., \& Purcell, L. C., (2006) Establishing a faculty mentoring program in an applied sciences department. NACTA Jotunal, 50(4), 19-24.

Schneider, C. G. (2002). PFF-the road ahead, Liberal Education-Washington, DC, $88(3), 2-5$

Scott, J. (Ed.). (2014). A Dictionary of sociology (4 ed.). Oxford University Press. Retrieved from http:/www.oxfordreference.com.ezproxy.fairmontstate.edu

Silber, J. R. (1985). Higher education in the United States, Vital Speeches of the Day, 101(23), $706-712$

Sledge, L. C. (1986). The community college scholar. Profession, 4-6.

Thornton, A. B. (2010). Understanding the socialization experiences of new technical faculty: A transition from industry to the technical college (Doctoral dissertation). University of New Orleans Theses and Dissertations. Paper 1152.Available from ScholarWorks@UNO dissertation and Theses database. Retrieved from http://scholarworks.uno.edu/td/1152

Townsend, B. K. \& LaPaglia, N. (2000). Are we marginalized within academe? Perceptions of 
two-year college faculty. Community College Review, 28(1), 41-48.

Troubled History of Vocational Education", Retrieved from

http://www.americanradioworks.org.

Trower, C. A. (2010). A new generation of faculty: Similar core values in a different world. Peer Review, 12(3), 27.

Twale, D. J. \& Stein, E. L. (2001). Socialization of graduate and professional students in higher education: A perilous passage? ASHE-ERIC Higher Education Report, Volume 28, Number 3. Jossey-Bass Higher and Adult Education Series. San Francisco, CA: Jossey-Bass Inc.

Twombly, S. B. (2005). Values, policies, and practices affecting the hiring process for full-time arts and sciences faculty in community colleges. The Journal of Higher Education, 76(4), $423-447$

Twombly, S. \& Townsend, B. K. (2008). Community college faculty what we know and need to know. Community College Review, 36(1), 5-24.

Ulmer, J. M., Koch, D. \& Ollison, T. (2014). Characteristics of today's applied engineering college-level educator. Journal Of Technology Studies, 40(1), 40-52.

U.S. Department of Education (2008, February). Organization of U.S. education: Tertiary institutions. Retrieved from http://www.ed.gov/international/usnei/edlite-index.html U.S. Department of Homeland Security. (March, 2012). What is community college? Retrieved from https://studyinthestates.dhs.gov/2012/03/what-is-community-college Weidman, J. C., The Case Study as a Research Method, (Spring 1997). Retrieved from www.ischool.utexas.edu 
Wetzler, W. F. (1954). Schools of Education and Preparation of College Teachers. Improving College and University Teaching, 2(1), 11-14.

Wolf, Z. R. (2003). Exploring the audit trail for qualitative investigations. Nurse Educator, 28(4), 175-178.

Yin, R. K. (2013). Case study research: Design and methods. Thousand Oaks, CA: Sage Publications, Inc.

Woods, J. Q. (1999). Establishing a teaching development culture. In Robert J. Menges, Faculty in New Jobs (pp. 268-290). San Francisco, CA. 


\section{Appendix 1}

\begin{tabular}{|c|c|c|c|c|c|}
\hline \multicolumn{6}{|c|}{ Interview Response Table } \\
\hline Question & Participant 1 & Participant 2 & Participant 3 & Participant 4 & Participant 5 \\
\hline $\begin{array}{l}\text { 1. When you } \\
\text { reflect on the } \\
\text { time when } \\
\text { you were in } \\
\text { college or in } \\
\text { your } \\
\text { professional } \\
\text { training } \\
\text { programs, } \\
\text { how did those } \\
\text { experiences } \\
\text { influence your } \\
\text { impression of } \\
\text { teaching in a } \\
\text { college level } \\
\text { program? }\end{array}$ & $\begin{array}{l}\text { At the time } \\
\text { they didn't. I } \\
\text { was going to } \\
\text { school, wanted } \\
\text { to get a degree, } \\
\text { didn't know } \\
\text { where that was } \\
\text { going to lead. } \\
\text { Here is your } \\
\text { degree, good } \\
\text { luck, find a } \\
\text { job. Never } \\
\text { thought of } \\
\text { teaching. } \\
\text { Today draws } \\
\text { lessons from } \\
\text { that experience } \\
\text { to use in } \\
\text { classroom. } \\
\text { Draws from } \\
\text { instructors } \\
\text { having and not } \\
\text { having } \\
\text { industry } \\
\text { experience, } \\
\text { distinguishes a } \\
\text { difference } \\
\text { between the } \\
\text { two styles. }\end{array}$ & $\begin{array}{l}\text { Did not } \\
\text { consider a } \\
\text { college } \\
\text { teaching career } \\
\text { until } \\
\text { retirement } \\
\text { from a } \\
\text { professional } \\
\text { career. } \\
\text { The ones that } \\
\text { motivated me } \\
\text { worked with } \\
\text { me one-on-one } \\
\text { over the } \\
\text { rougher } \\
\text { courses. Went } \\
\text { out of their } \\
\text { way, didn't cut } \\
\text { us any breaks, } \\
\text { but gave us all } \\
\text { the opportunity } \\
\text { to succeed. } \\
\text { I felt I had a } \\
\text { personal } \\
\text { relationship, } \\
\text { and they were } \\
\text { very } \\
\text { professional, } \\
\text { sonething I } \\
\text { would have } \\
\text { aspired to be. }\end{array}$ & $\begin{array}{l}\text { I went to a } \\
\text { large } \\
\text { university for } \\
\text { undergrad and } \\
\text { never talked to } \\
\text { a professor } \\
\text { until my senior } \\
\text { year. } \\
\text { I never thought } \\
\text { I would be a } \\
\text { teacher, ever. It } \\
\text { never crossed } \\
\text { my mind, even } \\
\text { going through } \\
\text { graduate } \\
\text { school. }\end{array}$ & $\begin{array}{l}\text { As a student, } \\
\text { my first } \\
\text { semester, I had } \\
\text { an advisor not } \\
\text { fluent in } \\
\text { English and } \\
\text { there was no } \\
\text { relationship. I } \\
\text { was a number: } \\
\text { "Here is your } \\
\text { schedule. } \\
\text { Follow this. } \\
\text { See you } \\
\text { Later." It } \\
\text { didn't work for } \\
\text { me, senior year } \\
\text { I was missing } \\
\text { some classes. } \\
\text { There was no } \\
\text { communicatio } \\
\text { n with } \\
\text { instructors. } \\
\text { Now I base } \\
\text { what I do off } \\
\text { my poor } \\
\text { experiences. I } \\
\text { sympathize } \\
\text { with students } \\
\text { when they say } \\
\text { they are lost. } \\
\text { They don't } \\
\text { know what to } \\
\text { do. I try to } \\
\text { provide a good } \\
\text { introduction, } \\
\text { orientation, } \\
\text { and guidance, } \\
\text { especially } \\
\text { because so }\end{array}$ & $\begin{array}{l}\text { Did not } \\
\text { originally } \\
\text { consider a } \\
\text { teaching } \\
\text { career. } \\
\text { You think it's } \\
\text { mostly } \\
\text { teaching, and a } \\
\text { lot less of } \\
\text { everything } \\
\text { else, but I } \\
\text { think you } \\
\text { really } \\
\text { underestimate, } \\
\text { even the } \\
\text { preparation for } \\
\text { courses, even } \\
\text { if you know } \\
\text { what you're } \\
\text { teaching, even } \\
\text { if you taught it } \\
\text { every year } \\
\text { since you've } \\
\text { been here,, we } \\
\text { constantly fine } \\
\text { tune it, and } \\
\text { that was } \\
\text { underestimated } \\
\text { by me. I just } \\
\text { grossly } \\
\text { underestimated } \\
\text { committee } \\
\text { work, and all } \\
\text { the other } \\
\text { things, stuff. }\end{array}$ \\
\hline
\end{tabular}




\begin{tabular}{|c|c|c|c|c|c|}
\hline & & & & $\begin{array}{l}\text { many are } \\
\text { non-traditional }\end{array}$ & \\
\hline $\begin{array}{l}\text { 2. At what } \\
\text { stage in your } \\
\text { educational } \\
\text { journey did } \\
\text { you begin to } \\
\text { think } \\
\text { seriously } \\
\text { about } \\
\text { pursuing a } \\
\text { career in } \\
\text { college } \\
\text { teaching in } \\
\text { tandem with } \\
\text { your } \\
\text { professional } \\
\text { career? }\end{array}$ & $\begin{array}{l}\text { Had no } \\
\text { thought about } \\
\text { teaching. } \\
\text { Was } \\
\text { coincidental } \\
\text { that a faculty } \\
\text { member asked } \\
\text { about teaching } \\
\text { as an adjunct } \\
\text { faculty } \\
\text { member. }\end{array}$ & $\begin{array}{l}\text { In industry I } \\
\text { never felt like I } \\
\text { ever had the } \\
\text { opportunity to } \\
\text { help anybody, } \\
\text { nothing, zero. I } \\
\text { feel like this } \\
\text { fulfills that } \\
\text { need. I'm } \\
\text { helping } \\
\text { somebody else } \\
\text { achieve their } \\
\text { goal. When I } \\
\text { retired from } \\
\text { industry I } \\
\text { thought, "Ok, } \\
\text { this chapter } \\
\text { has ended and } \\
\text { here is what } \\
\text { I'm missing } \\
\text { that I'd like to } \\
\text { do." }\end{array}$ & $\begin{array}{l}\text { It was } \\
\text { definitely not } \\
\text { until much } \\
\text { later that I } \\
\text { thought I } \\
\text { would go into } \\
\text { any sort of } \\
\text { teaching. } \\
\text { An opportunity } \\
\text { where I } \\
\text { worked, where } \\
\text { we kept having } \\
\text { students, the } \\
\text { door opened, } \\
\text { and I went } \\
\text { through it. } \\
\text { Even in my } \\
\text { early career of } \\
\text { having } \\
\text { students in the } \\
\text { clinic, I } \\
\text { enjoyed it, but } \\
\text { never tied it to } \\
\text { classroom } \\
\text { teaching. }\end{array}$ & $\begin{array}{l}\text { When I came } \\
\text { back to school } \\
\text { for the EMS } \\
\text { Associate } \\
\text { Degree, I } \\
\text { really enjoyed } \\
\text { it, and found I } \\
\text { was in my } \\
\text { niche. I just } \\
\text { love the } \\
\text { profession as a } \\
\text { whole and has } \\
\text { expressed an } \\
\text { interest in } \\
\text { teaching. Like, } \\
\text { "Hey, if you } \\
\text { need help in } \\
\text { the future, I'd } \\
\text { love to come } \\
\text { back and help } \\
\text { future } \\
\text { students, just } \\
\text { because I am } \\
\text { such an } \\
\text { advocate of the } \\
\text { program. Pay } \\
\text { it forward. }\end{array}$ & $\begin{array}{l}\text { First out of } \\
\text { college } \\
\text { thought about } \\
\text { teaching, then } \\
\text { after beginning } \\
\text { a career, didn't } \\
\text { consider it } \\
\text { again. } \\
\text { Always } \\
\text { worked at } \\
\text { places that had } \\
\text { students come } \\
\text { to us for } \\
\text { clinical } \\
\text { training, so } \\
\text { that was } \\
\text { enough } \\
\text { teaching for } \\
\text { me. }\end{array}$ \\
\hline
\end{tabular}




\begin{tabular}{|c|c|c|c|c|c|}
\hline $\begin{array}{l}\text { 3.Based on } \\
\text { your past } \\
\text { experiences } \\
\text { during your } \\
\text { years of } \\
\text { education and } \\
\text { professional } \\
\text { training or } \\
\text { employment, } \\
\text { how would } \\
\text { you describe } \\
\text { the traits or } \\
\text { teaching } \\
\text { philosophies } \\
\text { of teachers, } \\
\text { you consider } \\
\text { mentors, that } \\
\text { have been } \\
\text { most } \\
\text { influential in } \\
\text { your own } \\
\text { teaching } \\
\text { strategies? }\end{array}$ & $\begin{array}{l}30 \text { years } \\
\text { industry } \\
\text { experience in } \\
\text { electrical } \\
\text { power to } \\
\text { inspire } \\
\text { students. } \\
\text { "We're here to } \\
\text { ensure they } \\
\text { learn what } \\
\text { they need to } \\
\text { know. They } \\
\text { learn the } \\
\text { knowledge. } \\
\text { They learn the } \\
\text { basics of the } \\
\text { knowledge, } \\
\text { and to go on } \\
\text { from there, to } \\
\text { give them that } \\
\text { desire. This is } \\
\text { such the } \\
\text { difficult part; } \\
\text { to keep } \\
\text { learning." }\end{array}$ & $\begin{array}{l}\text { Accounting to } \\
\text { me is very } \\
\text { hands on, and } \\
\text { you don't just } \\
\text { pick it up by } \\
\text { sitting there } \\
\text { watching the } \\
\text { instructor. My } \\
\text { instructors } \\
\text { said, "you do it } \\
\text { and bring back } \\
\text { what you've } \\
\text { done. I want to } \\
\text { see the work." } \\
\text { I try not to just } \\
\text { lecture, I use } \\
\text { an interactive } \\
\text { approach. That } \\
\text { is how I } \\
\text { learned the } \\
\text { best, keeping } \\
\text { students } \\
\text { engaged. }\end{array}$ & $\begin{array}{l}\text { One was at my } \\
\text { first job in } \\
\text { Chicago, he } \\
\text { was very good } \\
\text { at showing me } \\
\text { things and was } \\
\text { always used } \\
\text { positive } \\
\text { reinforcement. } \\
\text { He never made } \\
\text { me feel stupid. } \\
\text { Another was } \\
\text { the former } \\
\text { Program } \\
\text { Coordinator } \\
\text { here. She was } \\
\text { very clear in } \\
\text { directing me } \\
\text { and would } \\
\text { always explain } \\
\text { the importance } \\
\text { of what as } \\
\text { being asked. }\end{array}$ & $\begin{array}{l}\text { With } \\
\text { undergard, } \\
\text { grad school, a } \\
\text { lot of job } \\
\text { specific } \\
\text { training I've } \\
\text { done, I've } \\
\text { encountered } \\
\text { multiple kinds } \\
\text { of instructors } \\
\text { and I try to } \\
\text { take away little } \\
\text { things from } \\
\text { each and } \\
\text { emulate them. } \\
\text { I am not a } \\
\text { believer in } \\
\text { PowerPoints. } \\
\text { The ones that } \\
\text { are passionate, } \\
\text { I think, are } \\
\text { more } \\
\text { reputable. } \\
\text { I think I just } \\
\text { tried to pick } \\
\text { little pieces } \\
\text { from every } \\
\text { instructor I've } \\
\text { ever had of } \\
\text { what's great } \\
\text { and what's not. } \\
\text { Just try to } \\
\text { mold'em into } \\
\text { myself. }\end{array}$ & $\begin{array}{l}\text { I like teachers } \\
\text { that challenge } \\
\text { you, and find } \\
\text { some way to } \\
\text { engage you in } \\
\text { what they're } \\
\text { trying to teach } \\
\text { you. They all } \\
\text { have different } \\
\text { ways. } \\
\text { I had this class } \\
\text { that was } \\
\text { advanced } \\
\text { graduate level } \\
\text { molecular, and } \\
\text { I said, "I'm } \\
\text { gonna have } \\
\text { problems, my } \\
\text { bar is really } \\
\text { low in this." } \\
\text { He said, "It } \\
\text { really doesn't } \\
\text { matter where } \\
\text { your bar is as } \\
\text { long as it } \\
\text { comes up," } \\
\text { and I just used } \\
\text { that as my } \\
\text { whole thing } \\
\text { through grad } \\
\text { school, } \\
\text { because that's } \\
\text { the, kind of, } \\
\text { outlook that } \\
\text { we need for } \\
\text { students. I } \\
\text { think those are } \\
\text { the ones }\end{array}$ \\
\hline
\end{tabular}




\begin{tabular}{|c|c|c|c|c|c|}
\hline $\begin{array}{l}\text { 4. Given your } \\
\text { professional } \\
\text { education and } \\
\text { experience, } \\
\text { will you } \\
\text { describe the } \\
\text { training or } \\
\text { education you } \\
\text { have that has } \\
\text { been } \\
\text { specifically } \\
\text { beneficial for } \\
\text { classroom } \\
\text { instruction, } \\
\text { both before } \\
\text { becoming a } \\
\text { college } \\
\text { teacher and } \\
\text { after } \\
\text { beginning } \\
\text { your college } \\
\text { teaching } \\
\text { career? }\end{array}$ & $\begin{array}{l}30 \text { years } \\
\text { experience. } \\
\text { You can't fake } \\
\text { that. } \\
\text { They know I } \\
\text { know, and so } \\
\text { when I tell } \\
\text { them, in this } \\
\text { book what l'm } \\
\text { trying to teach } \\
\text { you, is also } \\
\text { just as } \\
\text { important as } \\
\text { the physical } \\
\text { skills. They } \\
\text { tend to listen a } \\
\text { little more and } \\
\text { agree with me. } \\
\text { They say, } \\
\text { okay, he has } \\
\text { been through } \\
\text { this, he know } \\
\text { what he is } \\
\text { talking about, } \\
\text { and I get good } \\
\text { results. }\end{array}$ & $\begin{array}{l}\text { During } 30 \\
\text { years in } \\
\text { industry, I had } \\
\text { been recently } \\
\text { groomed for } \\
\text { resume } \\
\text { writing, inter- } \\
\text { viewing, } \\
\text { career } \\
\text { opportunities, } \\
\text { and } \\
\text { networking; } \\
\text { good } \\
\text { information for } \\
\text { students. In } \\
\text { industry we } \\
\text { learn its more } \\
\text { than what the } \\
\text { textbooks tell } \\
\text { you of how to } \\
\text { impress, and } \\
\text { how to get } \\
\text { ahead and how } \\
\text { to climb the } \\
\text { ladder. I can } \\
\text { go through } \\
\text { some real-life } \\
\text { situations } \\
\text { based on what } \\
\text { I've learned } \\
\text { from others. }\end{array}$ & $\begin{array}{l}\text { I think it was } \\
\text { trial and error } \\
\text { for most of it, } \\
\text { trying to find } \\
\text { my way. } \\
\text { Here's my } \\
\text { information } \\
\text { and thinking } \\
\text { I'm tying it } \\
\text { together, and } \\
\text { then realizing } \\
\text { that they } \\
\text { weren't getting } \\
\text { it. That was } \\
\text { big. } \\
\text { The Quality } \\
\text { Matters online } \\
\text { class, as much } \\
\text { as I hated it, } \\
\text { was a big help. } \\
\text { I got Bloom's } \\
\text { taxonomy and } \\
\text { I understood } \\
\text { learning } \\
\text { objectives and } \\
\text { learning } \\
\text { outcomes. } \\
\text { How to fit it } \\
\text { together and } \\
\text { how it fit with } \\
\text { curriculum. I } \\
\text { also had nine } \\
\text { credits of } \\
\text { teaching and } \\
\text { learning that } \\
\text { helped with } \\
\text { framework. }\end{array}$ & $\begin{array}{l}\text { The biggest } \\
\text { part is, never } \\
\text { stop educating } \\
\text { yourself. 1 } \\
\text { believe, if you } \\
\text { ever let your } \\
\text { students know } \\
\text { that you } \\
\text { haven't done } \\
\text { any training or } \\
\text { any } \\
\text { self-developm } \\
\text { ent that you } \\
\text { are just falling } \\
\text { behind and } \\
\text { you're not } \\
\text { level with the } \\
\text { current } \\
\text { technology. If } \\
\text { you're not } \\
\text { trying to better } \\
\text { yourself, how } \\
\text { do you tell } \\
\text { your students } \\
\text { education is } \\
\text { important. } \\
\text { I'm alway } \\
\text { going to } \\
\text { different } \\
\text { conferences to } \\
\text { find new ideas } \\
\text { for engaging } \\
\text { students, } \\
\text { delivery } \\
\text { methods, and } \\
\text { technology to } \\
\text { use. } \\
\text { Continuing } \\
\text { education is } \\
\text { essential. }\end{array}$ & $\begin{array}{l}\text { I think being a } \\
\text { mom really } \\
\text { teaches you } \\
\text { how to get lots } \\
\text { of patience, to } \\
\text { deal (with } \\
\text { students). } \\
\text { I think it } \\
\text { makes you } \\
\text { grow and see } \\
\text { things from a } \\
\text { whole different } \\
\text { perspective. I } \\
\text { think maybe } \\
\text { that's it. It } \\
\text { makes it easier } \\
\text { to put yourself } \\
\text { in other } \\
\text { people's shoes. } \\
\text { How to } \\
\text { conmunicate } \\
\text { better. }\end{array}$ \\
\hline
\end{tabular}




\begin{tabular}{|c|c|c|c|c|c|}
\hline $\begin{array}{l}\text { 5. Based on } \\
\text { your initial } \\
\text { impression of } \\
\text { what college } \\
\text { teaching roles } \\
\text { entail prior to } \\
\text { transitioning } \\
\text { into your } \\
\text { teaching } \\
\text { career, how } \\
\text { do you } \\
\text { perceive the } \\
\text { roles } \\
\text { differently } \\
\text { today, since } \\
\text { beginning an } \\
\text { academic } \\
\text { career? }\end{array}$ & $\begin{array}{l}\text { He gets up in } \\
\text { front of } \\
\text { everyone and } \\
\text { instructs. He } \\
\text { gives tests, he } \\
\text { gives } \\
\text { homework } \\
\text { assignments, } \\
\text { and grades } \\
\text { papers. } \\
\text { However, the } \\
\text { background } \\
\text { scene behind } \\
\text { the classroom } \\
\text { can be almost } \\
\text { overwhelming. } \\
\text { The activities } \\
\text { out of class are } \\
\text { time-consumin } \\
\text { g and more } \\
\text { than anyone } \\
\text { would think. }\end{array}$ & $\begin{array}{l}\text { I visualized I } \\
\text { would walk in } \\
\text { and teach what } \\
\text { I knew, and } \\
\text { spend my time } \\
\text { in front of the } \\
\text { class, working } \\
\text { with students } \\
\text { one-on-one } \\
\text { after classes. I } \\
\text { really didn't } \\
\text { think about the } \\
\text { relations that } \\
\text { you develop. I } \\
\text { never realized } \\
\text { how you blend } \\
\text { into their lives } \\
\text { too. You have } \\
\text { to get their } \\
\text { attention and } \\
\text { engage them. } \\
\text { When walk in } \\
\text { class the first } \\
\text { time I was } \\
\text { afraid of them, } \\
\text { terrified. I } \\
\text { didn't realize } \\
\text { how hard I'd } \\
\text { have to work } \\
\text { when I'm up in } \\
\text { front of them, } \\
\text { thought they } \\
\text { would be the } \\
\text { workers, in a } \\
\text { lot of ways. } \\
\text { Wondered } \\
\text { "you need this } \\
\text { course, so why } \\
\text { aren't you } \\
\text { meeting me } \\
\text { halfway to } \\
\text { learn." }\end{array}$ & $\begin{array}{l}\text { I didn't realize } \\
\text { how much } \\
\text { time and } \\
\text { thinking goes } \\
\text { into teaching. } \\
\text { This job, it } \\
\text { never ends. I } \\
\text { mean, you're } \\
\text { always } \\
\text { thinking about } \\
\text { how I could do } \\
\text { this, I could do } \\
\text { that. The } \\
\text { preparation for } \\
\text { one hour of } \\
\text { lecture, I had } \\
\text { no idea that it } \\
\text { would be so } \\
\text { much. It takes } \\
\text { a lot of time. }\end{array}$ & $\begin{array}{l}\text { It's a lot harder } \\
\text { than I thought } \\
\text { it was. In my } \\
\text { mind's eye, to } \\
\text { go and be a } \\
\text { progressive } \\
\text { educator is a } \\
\text { lot harder than } \\
\text { I ever } \\
\text { imagined. I } \\
\text { figured once } \\
\text { you got in, you } \\
\text { pretty much } \\
\text { just had a } \\
\text { cookie cutter } \\
\text { program. Your } \\
\text { just ran it the } \\
\text { same way, and } \\
\text { you just went } \\
\text { through the } \\
\text { motions all the } \\
\text { time. To go } \\
\text { and develop } \\
\text { that and } \\
\text { continually try } \\
\text { to better the } \\
\text { program is } \\
\text { difficult. } \\
\text { Being the } \\
\text { subject matter } \\
\text { expert } \\
\text { really--why } \\
\text { you gotta be } \\
\text { that expert to } \\
\text { be able to } \\
\text { apply the } \\
\text { material } \\
\text { instead of just } \\
\text { being the } \\
\text { deliverer--the } \\
\text { deliverer of }\end{array}$ & $\begin{array}{l}\text { I feel bad, I } \\
\text { think that's } \\
\text { what's wrong a } \\
\text { lot with } \\
\text { academic } \\
\text { collegiate } \\
\text { education now, } \\
\text { is that a very } \\
\text { small portion } \\
\text { of what faculty } \\
\text { does is teach. I } \\
\text { understand } \\
\text { committees are } \\
\text { important. I've } \\
\text { learned a lot } \\
\text { from the } \\
\text { committees } \\
\text { that I've been } \\
\text { on, academic } \\
\text { appeals, and } \\
\text { all that stuff. } \\
\text { I've learned a } \\
\text { lot, but I think } \\
\text { what our } \\
\text { institution is } \\
\text { lacking is how } \\
\text { much lack of } \\
\text { support } \\
\text { services we } \\
\text { have. I don't } \\
\text { mind advising } \\
\text { students. I } \\
\text { want to advise } \\
\text { students, but } \\
\text { all the } \\
\text { registrations } \\
\text { we work, we } \\
\text { have group }\end{array}$ \\
\hline
\end{tabular}




\begin{tabular}{|c|c|c|c|c|c|}
\hline & & & & knowledge. & $\begin{array}{l}\text { advising } \\
\text { parties, I } \\
\text { mean, } \\
\text { everything } \\
\text { here- }\end{array}$ \\
\hline $\begin{array}{l}\text { 6. What is } \\
\text { your } \\
\text { perception of } \\
\text { the transition } \\
\text { process from } \\
\text { a career } \\
\text { professional } \\
\text { to your early } \\
\text { stages of a } \\
\text { college } \\
\text { teaching role? } \\
\text { When you } \\
\text { made the } \\
\text { decision to } \\
\text { begin your } \\
\text { college } \\
\text { teaching } \\
\text { career, what } \\
\text { were your } \\
\text { expectations } \\
\text { regarding the } \\
\text { career } \\
\text { change? }\end{array}$ & $\begin{array}{l}\text { Understood } \\
\text { about test, } \\
\text { midterms, } \\
\text { finals, } \\
\text { assignments, } \\
\text { and grades to } \\
\text { give. Didn't } \\
\text { understand the } \\
\text { work } \\
\text { necessary to } \\
\text { arrange all } \\
\text { that. How to } \\
\text { plan, schedule } \\
\text { and pace } \\
\text { workloads, and } \\
\text { then } \\
\text { follow-up. } \\
\text { Didn't } \\
\text { consider } \\
\text { administrative } \\
\text { aspects of } \\
\text { teaching. }\end{array}$ & $\begin{array}{l}\text { I was scared. } \\
\text { The } \\
\text { atmosphere } \\
\text { was hard for } \\
\text { me, because I } \\
\text { come from an } \\
\text { atmosphere of } \\
\text { distrust. We } \\
\text { were in a very } \\
\text { competitive } \\
\text { mode in } \\
\text { industry. } \\
\text { Everybody } \\
\text { was trying to } \\
\text { hand onto their } \\
\text { job, trying to } \\
\text { up the next } \\
\text { guy, always } \\
\text { looking over } \\
\text { your shoulder. } \\
\text { When I started } \\
\text { here I felt like } \\
\text { everybody } \\
\text { seemed nice, } \\
\text { but I didn't } \\
\text { what to trust } \\
\text { anyone. I kept } \\
\text { watching for a } \\
\text { threat, so I'd } \\
\text { know where } \\
\text { my enemies } \\
\text { were coming } \\
\text { form. It never } \\
\text { happened, I'm } \\
\text { still waiting. } \\
\text { It's a whole } \\
\text { different } \\
\text { culture. }\end{array}$ & $\begin{array}{l}\text { I thought it } \\
\text { would be } \\
\text { much easier. I } \\
\text { thought I had } \\
\text { so much } \\
\text { knowledge in } \\
\text { my profession } \\
\text { that it should } \\
\text { be easy to } \\
\text { translate it to } \\
\text { the students. } \\
\text { Things I had } \\
\text { been doing for } \\
\text { so long that I } \\
\text { forgot how to } \\
\text { explain it and I } \\
\text { thought they } \\
\text { should just } \\
\text { know because } \\
\text { to me it's so } \\
\text { easy, why } \\
\text { would this be } \\
\text { hard. } \\
\text { I didn't expect } \\
\text { the } \\
\text { relationship of } \\
\text { the student and } \\
\text { myself to be } \\
\text { different than } \\
\text { my patients } \\
\text { and me. I } \\
\text { didn't realize } \\
\text { with students, } \\
\text { you have to } \\
\text { put a wall } \\
\text { because you } \\
\text { can't get that } \\
\text { relationship to } \\
\text { that level of } \\
\text { what you }\end{array}$ & $\begin{array}{l}\text { The biggest } \\
\text { thing was that } \\
\text { you have the } \\
\text { knowledge, } \\
\text { but how to } \\
\text { deliver the } \\
\text { material to } \\
\text { make it } \\
\text { interesting and } \\
\text { make it that } \\
\text { kind of a -- } \\
\text { step process of } \\
\text { how to get the } \\
\text { student to the } \\
\text { point where } \\
\text { you're at to } \\
\text { make the try to } \\
\text { be better than } \\
\text { you. } \\
\text { Just trying to } \\
\text { figure out how } \\
\text { to explain and } \\
\text { engage stuff, } \\
\text { especially } \\
\text { material that } \\
\text { they need to } \\
\text { know that's a } \\
\text { lot drier. It's } \\
\text { hard to deliver. } \\
\text { If you're } \\
\text { exceptional } \\
\text { motivated and } \\
\text { passionate } \\
\text { about what } \\
\text { you do, trying } \\
\text { to convey that } \\
\text { to the students, } \\
\text { too, to get } \\
\text { them to be } \\
\text { passionate and }\end{array}$ & $\begin{array}{l}\text { I think they } \\
\text { give you } \\
\text { freedom that I } \\
\text { really wasn't } \\
\text { used too. I } \\
\text { remember } \\
\text { coming in and } \\
\text { sitting at my } \\
\text { desk and } \\
\text { thinking, } \\
\text { "Okay, where } \\
\text { am I supposed } \\
\text { to be," I didn't } \\
\text { really even } \\
\text { know how to } \\
\text { pace that, or } \\
\text { all the work } \\
\text { that entails. } \\
\text { I think as an } \\
\text { institution } \\
\text { there was-I } \\
\text { felt there was } \\
\text { no real set up, } \\
\text { like yeah, we } \\
\text { had faculty } \\
\text { development } \\
\text { week, but } \\
\text { honestly if } \\
\text { you're new } \\
\text { faculty, how } \\
\text { much effect on } \\
\text { a development } \\
\text { week can you } \\
\text { even use. I felt } \\
\text { as an } \\
\text { institution that }\end{array}$ \\
\hline
\end{tabular}




\begin{tabular}{|c|c|c|c|c|c|}
\hline & & & $\begin{array}{l}\text { would with a } \\
\text { patient. If you } \\
\text { have to fail } \\
\text { someone, that } \\
\text { is hard. }\end{array}$ & $\begin{array}{l}\text { motivated } \\
\text { about } \\
\text { education to } \\
\text { get to where } \\
\text { you're at. }\end{array}$ & $\begin{array}{l}\text { the ball was } \\
\text { dropped as far } \\
\text { as mentoring } \\
\text { new faculty. }\end{array}$ \\
\hline $\begin{array}{l}\text { 7. When you } \\
\text { recall the } \\
\text { initial job } \\
\text { interviews, } \\
\text { the hiring, } \\
\text { and the first } \\
\text { semester of } \\
\text { college } \\
\text { teaching, will } \\
\text { you describe } \\
\text { for me the } \\
\text { processes } \\
\text { and/or } \\
\text { programs you } \\
\text { experienced } \\
\text { whereby the } \\
\text { institution } \\
\text { provided a } \\
\text { means for you } \\
\text { to socialize } \\
\text { and acclimate } \\
\text { into your new } \\
\text { teaching } \\
\text { career? }\end{array}$ & $\begin{array}{l}\text { There wasn't } \\
\text { any } \\
\text { institutional } \\
\text { socialization } \\
\text { and } \\
\text { acclimation } \\
\text { process. } \\
\text { Handed a file } \\
\text { and a book, } \\
\text { was told, "see } \\
\text { you Monday." } \\
\text { Was observed } \\
\text { after a couple } \\
\text { weeks and told } \\
\text { "you will be } \\
\text { fine." Pgrm. } \\
\text { Coordinator } \\
\text { was available } \\
\text { for advice. } \\
\text { While } \\
\text { adjuncting was } \\
\text { briefly } \\
\text { interviewed } \\
\text { and hired as } \\
\text { new Program } \\
\text { Coordinator }\end{array}$ & $\begin{array}{l}\text { It was odd, } \\
\text { they brought } \\
\text { me here and } \\
\text { gave me a } \\
\text { desk. They } \\
\text { didn't even } \\
\text { have books, } \\
\text { They hadn't } \\
\text { ordered the } \\
\text { textbooks. } \\
\text { Classes were } \\
\text { starting in a } \\
\text { couple weeks } \\
\text { and I didn't } \\
\text { have anything. } \\
\text { There was no } \\
\text { model of what } \\
\text { whoever did } \\
\text { this before me } \\
\text { did. I was } \\
\text { creating the } \\
\text { wheel. Just } \\
\text { gave me an } \\
\text { office and said, } \\
\text { "Do you like } \\
\text { your } \\
\text { computer? Do } \\
\text { you like your } \\
\text { office?" No } \\
\text { plan, nothing. }\end{array}$ & $\begin{array}{l}\text { Nothing. } \\
\text { I never had an } \\
\text { interview like } \\
\text { that before, it } \\
\text { was like a } \\
\text { board and they } \\
\text { were asking } \\
\text { me all types of } \\
\text { questions } \\
\text { about diversity } \\
\text { and I was } \\
\text { moving from } \\
\text { Chicago. It } \\
\text { was very } \\
\text { intimidating, } \\
\text { so much of it } \\
\text { either just } \\
\text { thrown at you, } \\
\text { here you go, } \\
\text { like mark and } \\
\text { set, go. I've } \\
\text { seen how now } \\
\text { they are } \\
\text { handling it } \\
\text { with new hires } \\
\text { and we're } \\
\text { lucky we have } \\
\text { anybody } \\
\text { working here } \\
\text { honestly. } \\
\text { Because the } \\
\text { expectation are } \\
\text { just unreal. }\end{array}$ & $\begin{array}{l}\text { A mentor } \\
\text { would have } \\
\text { been great. In } \\
\text { theory, when } \\
\text { the past } \\
\text { program } \\
\text { director was } \\
\text { leaving, I was } \\
\text { supposed to } \\
\text { shadow her for } \\
\text { a few months. } \\
\text { Due to her } \\
\text { schedule } \\
\text { changes and } \\
\text { relocating, it } \\
\text { just never } \\
\text { worked out. } \\
\text { She was } \\
\text { available for } \\
\text { phone calls to } \\
\text { answer } \\
\text { questions, but } \\
\text { it was pretty } \\
\text { much thrown } \\
\text { in my lap. } \\
\text { "Here's your } \\
\text { office." }\end{array}$ & $\begin{array}{l}\text { I think school } \\
\text { meetings and } \\
\text { things were the } \\
\text { most helpful, } \\
\text { cause you } \\
\text { don't really do } \\
\text { committee } \\
\text { work that first } \\
\text { little bit, so } \\
\text { you don't } \\
\text { really know } \\
\text { what's going } \\
\text { on with that. I } \\
\text { think there's a } \\
\text { little bit of a } \\
\text { disconnect. } \\
\text { She had } \\
\text { agendas they'd } \\
\text { go out before, } \\
\text { there's very } \\
\text { lively } \\
\text { discussion in } \\
\text { those too. And } \\
\text { there was } \\
\text { always } \\
\text { follow-ups, so } \\
\text { I think our } \\
\text { school } \\
\text { meetings were } \\
\text { very good. I } \\
\text { understand the } \\
\text { purpose of } \\
\text { faculty } \\
\text { development } \\
\text { week, but, it }\end{array}$ \\
\hline
\end{tabular}




\begin{tabular}{|c|c|c|c|c|c|}
\hline & & & & & $\begin{array}{l}\text { just stresses } \\
\text { me more than } \\
\text { it enlightens } \\
\text { me. }\end{array}$ \\
\hline $\begin{array}{l}\text { 8. When you } \\
\text { began } \\
\text { teaching at } \\
\text { this } \\
\text { institution, to } \\
\text { aid your } \\
\text { transition and } \\
\text { socialization, } \\
\text { were you } \\
\text { assigned a } \\
\text { faculty } \\
\text { mentor? If so, } \\
\text { how was that } \\
\text { that mentor } \\
\text { selected for } \\
\text { you? } \\
\text { If not, how } \\
\text { would you } \\
\text { perceive a } \\
\text { mentor would } \\
\text { have } \\
\text { benefited you } \\
\text { during your } \\
\text { transition? } \\
\text { Was there a } \\
\text { formal } \\
\text { mentoring } \\
\text { process? Will } \\
\text { you describe } \\
\text { your } \\
\text { perception } \\
\text { about what } \\
\text { that entailed } \\
\text { and how that }\end{array}$ & $\begin{array}{l}\text { There wasn't } \\
\text { any mentoring } \\
\text { program. } \\
\text { Other faculty } \\
\text { would } \\
\text { informally see } \\
\text { concern and } \\
\text { offer } \\
\text { assistance. } \\
\text { "My } \\
\text { mentoring } \\
\text { comes from } \\
\text { people just } \\
\text { because I } \\
\text { could talk to } \\
\text { people, and I } \\
\text { was social, and } \\
\text { I was wanting } \\
\text { to learn." } \\
\text { Don't think an } \\
\text { assigned } \\
\text { mentor would } \\
\text { have been } \\
\text { beneficial due } \\
\text { to } \\
\text { personalities. } \\
\text { It becomes a } \\
\text { job for } \\
\text { somebody } \\
\text { already } \\
\text { overworked } \\
\text { and underpaid. } \\
\text { Better to be } \\
\text { allowed to } \\
\text { gravitate to an } \\
\text { informal }\end{array}$ & $\begin{array}{l}\text { The former } \\
\text { Program } \\
\text { Coordinator } \\
\text { was the best } \\
\text { mentor I've } \\
\text { had in my } \\
\text { whole life. } \\
\text { Energetic, } \\
\text { positive, } \\
\text { upbeat, } \\
\text { knowledgeable } \\
\text {, amazingly } \\
\text { hardworking. } \\
\text { He was very } \\
\text { informal. It } \\
\text { was funny } \\
\text { because, when } \\
\text { he would give } \\
\text { me something } \\
\text { to do, there } \\
\text { was never a } \\
\text { deadline on it. } \\
\text { They did not } \\
\text { assign a formal } \\
\text { mentor. } \\
\text { Related to } \\
\text { mentoring and } \\
\text { the institution, } \\
\text { I really do } \\
\text { struggle with } \\
\text { the mentality } \\
\text { of these } \\
\text { institutions. } \\
\text { (coming from a } \\
\text { corporate } \\
\text { background) I }\end{array}$ & $\begin{array}{l}\text { The former } \\
\text { Program } \\
\text { Coordinator } \\
\text { took the role as } \\
\text { a mentor. } \\
\text { I think it } \\
\text { would have } \\
\text { been nice to } \\
\text { also have } \\
\text { somebody } \\
\text { outside my } \\
\text { program, here } \\
\text { we are } \\
\text { isolated, we're } \\
\text { here by } \\
\text { ourselves. } \\
\text { In my case it } \\
\text { was one } \\
\text { person that did } \\
\text { it all, so my } \\
\text { interaction } \\
\text { with the rest of } \\
\text { the institution } \\
\text { was not there. }\end{array}$ & $\begin{array}{l}\text { I didn't } \\
\text { directly have } \\
\text { an institutional } \\
\text { mentor just } \\
\text { because of } \\
\text { how } \\
\text { everything } \\
\text { worked out. } \\
\text { The other } \\
\text { full-time } \\
\text { faculty in our } \\
\text { program had } \\
\text { been here a } \\
\text { good while. He } \\
\text { kind of served } \\
\text { as my mentor } \\
\text { and told me, } \\
\text { "This is how } \\
\text { we run things." } \\
\text { He was } \\
\text { unofficially } \\
\text { my mentor. } \\
\text { Having } \\
\text { graduated from } \\
\text { the program it } \\
\text { really helped. } \\
\text { If i was a } \\
\text { complete } \\
\text { outsider and } \\
\text { just transferred } \\
\text { here and didn't } \\
\text { have any of the } \\
\text { experience, If I } \\
\text { went to a } \\
\text { different } \\
\text { program, and } \\
\text { than came to }\end{array}$ & $\begin{array}{l}\text { don't know if } \\
\text { anybody was } \\
\text { specifically } \\
\text { assigned to } \\
\text { me. Not } \\
\text { that-but } \\
\text { might be just } \\
\text { because I } \\
\text { never saw it on } \\
\text { paper. For } \\
\text { classroom } \\
\text { teaching the } \\
\text { program } \\
\text { coordinator } \\
\text { was assigned } \\
\text { to keep me on } \\
\text { pace. Other } \\
\text { faculty were } \\
\text { relied on for } \\
\text { committee } \\
\text { work and } \\
\text { promotion } \\
\text { portfolios. } \\
\text { Things you } \\
\text { don't get day } \\
\text { to day. }\end{array}$ \\
\hline
\end{tabular}




\begin{tabular}{|c|c|c|c|c|c|}
\hline $\begin{array}{l}\text { experience } \\
\text { help your } \\
\text { transition to } \\
\text { the norms } \\
\text { and culture of } \\
\text { higher } \\
\text { education? } \\
\text { If not, how } \\
\text { would you } \\
\text { perceive a } \\
\text { mentor would } \\
\text { have } \\
\text { benefited you } \\
\text { during your } \\
\text { transition? }\end{array}$ & mentor. & $\begin{array}{l}\text { feel like } \\
\text { sometimes I } \\
\text { speak French } \\
\text { and they speak } \\
\text { Spanish. }\end{array}$ & & $\begin{array}{l}\text { this one and } \\
\text { tried to be the } \\
\text { director of it, I } \\
\text { would have } \\
\text { been lost. } \\
\text { The fine } \\
\text { details of what } \\
\text { needed to be } \\
\text { done was some } \\
\text { from him, and } \\
\text { the college } \\
\text { sent me to a lot } \\
\text { of workshops } \\
\text { and other } \\
\text { training. }\end{array}$ & \\
\hline $\begin{array}{l}8 \text { a. Were } \\
\text { there } \\
\text { informal } \\
\text { mentors to } \\
\text { whom you } \\
\text { gravitated to } \\
\text { and } \\
\text { associated } \\
\text { with? Will } \\
\text { you describe } \\
\text { your } \\
\text { perception } \\
\text { about what } \\
\text { that entailed } \\
\text { and how that } \\
\text { experience } \\
\text { help your } \\
\text { transition? }\end{array}$ & $\begin{array}{l}\text { See notes } \\
\text { above. } \\
\text { Prior program } \\
\text { coordinator } \\
\text { was helpful as } \\
\text { informal } \\
\text { mentor along } \\
\text { with other } \\
\text { faculty in the } \\
\text { program }\end{array}$ & $\begin{array}{l}\text { See notes } \\
\text { above. }\end{array}$ & $\begin{array}{l}\text { There was an } \\
\text { informal } \\
\text { mentor in the } \\
\text { testing center } \\
\text { that would } \\
\text { answer } \\
\text { questions } \\
\text { when called } \\
\text { upon. }\end{array}$ & $\begin{array}{l}\text { See notes } \\
\text { above. }\end{array}$ & $\begin{array}{l}\text { Yeah. the } \\
\text { coordinator } \\
\text { was informal, } \\
\text { but I think } \\
\text { since it was } \\
\text { mostly } \\
\text { program, I } \\
\text { think that } \\
\text { colleagues } \\
\text { were informal. } \\
\text { it fit into our } \\
\text { workplace. } \\
\text { Because if you } \\
\text { just have it all } \\
\text { within your } \\
\text { little program, } \\
\text { it's easy to just } \\
\text { become-well, } \\
\text { you just feel } \\
\text { like you're in } \\
\text { your little } \\
\text { vacuum, you } \\
\text { know. }\end{array}$ \\
\hline
\end{tabular}




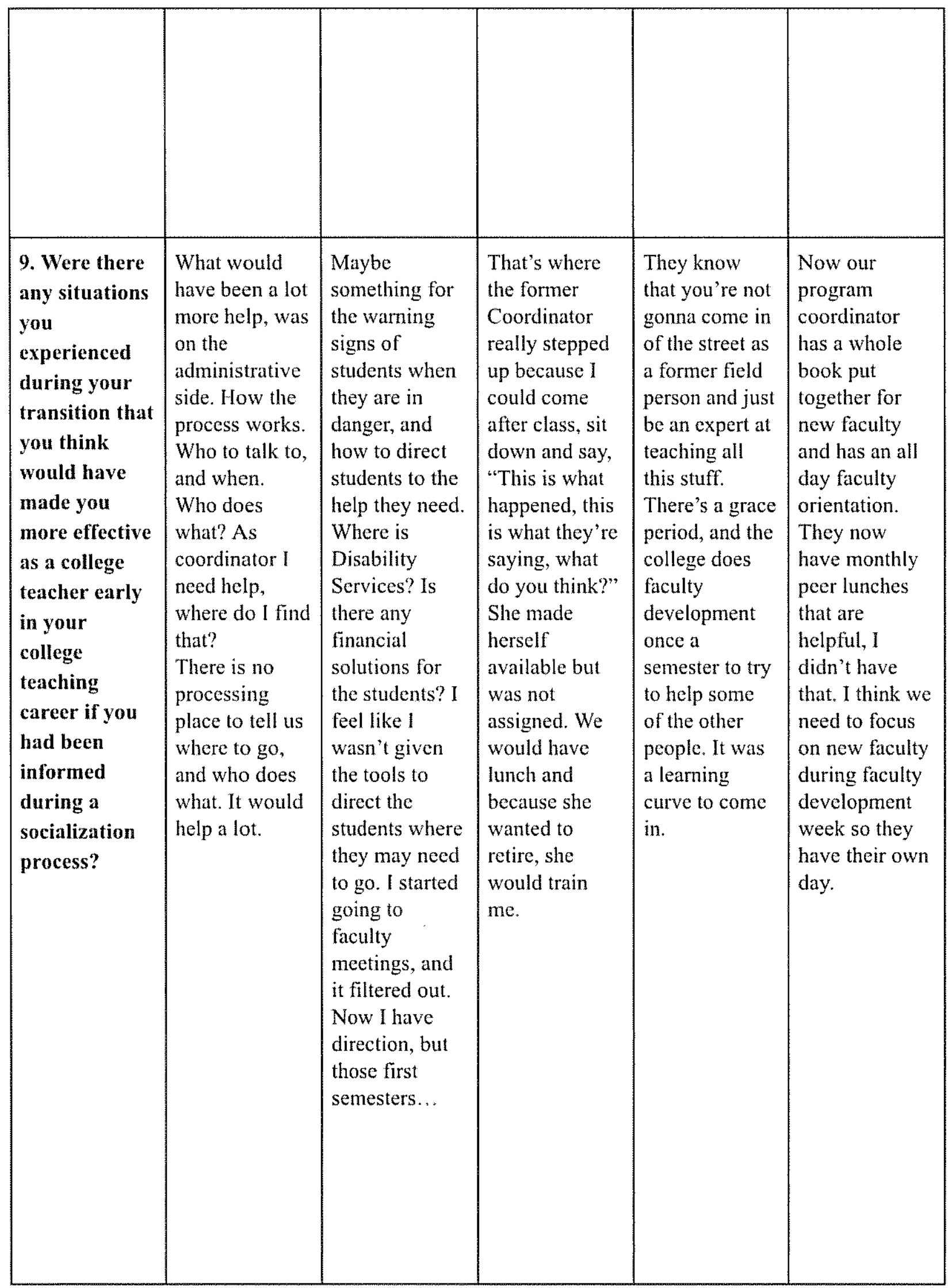




\begin{tabular}{|c|c|c|c|c|c|}
\hline $\begin{array}{l}\text { 10. Will you } \\
\text { describe any } \\
\text { programs } \\
\text { provided by } \\
\text { the institution } \\
\text { that aided } \\
\text { your } \\
\text { pedagogical } \\
\text { and collegial } \\
\text { expertise for } \\
\text { teaching your } \\
\text { specific } \\
\text { content } \\
\text { matter and } \\
\text { actively } \\
\text { engaging in } \\
\text { service to the } \\
\text { institution? }\end{array}$ & $\begin{array}{l}\text { The institution } \\
\text { did not lay } \\
\text { anything out } \\
\text { for me. Call } \\
\text { that a sorry } \\
\text { state of affairs, } \\
\text { but they } \\
\text { simply did not. } \\
\text { They knew I } \\
\text { had never } \\
\text { taught before. } \\
\text { The } \\
\text { conversation } \\
\text { never came up, } \\
\text { or the question } \\
\text { never arose. I } \\
\text { draw on all the } \\
\text { different } \\
\text { teaching } \\
\text { methods I was } \\
\text { fortunate to } \\
\text { remember and } \\
\text { use bits and } \\
\text { parts. }\end{array}$ & $\begin{array}{l}\text { I think the } \\
\text { tutoring } \\
\text { program is } \\
\text { very good. I've } \\
\text { been amazed } \\
\text { with that } \\
\text { program and } \\
\text { their } \\
\text { responsiveness } \\
\\
\text { The institution } \\
\text { did not provide } \\
\text { help with } \\
\text { learning how } \\
\text { to teach. I was } \\
\text { learned } \\
\text { through } \\
\text { networking } \\
\text { with other } \\
\text { people. } \\
\text { Lunchtime } \\
\text { conversations } \\
\text { with } \\
\text { experienced } \\
\text { faculty. } \\
\text { Through the } \\
\text { informal } \\
\text { network of } \\
\text { asking } \\
\text { questions of } \\
\text { other } \\
\text { instructors that } \\
\text { have been here } \\
\text { longer. As far } \\
\text { as anything } \\
\text { besides the }\end{array}$ & $\begin{array}{l}\text { The first year I } \\
\text { taught there } \\
\text { was a writing } \\
\text { workshop on } \\
\text { assessment day } \\
\text { that was really } \\
\text { good. As a } \\
\text { group we } \\
\text { helped to } \\
\text { rewrite } \\
\text { directions to } \\
\text { assignments, } \\
\text { and then we } \\
\text { looked at our } \\
\text { rubrics and } \\
\text { helped to } \\
\text { rewrite the } \\
\text { rubrics to } \\
\text { better fit the } \\
\text { assignments. It } \\
\text { was great. }\end{array}$ & $\begin{array}{l}\text { The biggest } \\
\text { thing is from } \\
\text { the } \\
\text { administrative } \\
\text { side. I think } \\
\text { the education } \\
\text { side wasn't too } \\
\text { bad, there is } \\
\text { material and } \\
\text { technology out } \\
\text { there to help. } \\
\text { The hardest } \\
\text { part is all the } \\
\text { fine details of } \\
\text { students, when } \\
\text { they have } \\
\text { questions } \\
\text { about } \\
\text { scheduling, } \\
\text { who they're } \\
\text { supposed to go } \\
\text { see, and what } \\
\text { they do in } \\
\text { situations. } \\
\text { The college } \\
\text { sent me to } \\
\text { workshops for } \\
\text { our national } \\
\text { accreditation } \\
\text { and some other } \\
\text { fundamental } \\
\text { educational } \\
\text { things. First } \\
\text { year I was } \\
\text { here, I went to } \\
\text { three or four } \\
\text { pretty big } \\
\text { workshops, }\end{array}$ & $\begin{array}{l}\text { As the } \\
\text { institution, I } \\
\text { was on the } \\
\text { quantitative } \\
\text { literacy team } \\
\text { that went to a } \\
\text { conference, } \\
\text { and we heard } \\
\text { an outside } \\
\text { speaker on } \\
\text { assessment, } \\
\text { who is on } \\
\text { quantitative } \\
\text { literacy, and } \\
\text { work with } \\
\text { other colleges. } \\
\text { That was a } \\
\text { good } \\
\text { experience. } \\
\text { There was a } \\
\text { Quality } \\
\text { Matters } \\
\text { course, but I } \\
\text { didn't have } \\
\text { time for it. We } \\
\text { also go to the } \\
\text { clinical } \\
\text { laboratory } \\
\text { education } \\
\text { conference, the } \\
\text { national } \\
\text { conference the } \\
\text { institution } \\
\text { support that.. }\end{array}$ \\
\hline
\end{tabular}




\begin{tabular}{|c|c|c|c|c|c|}
\hline & & $\begin{array}{l}\text { handbook, } 1 \\
\text { can't think of } \\
\text { any. }\end{array}$ & & $\begin{array}{l}\text { and } \\
\text { symposiums, } \\
\text { and events. }\end{array}$ & \\
\hline $\begin{array}{l}\text { 11. Will you } \\
\text { describe your } \\
\text { perception of } \\
\text { how } \\
\text { socialization } \\
\text { and } \\
\text { mentoring at } \\
\text { the institution } \\
\text { has helped (or } \\
\text { could have } \\
\text { helped you) to } \\
\text { be effective in } \\
\text { the classroom } \\
\text { and enhance } \\
\text { student } \\
\text { learning? }\end{array}$ & $\begin{array}{l}\text { In industry, } \\
\text { you're told to } \\
\text { do things and } \\
\text { you either do } \\
\text { it, or you no } \\
\text { longer work } \\
\text { there. In the } \\
\text { world of } \\
\text { academia there } \\
\text { is more of an } \\
\text { open } \\
\text { discussion on } \\
\text { how processes } \\
\text { should evolve. } \\
\text { l get to have } \\
\text { input to the } \\
\text { process. You } \\
\text { feel your } \\
\text { perspective has } \\
\text { more value to } \\
\text { it. }\end{array}$ & $\begin{array}{l}\text { I'm working } \\
\text { with the } \\
\text { former } \\
\text { Coordinator } \\
\text { for creating } \\
\text { web pages } \\
\text { within } \\
\text { Blackboard. If } \\
\text { not for him, I } \\
\text { wouldn't know } \\
\text { about it. } \\
\text { I notice at the } \\
\text { institution } \\
\text { everybody } \\
\text { stays within } \\
\text { their own } \\
\text { school. } \\
\text { Everybody } \\
\text { stays within } \\
\text { their own little } \\
\text { group. } \\
\text { Everyone is } \\
\text { friendly, but } \\
\text { stays in their } \\
\text { own clique. } \\
\text { They don't } \\
\text { withhold } \\
\text { things, but } \\
\text { there's not } \\
\text { always sharing } \\
\text { of information. }\end{array}$ & $\begin{array}{l}\text { The writing } \\
\text { workshop } \\
\text { mentioned } \\
\text { above. } \\
\text { Also, Quality } \\
\text { Matter course } \\
\text { was helpful to } \\
\text { look and see } \\
\text { Bloom's } \\
\text { taxonomy for } \\
\text { teaching to the } \\
\text { level I want for } \\
\text { the students to } \\
\text { learn. }\end{array}$ & $\begin{array}{l}\text { Being able to } \\
\text { talk with other } \\
\text { educators in } \\
\text { the field } \\
\text { running similar } \\
\text { programs is } \\
\text { important. } \\
\text { With a } \\
\text { "hands-on" } \\
\text { program, 1 } \\
\text { couldn't go to } \\
\text { an educator in } \\
\text { the English } \\
\text { department } \\
\text { and say, "I } \\
\text { need help } \\
\text { trying...with } \\
\text { delivery } \\
\text { methods," } \\
\text { because it's } \\
\text { apples and } \\
\text { oranges, } \\
\text { Finding some } \\
\text { other people } \\
\text { that have been } \\
\text { in the business } \\
\text { a while is } \\
\text { important. } \\
\text { Institutional } \\
\text {-wise, } \\
\text { probably not } \\
\text { so much }\end{array}$ & $\begin{array}{l}\text { We are } \\
\text { working on } \\
\text { things, to } \\
\text { maybe see } \\
\text { each other in } \\
\text { the classroom } \\
\text { and that will } \\
\text { be a big help. } \\
\text { We are very } \\
\text { open. There is } \\
\text { no wrong way, } \\
\text { just different } \\
\text { ways to do } \\
\text { things. We } \\
\text { share things } \\
\text { that we do, we } \\
\text { visit each } \\
\text { other's classes } \\
\text { and offer } \\
\text { suggestions. }\end{array}$ \\
\hline
\end{tabular}




\begin{tabular}{|c|c|c|c|c|c|}
\hline $\begin{array}{l}\text { 12. What } \\
\text { recommendat } \\
\text { ions do you } \\
\text { have for } \\
\text { improving the } \\
\text { institutional } \\
\text { socialization } \\
\text { and } \\
\text { mentoring } \\
\text { processes for } \\
\text { transitioning } \\
\text { from career } \\
\text { professional } \\
\text { to college } \\
\text { teaching } \\
\text { professional? }\end{array}$ & $\begin{array}{l}\text { There should } \\
\text { be a process or } \\
\text { program to } \\
\text { train new } \\
\text { faculty in Felix } \\
\text { and } \\
\text { Blackboard } \\
\text { programs. } \\
\text { Training for } \\
\text { adjuncts in } \\
\text { basic computer } \\
\text { techniques. } \\
\text { Administrative } \\
\text { assistance. } \\
\text { There are none } \\
\text { currently }\end{array}$ & $\begin{array}{l}\text { I wish there } \\
\text { were posted a } \\
\text { series of online } \\
\text { training or } \\
\text { information } \\
\text { that could be } \\
\text { watched as } \\
\text { time permits, } \\
\text { and some } \\
\text { face-to-face } \\
\text { group } \\
\text { meetings. } \\
\text { Who does } \\
\text { what, where to } \\
\text { go whenever } \\
\text { you have } \\
\text { questions? } \\
\text { After three } \\
\text { semester I was } \\
\text { the Program } \\
\text { Coordinator } \\
\text { and had no } \\
\text { Banner } \\
\text { Training. } \\
\text { Just to get a } \\
\text { question } \\
\text { answered is } \\
\text { difficult. } \\
\text { Nobody seems } \\
\text { on protocol or } \\
\text { procedures, } \\
\text { very little } \\
\text { responsiveness } \\
\text { to questions. } \\
\text { I've never } \\
\text { been }\end{array}$ & $\begin{array}{l}\text { There should } \\
\text { be a faculty } \\
\text { mentor from } \\
\text { outside the } \\
\text { program would } \\
\text { be great. We } \\
\text { are remote } \\
\text { from the main } \\
\text { campus, we } \\
\text { are left out a } \\
\text { lot because } \\
\text { nobody thinks } \\
\text { of us, or } \\
\text { automatically } \\
\text { excludes based } \\
\text { on location. } \\
\text { Technology } \\
\text { should be used } \\
\text { to include } \\
\text { remote sites in } \\
\text { main campus } \\
\text { meetings. } \\
\text { They talk } \\
\text { about } \\
\text { inclusiveness, } \\
\text { but we have } \\
\text { yet to see it. }\end{array}$ & $\begin{array}{l}\text { There needs to } \\
\text { be a } \\
\text { orientation, } \\
\text { some kind of } \\
\text { faculty map of } \\
\text { contacts. The } \\
\text { administrative } \\
\text { side is the } \\
\text { biggest thing. } \\
\text { On the } \\
\text { education side, } \\
\text { new faculty } \\
\text { should shadow } \\
\text { educators with } \\
\text { good } \\
\text { reputations for } \\
\text { teaching, to } \\
\text { see how they } \\
\text { do things. } \\
\text { A handbook of } \\
\text { who you } \\
\text { should call in } \\
\text { the event you } \\
\text { need things. } \\
\text { More info } \\
\text { about who to } \\
\text { contact. } \\
\text { We are at a } \\
\text { remote site, so } \\
\text { out of sight out } \\
\text { of mind } \\
\text { making it } \\
\text { difficult to } \\
\text { answer student } \\
\text { questions } \\
\text { administrativel } \\
\text { y. Being a new } \\
\text { educator, when }\end{array}$ & $\begin{array}{l}\text { School having } \\
\text { orientation } \\
\text { day, and } \\
\text { introduced that } \\
\text { stuff, and then } \\
\text { the faculty } \\
\text { lunch, I think } \\
\text { that needs to } \\
\text { be definitely } \\
\text { be an } \\
\text { institution. } \\
\text { In my } \\
\text { education class } \\
\text { I took at } \\
\text { Michigan } \\
\text { State, we had } \\
\text { to write a } \\
\text { proposal, and } \\
\text { it was different } \\
\text { for me, } \\
\text { because along } \\
\text { with it I took } \\
\text { the education } \\
\text { course } \\
\text { with-it was } \\
\text { for teaching, }\end{array}$ \\
\hline
\end{tabular}




\begin{tabular}{|l|l|l|l|}
\hline & $\begin{array}{l}\text { somewhere } \\
\text { where } \\
\text { customer } \\
\text { service isn't } \\
\text { high priority, } \\
\text { because, in } \\
\text { industry, } \\
\text { customers } \\
\text { being all of us. }\end{array}$ & $\begin{array}{l}\text { students have } \\
\text { questions and } \\
\text { the instructor } \\
\text { is clueless, that } \\
\text { looks bad. } \\
\text { Students get } \\
\text { discouraged, } \\
\text { making it } \\
\text { harder for } \\
\text { them to learn. }\end{array}$ \\
\hline
\end{tabular}

